\title{
Un réseau de fermes du second âge du Fer au nord de Falaise (Calvados) : les enclos d'habitat de «L'Attache » et « Expansia »
}

A network of farms of the Second Iron Age in the North of Falaise (Calvados): The farmsteads of "L'Attache" and "Expansia"

Ein Netzwerk aus ländlichen Gehöften im Norden von Falaise (Calvados): Die eingehegten Gehöfte von „L'Attache " und „Expansia“

Una red de granjas de la segunda Edad del Hierro al norte de Falaise (Calvados): los recintos de hábitat "L'Attache" y "Expansia"

Chris-Cécile Besnard-Vauterin, Michel Besnard, Nina Boulogne, Anne-Loïse Manson, Xavier Savary, Elise Sehier et Nolwenn Zaour

\section{(2) OpenEdition}

\section{Journals}

Édition électronique

URL : https://journals.openedition.org/rao/2511

DOI : $10.4000 /$ rao. 2511

ISBN : 978-2-7535-4053-8

ISSN : $1775-3732$

Éditeur

Presses universitaires de Rennes

Édition imprimée

Date de publication : 15 décembre 2014

Pagination : 107-149

ISBN : 978-2-7535-4051-4

ISSN : 0767-709X

Référence électronique

Chris-Cécile Besnard-Vauterin, Michel Besnard, Nina Boulogne, Anne-Loïse Manson, Xavier Savary, Elise Sehier et Nolwenn Zaour, « Un réseau de fermes du second âge du Fer au nord de Falaise (Calvados) : les enclos d'habitat de "L'Attache » et "Expansia » ", Revue archéologique de l'Ouest [En ligne], 31 | 2014, mis en ligne le 15 décembre 2016, consulté le 22 août 2022. URL : http:// journals.openedition.org/rao/2511; DOI : https://doi.org/10.4000/rao.2511 


\title{
Un réseau de fermes du second âge du Fer au nord de Falaise (Calvados) : les enclos d'habitat de « L'Attache " et « Expansia "
}

\author{
A Network of Farms of the Second Iron Age in the North of Falaise (Calvados): \\ The Farmsteads of "L'Attache" and "Expansia"
}

\author{
Chris-Cécile Besnard-Vauterin*, Michel Besnard**, Nina Boulogne***, \\ Anne-Loïse Manson ${ }^{* * *}$, Xavier SAVArY ${ }^{* * * *}$, Élise Ś́HIer ${ }^{* * * * *}$ \\ et Nolwenn ZAOUR ${ }^{* * * * * *}$
}

\begin{abstract}
Résumé : À travers deux campagnes de fouilles réalisées au nord de Falaise aux lieux-dits «L'Attache » et "Expansia » auxquelles s’ajoutent diverses données de survols aériens et de diagnostics préventifs, il est possible d'aborder pour ce secteur la question de l'organisation spatiale et des modes d'exploitation des terroirs avant la conquête romaine, à l'image des réseaux laténiens du nord de la plaine de Caen et du bassin de la Seulles. L'étude des vestiges domestiques de ces deux établissements permet d'appréhender des différences régionales, notamment dans les besoins de stockage, entre ce secteur aux portes de la plaine d'Argentan et d'Alençon et les réseaux de fermes du nord de la plaine de Caen. L'étude typo-chronologique et pétrographique des corpus céramiques contribue à ce questionnement sur des mobiliers composant un assemblage à la marge des productions de la plaine de Caen et tourné vers celles de l'Orne, plus influencées par le domaine armoricain.
\end{abstract}

Abstract: The spatial organization and land use before the Roman conquest is a subject that can be tackled from two seasons of excavations to the north of Falaise at "LAttache" and "Expansia" and also from aerial and mechanical surveys carried out in this sector. This data shows that land organisation is modelled on a similar network of latenian farms to the north of the Caen Plain and the Seulles valley. The study of these two settlement sites brings to light regional differences between this area near to the department of Orne and the Caen Plain, one example being storage capacity. The typo-chronological and petrographic study of the pottery corpus raises questions about the assemblage more characteristic of the productions of the Orne, influenced by the Armorican domain, rather than those of the Caen Plain.

Mots clés : La Tène, enclos d'habitat, réseau de fermes, vestiges d'habitat, mobiliers domestiques et agro-pastorales, céramiques, étude typochronologique et pétrographique.

Keywords: La Tene period, farmstead, network offarms, domestic remains, domestic and agricultural artefacts, pottery, typo-chronologic and petrographic study.

\footnotetext{
* Direction de l'article/Inrap Basse-Normandie, Boulevard de l'Europe, 14450 BOURGUÉBUS. (chris-cecile.vauterin@inrap.fr)

** Dessins, plans/Inrap Basse-Normandie, Boulevard de l'Europe, 14450 BoURGUÉBUS.

*** Mise à jour de l'étude des céramiques/Inrap Basse-Normandie, Boulevard de l'Europe, 14450 BOURGUÉBUS.

**** Étude pétrographique/Conseil général du Calvados-Service d'Archéologie, 36 Rue Fred-Scamaroni, 14000 CAEN.

***** Etude textilotechnique/Inrap Basse-Normandie, Boulevard de l'Europe, 14450 BoURGUÉBUS.

****** Etude métallurgiquelInrap Basse-Normandie, Boulevard de l'Europe, 14450 BOURGUÉBUS.
} 


\section{Présentation}

Létude de deux établissements fossoyés du second âge du Fer distants de seulement 500 mètres et leur mise en corrélation avec des données de prospection aux alentours permettent de présenter ici les premières connaissances sur un réseau d'établissements agricoles laténiens au nord de la commune de Falaise. La contemporanéité de ces gisements et leur proximité évoquent les ensembles gaulois du nord de la plaine de Caen dans le secteur au sud-est de la périphérie caennaise (Mondeville, Cagny, Cormelles-le-Royal, Ifs, Fleury-sur-Orne ${ }^{1}$ ) et ceux du plateau de Thaon dans le Bassin de la Seulles². Dans cette approche, il faut souligner que les données archéologiques qui fondent la réflexion de cette contribution sont issues de diverses interventions - prospection aérienne, diagnostic, fouille préventive - ayant été menées de manière échelonnée sur une période de plus de vingt ans de recherche. De ce fait, les résultats obtenus sont très hétérogènes. La fouille la mieux documentée a été menée en 2006 sur la zone d'activités Expansia, un projet d'aménagement de la communauté de communes de Falaise sur une trentaine d'hectares au nord de l'agglomération (fig. 1). Le site comporte un habitat du second âge du Fer dont les enclos imbriqués et accolés couvrant une surface de plus d'un hectare ont pu être étudiés intégralement (Besnard-Vauterin, 2008). Les résultats de cette fouille constituent le socle de notre analyse. La fouille menée en 1994 sur la zone d'activités de L'Attache n'a touché que la partie méridionale d'un établissement s'étendant sur une superficie d'à peine un demihectare. Les moyens d'investigation étant bien moindres qu'en 2006, ce site n'a pu être exploré qu'à hauteur de $20 \%$ pour les clôtures fossoyées et de moins de $50 \%$ pour les vestiges domestiques internes (Besnard-Vauterin, 1994). La quantité et la diversité des mobiliers recueillis sont donc largement inférieures à celles du site d'Expansia.

\section{Contexte géologique}

Le pays de Falaise constitue le prolongement méridional de la plaine de Caen et se situe géologiquement au contact de la couverture sédimentaire du Bassin parisien et du vieux socle du Massif armoricain. Constituée principalement de calcaires jurassiques (Bajocien supérieur à Bathonien moyen) (Gigot et al., 1999), cette couverture d'origine marine occupe les campagnes de Caen, Falaise et Argentan et y détermine un paysage de plateaux voués à la culture céréalière. Le plateau calcaire, où se situent les gisements à

1. Marcigny et al., 2006, Besnard-Vauterin 2009a, Van den Bossche et al., 2009, Lepaumier et al., 2010.

2. San Juan et al., 1999; San Juan, 2012 une altitude d'environ 155 mètres NGF, est coupé à $1,5 \mathrm{~km}$ au sud par la profonde vallée de l'Ante et par les émergences gréseuses des synclinaux du Massif armoricain.

La couverture superficielle, qui s'est formée sur le calcaire fortement altéré, est constituée d'un épais manteau de limons quaternaires, d'environ 2 mètres à l'emplacement des sites. On y distingue quatre horizons avec des variables selon les endroits : à la base des loess sur 20 à $30 \mathrm{~cm}$, ensuite des limons argileux brun orangé sur près de 1,2 mètre, un horizon de limon brun lessivé sur 30 à $40 \mathrm{~cm}$ et, au sommet, la terre végétale sur $30 \mathrm{~cm}$. Ces terres limoneuses sont toujours propices à une forte activité biologique, qui, d'un point de vue archéologique, peut causer des difficultés de lecture quand la bioturbation entraîne un effacement des limites de vestiges et des stratigraphies.

\section{Contexte archéologique}

Les établissements de L'Attache et d'Expansia s'inscrivent dans un réseau d'établissements, dont le plus proche est celui d'Aubigny qui se situe à 700 mètres au nord (Jahier et Peuchet, 1994) et est daté de La Tène moyenne et finale (fig. 2). Un autre, plus éloigné, se localise à $2,5 \mathrm{~km}$ au nord sur la commune de Soulangy (Peuchet et Naizet, 1994). Son implantation remonte à La Tène ancienne. Les deux gisements ont fait l'objet de fouilles préventives mais leur exploration a été très partielle du fait des contraintes de limites imposées par le projet d'aménagement linéaire de la RN 58 . À ces données de fouille s'ajoutent des données de diagnostics archéologiques. Sur la moitié sud de la ZAC d'Expansia ont été mises au jour des fosses d'extraction abritant des sépultures de l'âge du Fer, datées vraisemblablement de La Tène ancienne (Hérard, 2006) (Carte archéologique, site nº 73). À l'emplacement du bassin d'orage de l'échangeur d'Aubigny, à seulement 150 mètres à l'ouest du site d'Expansia, a été diagnostiqué un complexe de fossés appartenant à un enclos et son parcellaire (Ghesquière, 2003) (site $\left.{ }^{\circ} 65\right)$. Ces vestiges sont datés de la fin du second âge du Fer et de la période antique. D'autres sites d'habitat sont soupçonnés dans les environs grâce à la prospection aérienne (Carte archéologique, SRA Basse-Normandie). Des systèmes d'enclos quadrangulaires jointifs ou imbriqués, dont les datations restent pour l'instant indéterminées, pourraient en effet correspondre à des établissements fossoyés du second âge du Fer. Pour les plus proches, il s'agit des ensembles fossoyés au lieu-dit Les Sentes, à seulement 250 mètres au nord du site d'Expansia (site $\mathrm{n}^{\circ} 32$ ), et à environ 600 mètres au nord-est de celui-ci (site $\mathrm{n}^{\circ} 56$ ), ainsi qu'au nord-est de Vaston et Rougemont à environ 800 mètres du gisement d'Expansia (n 33).

Pour la période qui suit celle qui nous intéresse ici, il est intéressant d'évoquer la présence d'une importante villa 


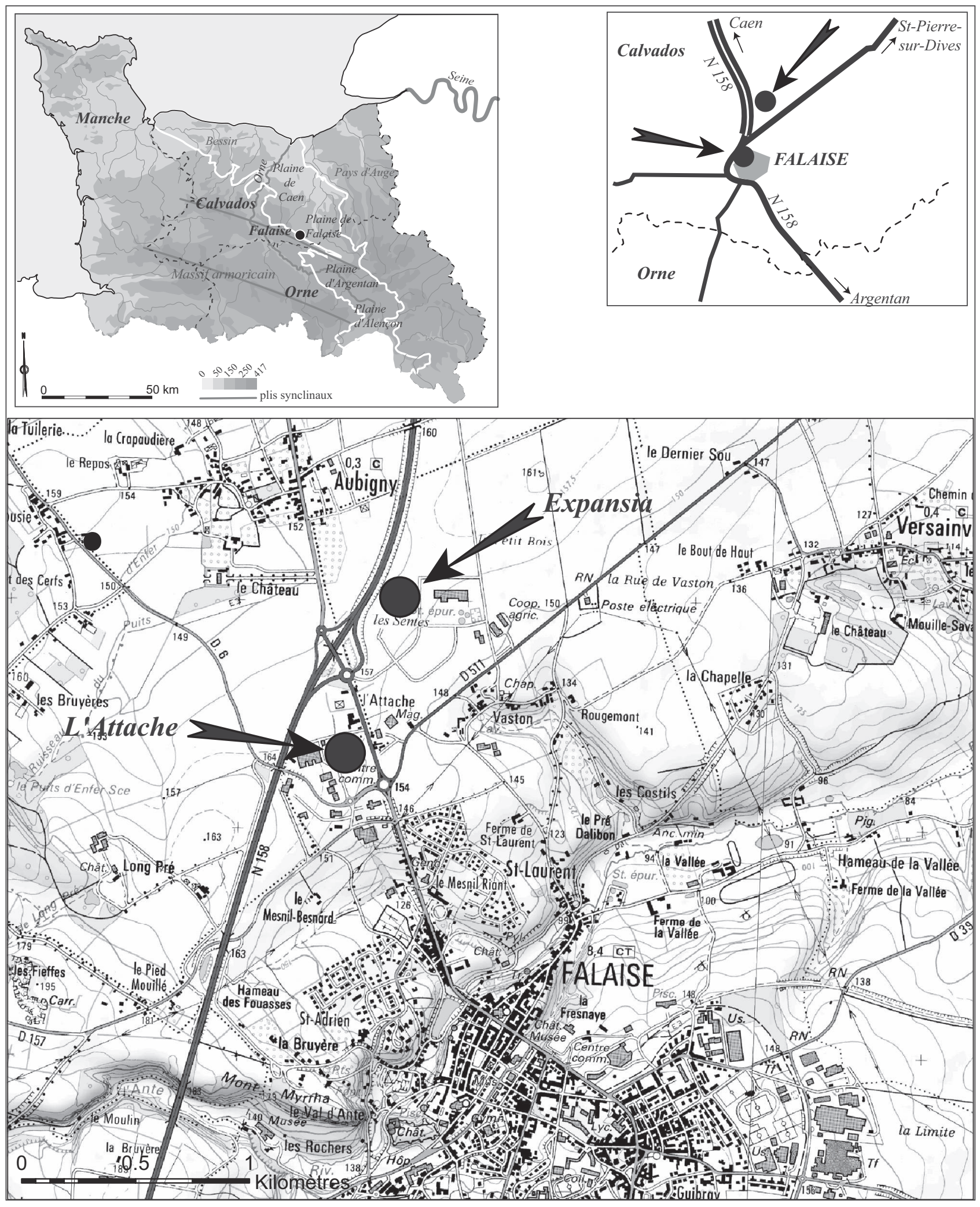

Figure 1 : Localisation des sites de L'Attache et Expansia (Scan $25^{\oplus}$ - (C) IGN 2011). M. Besnard/Inrap.

Figure 1: Location of L'Attache and Expansia sites (Scan $25^{\circ}-$ (C) IGN 2011). M. Besnard/Inrap. 


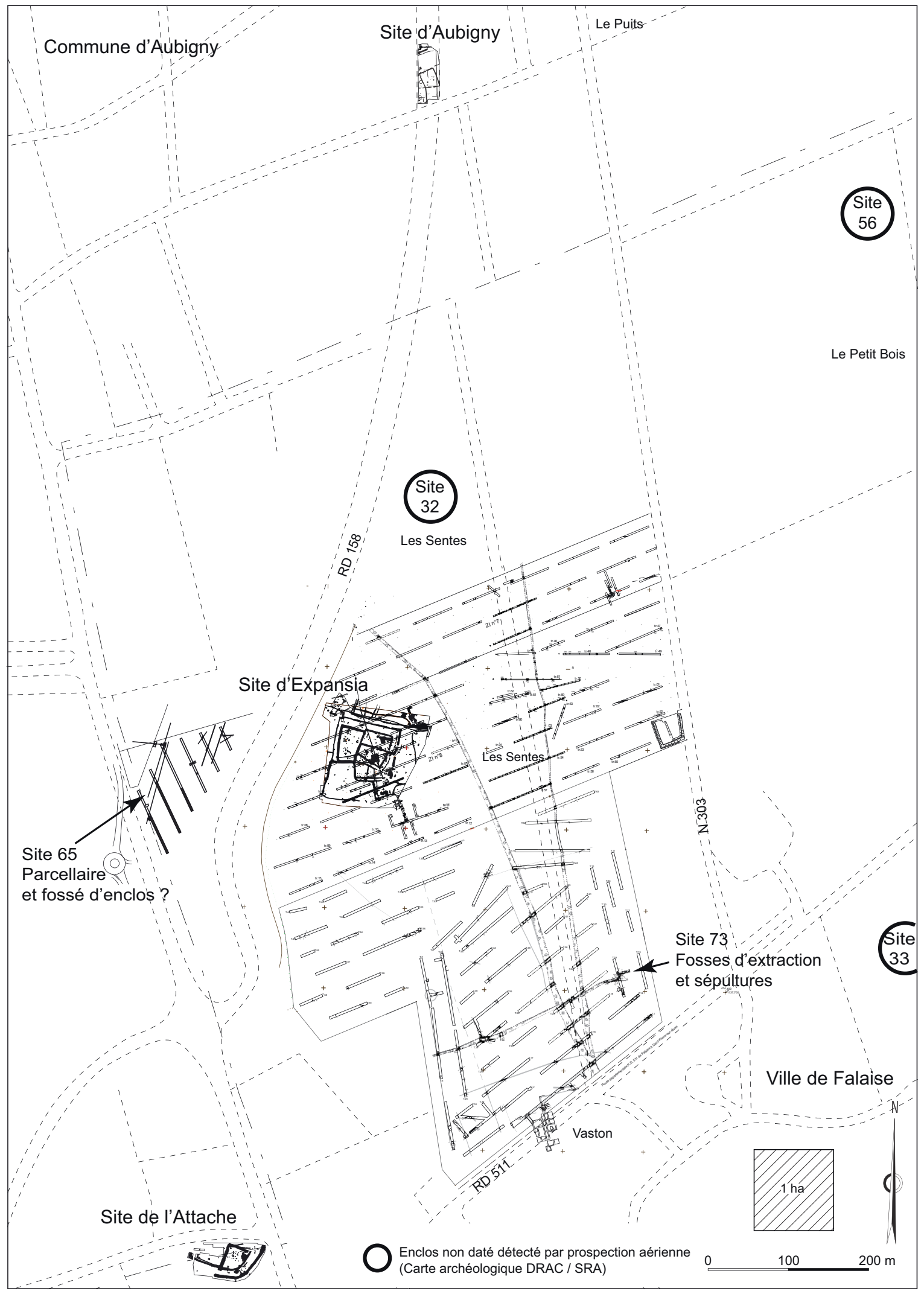

Figure 2 : Secteur nord de Falaise, habitats et parcellaires du second âge du Fer. M. Besnard/Inrap. Figure 2: Northern area of Falaise, farmsteads and field systems of the Late Iron Age. M. Besnard/Inrap. 
antique au lieu-dit Vaston, située au sud de l'emprise de la ZAC d'Expansia. Découverte lors de l'aménagement de la route RD 511 entre Falaise et Saint-Pierre-sur-Dives, la pars urbana de la villa a été partiellement explorée en 1834 lors d'une fouille de sauvetage (Galleron, 1834). Ces investigations ont permis de reconnaître un grand bâtiment cloisonné, dont la suite a été mise en évidence lors du diagnostic de la deuxième tranche de la ZAC et pour laquelle une datation $\mathrm{du} \mathrm{II}^{\mathrm{e}}$ au $\mathrm{III}^{\mathrm{e}}$ siècle a été avancée (Hérard, 2006). Cet ensemble s'insère dans une trame parcellaire attribuée à l'époque gallo-romaine mais d'origine probablement plus ancienne d'après certains indices ressortant de la fouille d'Aubigny (Jahier et Peuchet, 1994). Signalons également la présence d'un monument funéraire antique tout près du gisement d'Expansia. Découvert lors de la fouille de cet habitat puis étudié en fouille programmée (Hincker et al., 2012), le gisement concerne un monument funéraire unique à ce jour en Basse-Normandie.

\section{L'HABitaT de L'AtTAChe}

Fouillé en 1994 à l'occasion de l'aménagement de la zone d'activités Nord de la ville de Falaise, le site comporte un enclos fossoyé dont seulement la partie méridionale a pu être explorée sur une superficie de 4500 mètres carrés. La partie septentrionale se prolonge sous le chemin départemental $n^{\circ} 6$. Dans l'emprise de la fouille, l'établissement comporte un double système d'enclos, correspondant à deux phases d'aménagement s'étalant sur les périodes de La Tène moyenne et finale (fig. 3).

\section{La première phase : la création d'un enclos d'habitat}

Reconnue sur une superficie de 3200 mètres carrés, cette première phase est matérialisée par un enclos fossoyé dont le plan associe tracé curviligne au sud-est et côtés rectilignes à l'ouest. L'ensemble suit une orientation nord-nord-est/sudsud-ouest ou perpendiculaire. Une interruption du fossé à l'est marque sans doute l'entrée, sans qu'on puisse estimer la largeur du passage, puisque la face opposée n'a pas été mise en évidence dans l'emprise de la fouille.

\section{La clôture}

Le fossé d'enclos comporte un creusement à large profil en $\mathrm{U}$, mesurant 1,5 mètre de profondeur à partir du sol actuel et 2 mètres de large au niveau du décapage (fig. 4, fossé 12/26/78). Le fossé s'approfondit progressivement vers l'ouest où le fond atteint 2 mètres de profondeur. Le comblement de cette structure est généralement constitué de limons brun-gris, assez homogénéisés par la bioturbation

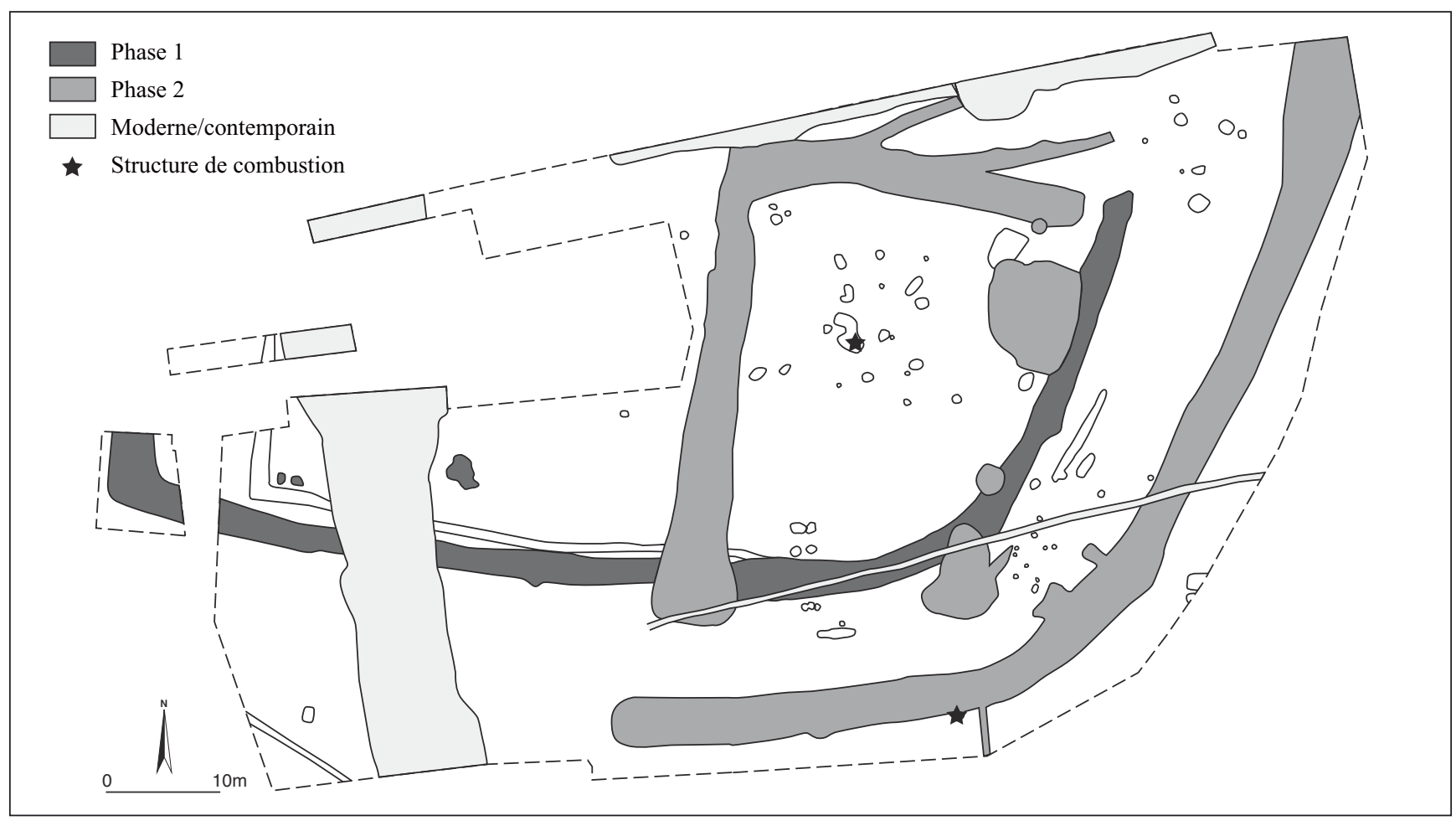

Figure 3 : Falaise "L'Attache", plan des vestiges. M. Besnard/Inrap.

Figure 3: Falaise "L'Attache", site plan. M. Besnard/Inrap. 
et contenant ponctuellement des traces de charbon de bois et de terre rubéfiée. Dans la partie profonde du fossé, le fond est marqué par des dépôts limoneux hydromorphes. Sur la partie orientale du tracé, les niveaux intermédiaires et supérieurs sont parfois entrecoupés de rejets de combustion composés de cendres et de charbons de bois ou de pierres calcaires brûlées. Associé à ces mêmes niveaux, le mobilier détritique se limite à des éléments de céramique très fragmentés, des restes d'ossements de faune mal conservés, quelques scories et un fragment de creuset témoignant d'activités métallurgiques. De manière générale, ce comblement peu stratifié ne permet pas de déceler des traces de démantèlement d'un talus qui a probablement bordé le fossé sur l'une de ces rives.

Sur la partie occidentale de l'enclos, on observe un doublement de la limite fossoyée du côté interne (fossé 92). Antérieur à la deuxième phase d'occupation, on ignore si ce dispositif est contemporain de la première phase, s'il s'agit d'une réfection ou s'il constitue, au contraire, la toute première étape d'aménagement de la clôture. Il s'agit d'un fossé de 1,2 mètre de profondeur qui, d'après son comblement limoneux stratifié et légèrement anthropisé, a fonctionné à ciel ouvert.

\section{Les aménagements internes}

Peu de vestiges domestiques peuvent être associés à cette phase, puisque la partie orientale de l'aire interne est chevauchée par l'occupation de la deuxième phase. Quant à la partie occidentale, elle n'a été que partiellement explorée en raison de la présence de multiples perturbations modernes et contemporaines. Il en ressort néanmoins que peu d'aménagements domestiques ont investi ce secteur. Cinq excavations, toutes de dimensions modestes (moins d'un mètre sous le sol actuel), ont été identifiées parmi lesquelles deux fosses, situées dans l'angle sud-ouest de l'enclos, présentent des comblements riches en rejets de combustion.

\section{La deuxième phase : la réfection des clôtures}

Tout comme la précédente phase, l'enclos de cette étape ne présente probablement qu'une partie de l'établissement, bien que le dispositif fossoyé délimite une aire entièrement reconnue dans l'emprise de la fouille. Cette clôture est formée par deux fossés dissociés qui reprennent les axes d'orientation de la phase précédente. Le fossé au sud-est (fossé 1) décrit un tracé curviligne, reprenant la courbe de la phase précédente mais en s'implantant à 8 mètres à l'extérieur. Les côtés à l'ouest (fossé 6) et au nord (fossé 5/27) sont délimités par un tracé rectiligne formant un angle droit. Deux

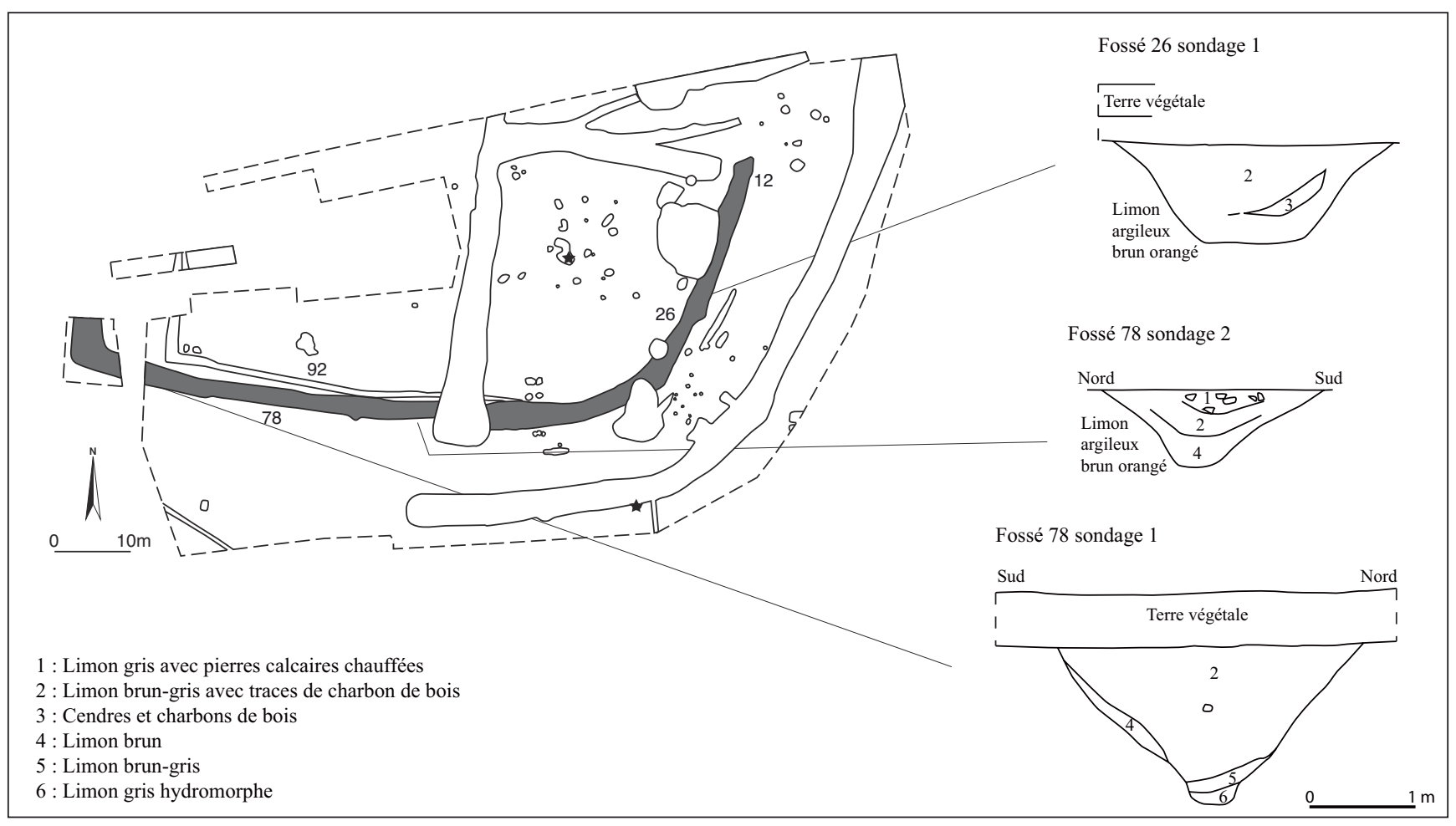

Figure 4 : Falaise "L’Attache ", fossé d'enclos de la phase 1. M. Besnard/Inrap.

Figure 4: Falaise "L'Attache", ditch enclosure dating to the first period. M. Besnard/Inrap. 
passages, larges de 7 mètres au sud-ouest et de 15 mètres au nord, donnent accès à cet espace de 1700 mètres carrés de superficie. À partir du constat que le fossé au sud-est (fossé 1) se prolonge au nord, en dehors de l'emprise, et que le fossé occidental (fossé 6) s'y poursuit également, on peut supposer que cette aire clôturée ne constitue qu'une subdivision d'un espace clos plus vaste. La présence de structures excavées à usage domestique dans le secteur au nord-est semble conforter cette hypothèse.

\section{La clôture}

Les fossés d'enclos présentent des creusements assez réguliers avec un profil en $V$ à fond arrondi (fig. 5). D'une largeur moyenne de 4 mètres au niveau du décapage, ils atteignent une profondeur de 2,4 mètres sous la terre végétale et s'inscrivent légèrement dans la roche calcaire. Le comblement inférieur est constitué de sédiments issus du lessivage des flancs du creusement et composé de limons bruns stériles souvent à caractère hydromorphe. Les niveaux intermédiaires sont constitués par des limons brun-gris contenant des traces de charbon de bois, des nodules de terre rubéfiée et parfois des pierres calcaires brûlées. À certains endroits, les niveaux sommitaux sont plus fortement mêlés à des rejets de combustion. Ils ont également livré une petite quantité de céramique et des restes osseux de faune très mal conservés. Bien que l'existence d'un talus puisse être supposée, la dis-

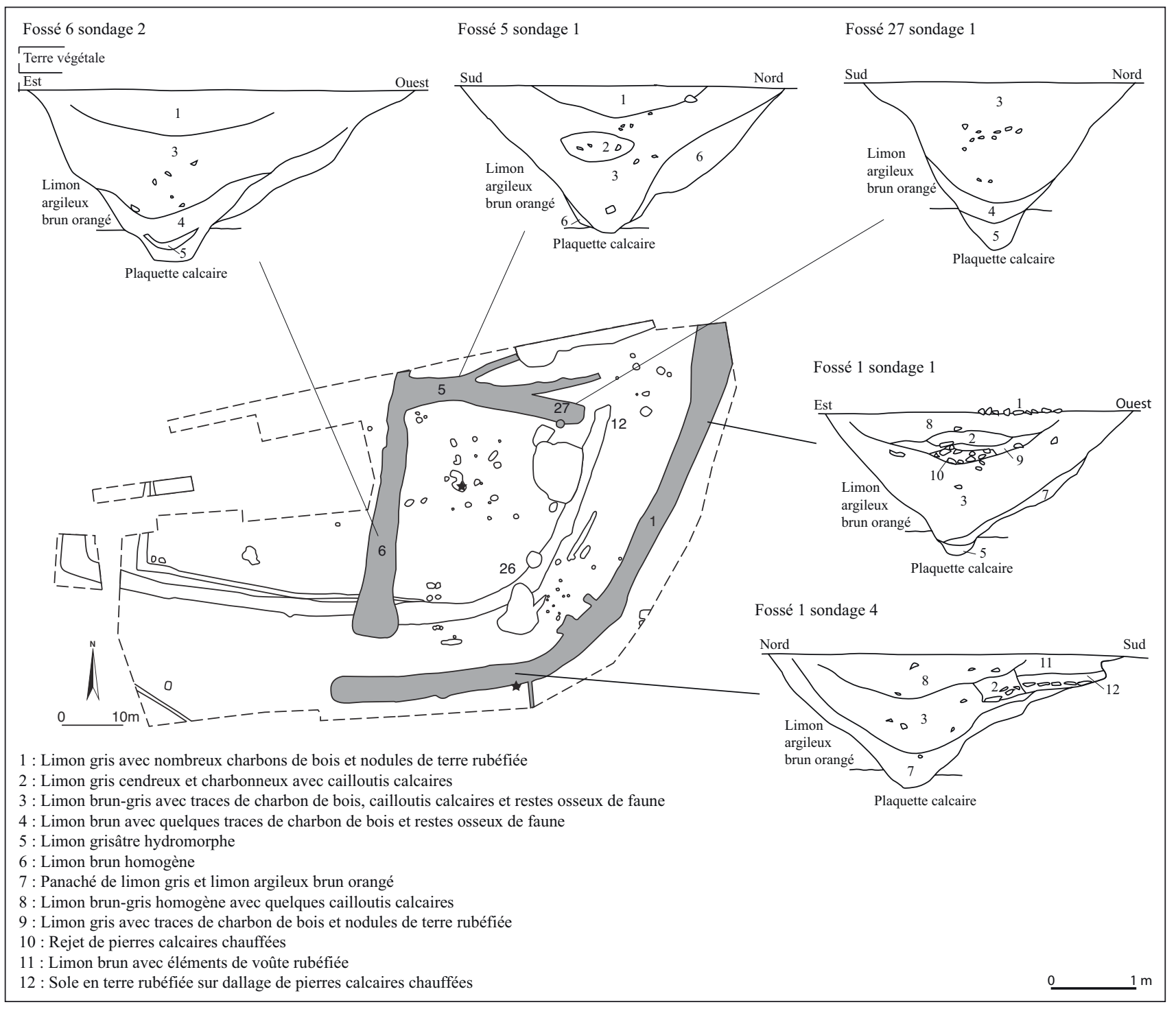

Figure 5 : Falaise «L'Attache", fossé d'enclos de la phase 2. M. Besnard/Inrap.

Figure 5: Falaise "L'Attache", ditch enclosure dating to the second period. M. Besnard/Inrap. 
position symétrique des strates par rapport à l'axe central du fossé ne permet pas de supposer son emplacement sur l'un ou l'autre côté de la structure.

\section{Les aménagements internes}

Dans l'espace ceinturé par ces deux fossés se situent une cinquantaine d'excavations, comprenant des fosses de diverses tailles et des trous de poteau. La moitié se trouvent au sein de l'espace cerné par les clôtures des deux phases et ne peuvent donc être attribuées à l'une ou l'autre de manière certaine. Celles situées dans le secteur à l'extérieur de la première clôture sont logiquement attribuables à cette deuxième phase, tout comme celles qui recoupent le comblement du premier fossé.

\section{Les fosses}

La grande majorité des creusements ont des dimensions modestes, mesurant entre $25 \mathrm{~cm}$ et 1 mètre de profondeur sous le sol actuel. Ils sont généralement comblés de limon brun sombre, renfermant quelques débris ténus de charbon de bois et de terre cuite. Très peu de matériel osseux, céramique ou autre en est issu. L'usage de ces petites fosses reste indéterminé, hormis peut-être pour une excavation dont les dimensions sont nettement plus grandes. Il s'agit d'une fosse de plan circulaire, mesurant 1,7 mètre de profondeur pour un diamètre maximal de 2,7 mètres (fosse 48, fig. 6). Son profil légèrement voûté et la présence d'un épais dépôt de loess dû à un effondrement de paroi laisse supposer qu'il s'agit d'un creusement en sape, rappelant le profil d'un silo piriforme. Si la fonction initiale de cette structure est probablement celle du stockage, son usage final est indéniablement celui d'un dépotoir. Son comblement est en effet composé de plusieurs strates de limons gris, dont un épais horizon de limon rubéfié très charbonneux renfermant des plaques de terre cuite. Le rejet d'une quantité non négligeable de scories témoigne d'une activité sidérurgique, tandis que deux fragments de meules en granite évoquent le traitement de produits agricoles.

Parmi ces excavations se distinguent deux fosses de grande envergure, recoupant le fossé de la première phase. Larges de près de 8 mètres, ces excavations présentent un profil à pente douce profond de 1,2 mètre sous le sol actuel. Leurs comblements sont constitués de limons grisâtres, contenant des traces de rubéfaction, des charbons de bois, plus rarement des pierres brûlées, des restes osseux de faune ou des fragments de céramique. La question de fosses d'extraction peut être posée pour ce type d'excavation, bien qu'elles puissent aussi être rapprochées des vastes excavations du site d'Ex-

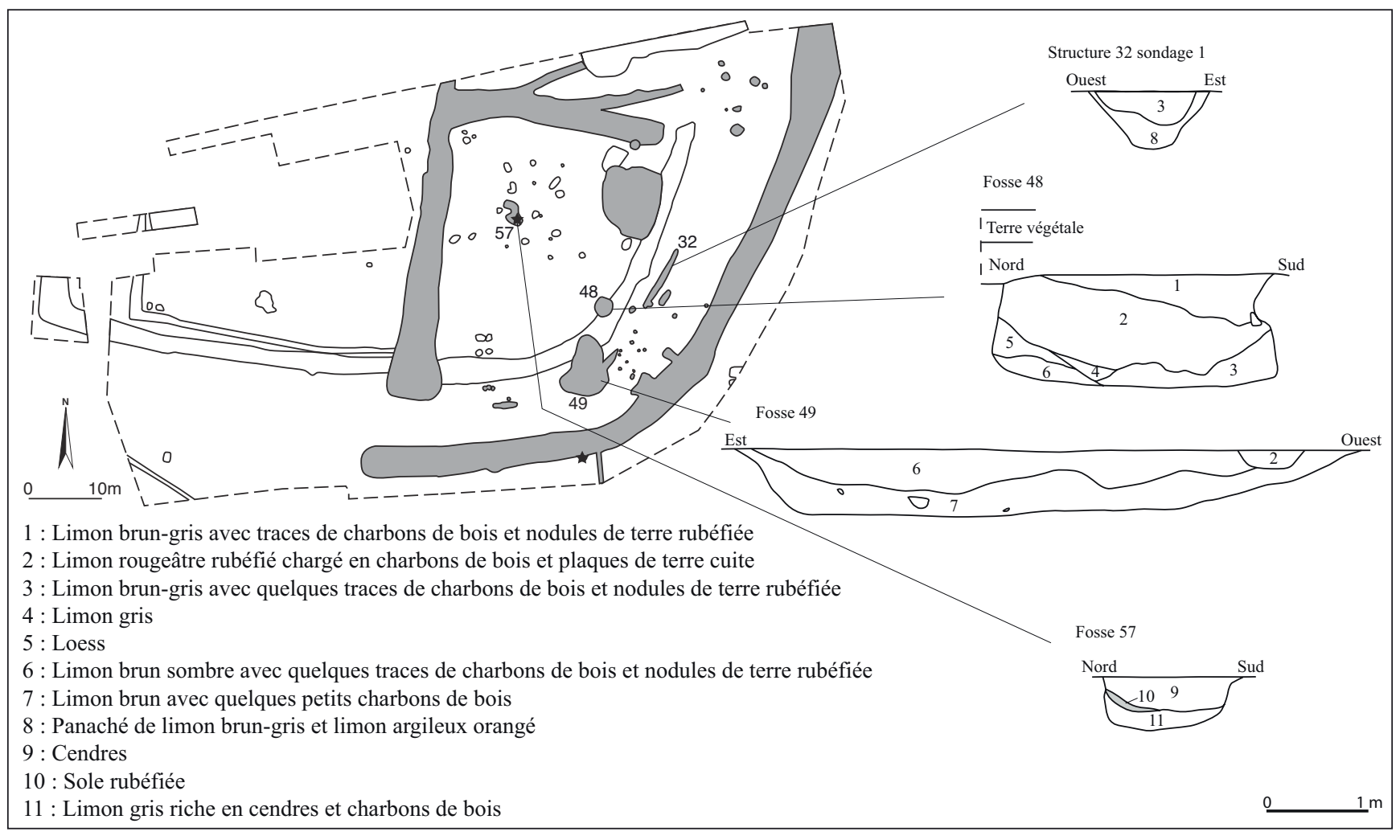

Figure 6 : Falaise "L'Attache", structures diverses attribuables à la phase 2. M. Besnard/Inrap.

Figure 6: Falaise "L'Attache", various remains from the second period. M. Besnard/Inrap. 
pansia et pour lesquelles une autre hypothèse est proposée (cf. infra).

\section{Les traces de bâti}

Plusieurs dizaines de trous de poteau ont pu être identifiés. De dimensions très variables, les excavations les plus profondes atteignent une profondeur de 0,80 mètre voire 1 mètre sous le sol actuel. D'autres s'avèrent creusées de quelques centimètres sous le niveau du décapage. Malgré le repérage de plusieurs ensembles, notamment au cœur de l'habitat et dans les secteurs au sud-est et au nord-est, aucun d'entre eux ne dessine un plan de bâtiment. Il faut en déduire qu'un certain nombre de trous de poteau, illisibles, s'inscrivaient certainement dans l'horizon décapé.

Dans le secteur sud-est de l'aire interne ont été aperçus des aménagements fossoyés de plan longitudinal, disposés à environ 6 ou 7 mètres du fossé d'enclos. Parmi ces structures, la mieux conservée mesure 9 mètres de long (structure 32, fig. 6). Il s’agit d'un creusement à profil en $U$ ouvert atteignant 0,90 mètre sous le sol actuel et comblé par un limon brun-gris contenant de rares particules de charbon de bois et de terre rubéfiée. Un autre creusement de ce type recoupe la vaste fosse 49 (fosse 49, US 2, fig. 6). Nettement moins profond, il est comblé par un limon fortement rubéfié, mêlé de gros charbons de bois et de fragments de plaques de terre cuite portant des traces de clayonnage. D'autres traces sont perceptibles plus à l'ouest, toujours parallèles au tracé curviligne du fossé d'enclos. S'agit-il d'un fond de fossé conservé très partiellement qui aurait joué le rôle de clôture en complément ou en remplacement de la clôture externe? Ou bien faut-il supposer qu'il s'agisse de tranchées d'implantation de poteaux, dernières traces conservées de constructions en bois? Cette dernière hypothèse s'appuie sur les résultats des fouilles du site d'Expansia où la base de l'architecture principale associe portions de tranchée de fondation et trous de poteau creusés individuellement. Malheureusement, l'organisation des trous de poteau sur le site de L'Attache ne permet pas de définir un plan de bâtiment. Ces tranchées suggéreraient l'emplacement de trois édifices, dont l'un d'eux aurait disparu dans un incendie en considérant les nombreux restes de torchis brûlés dans la tranchée.

Les structures de combustion

Alors que de multiples rejets de combustion dans le comblement du fossé d'enclos indiquent le démantèlement de plusieurs fours et foyers, seulement deux structures de ce type sont été retrouvées en place. Une sole rubéfiée d'un four ou foyer a été observée au sein d'une fosse au cœur de l'habitat (fosse $57^{3}$, fig. 6). La deuxième structure (fossé 1 , sondage 4 ,

3. Cette fosse est attribuée à la deuxième phase d'occupation en raison des éléments de céramique caractéristiques des phases tardives de La Tène (cf. infra). fig. 5) est un four constitué d'une chambre de cuisson creusée en sape à partir du flanc du fossé d'enclos. De plan circulaire d'environ un mètre de diamètre, la sole en terre cuite indurée est agencée sur un dallage de pierres calcaires chauffées. Louverture d'enfournement est orientée vers le fossé. Ce type de four est bien connu dans les contextes domestiques du second âge du Fer au niveau régional.

\section{L'HABITAT D'EXPANSIA}

Réalisée en 2006 dans le cadre de l'aménagement de la ZAC Expansia au nord de la ville de Falaise, la fouille a permis de cerner, sur une superficie de 11500 mètres carrés, la totalité d'un habitat clos laténien, autour duquel se structurent des lambeaux de chemin en terre, l'amorce d'un parcellaire environnant, plusieurs carrières à ciel ouvert, ainsi que deux sépultures isolées qui sont probablement contemporaines de l'habitat. D'après les données chronologiques apportées par l'ensemble céramique, l'établissement trouve ses racines vers le $\mathrm{IV}^{\mathrm{e}}$ siècle av. J.-C. et perdure à peu près jusqu'au milieu du $\mathrm{I}^{\mathrm{er}}$ siècle av. J.-C. Cette longue période, de l'ordre de trois cent cinquante ans, est marquée par trois grandes phases d'aménagements qui se manifestent surtout dans les clôtures (fig. 7). Si l'habitat se déploie sur une superficie proche d'un hectare, les espaces parcellaires qui s'y raccordent ont été reconnus sur plusieurs hectares à travers le maillage des tranchées de diagnostic. Ils témoignent donc, par leur étendue, d'une exploitation agraire de grande envergure.

\section{La première phase : la création d'un enclos d'habitat}

La première installation, qui se place chronologiquement dans la seconde moitié de La Tène ancienne ( $\mathrm{VV}^{\mathrm{e}}$ siècle av. J.-C.), est matérialisée par un enclos de plan trapézoïdal d'un peu plus de 1400 mètres carrés de superficie. Orienté nord-nord-est/sud-sud-ouest, l'enclos s'ouvre du côté oriental sur une allée. Des fossés parcellaires ont été aménagés au nord, où ils semblent se structurer autour d'un axe de circulation venant du côté est de l'habitat. Le caractère domestique de cet enclos est confirmé par les mobiliers, qui, bien que mal conservés, témoignent de pratiques culinaires et d'activités artisanales, telles que la mouture et la filature. À cette phase de création remonte peut-être une sépulture isolée, située au sud-est de l'habitat. 


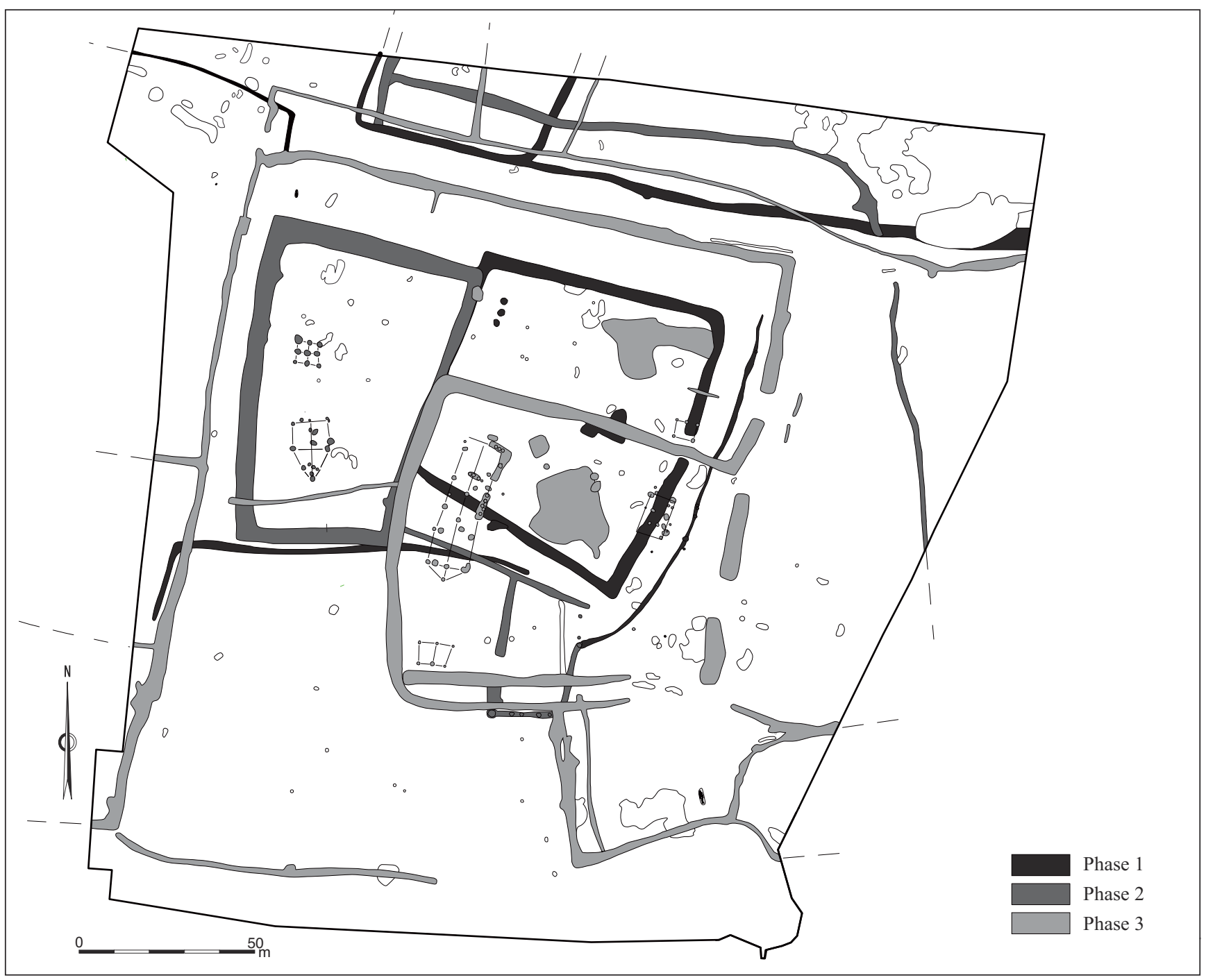

Figure 7 : Falaise "Expansia ", plan des vestiges. M. Besnard/Inrap.

Figure 7: Falaise "Expansia", site plan. M. Besnard/Inrap.

\section{Les clôtures}

\section{L'enceinte}

Le fossé d'enclos présente un profil en $\mathrm{V}$ à fond arrondi, d'une profondeur comprise entre 1,4 et 1,6 mètre à partir du niveau actuel pour une largeur de 1,7 mètre au niveau du décapage (fossés $77,107,155$ et 170, fig. 8). Une interruption au milieu du côté oriental marque l'entrée, laissant un passage d'environ 3,5 mètres de large. Le comblement du fossé est constitué de trois ou quatre horizons, résultant d'une sédimentation progressive en contexte ouvert. Les premiers dépôts sont apportés par l'érosion depuis les flancs du creusement et son environnement direct. Les limons sont stériles et présentent un aspect hydromorphe, témoignant du ruissellement de l'eau au fond du fossé. Les limons intermédiaires et supérieurs, plus sombres, sont mêlés ponctuellement à des rejets de combustion et des détritus en provenance de l'habitat. Le mobilier est peu représenté et se résume à des rejets de combustion, des ossements fauniques, des éléments de céramiques, un fragment de meule et une fusaïole, le tout étant essentiellement issu des strates supérieures. Leur disposition équilibrée, dans la largeur du fossé, n'apporte guère d'indice quant à l'emplacement d'un talus sur l'une des deux rives. Le côté ouest de la clôture a subi un re-creusement lors de la deuxième phase, effaçant entièrement le profil initial. Le comblement limoneux brun sombre du fossé 77 est en effet recoupé au niveau de l'angle nord-ouest par le fossé de la phase suivante qui est caractérisé par un remplissage limoneux brun-gris compact, plus anthropisé. 
La façade orientale du fossé d'enclos est doublée à l'extérieur par un petit fossé, qui longe la clôture principale en laissant un intervalle de 4 mètres (fossé 156/184, fig. 8). Il s'agit d'une tranchée de palissade qui se termine au nord à la même hauteur que l'angle de l'enceinte et se poursuit au sud sur une dizaine de mètres, suivant un tracé légèrement incurvé vers le sud-ouest. Le creusement, d'à peine $5 \mathrm{~cm}$ de profondeur sous le niveau d'apparition, montre des empreintes régulières de poteaux de 7 à $10 \mathrm{~cm}$ de profondeur. La palissade ne présente pas d'interruption en face de l'entrée de l'enclos, ce qui permet d'interpréter l'intervalle comme une allée. En conséquence, le talus présumé le long du fossé d'enclos a dû être dressé à l'intérieur de l'enceinte.

\section{Le parcellaire}

Les espaces autour de l'enclos montrent plusieurs aménagements fossoyés, dont le but est d'agencer des lieux de circulation et de clôturer des parcelles agraires. Contemporains à cette phase d'habitat puisque leurs tracés sont recoupés par les clôtures des deux phases suivantes, ces fossés respectent l'orientation de l'enclos, c'est-à-dire un axe ouest-nordouest/est-sud-est ou perpendiculaire à celui-ci. On observe notamment un agencement fossoyé au sud-ouest de l'habitat sur une longueur de 53 mètres (fossé 61/130, fig. 8). Il semble clôturer une parcelle au sud tout en formant un passage menant vers le secteur à l'ouest. Cette structure présente un creusement en $\mathrm{V}$ à fond arrondi, profond de

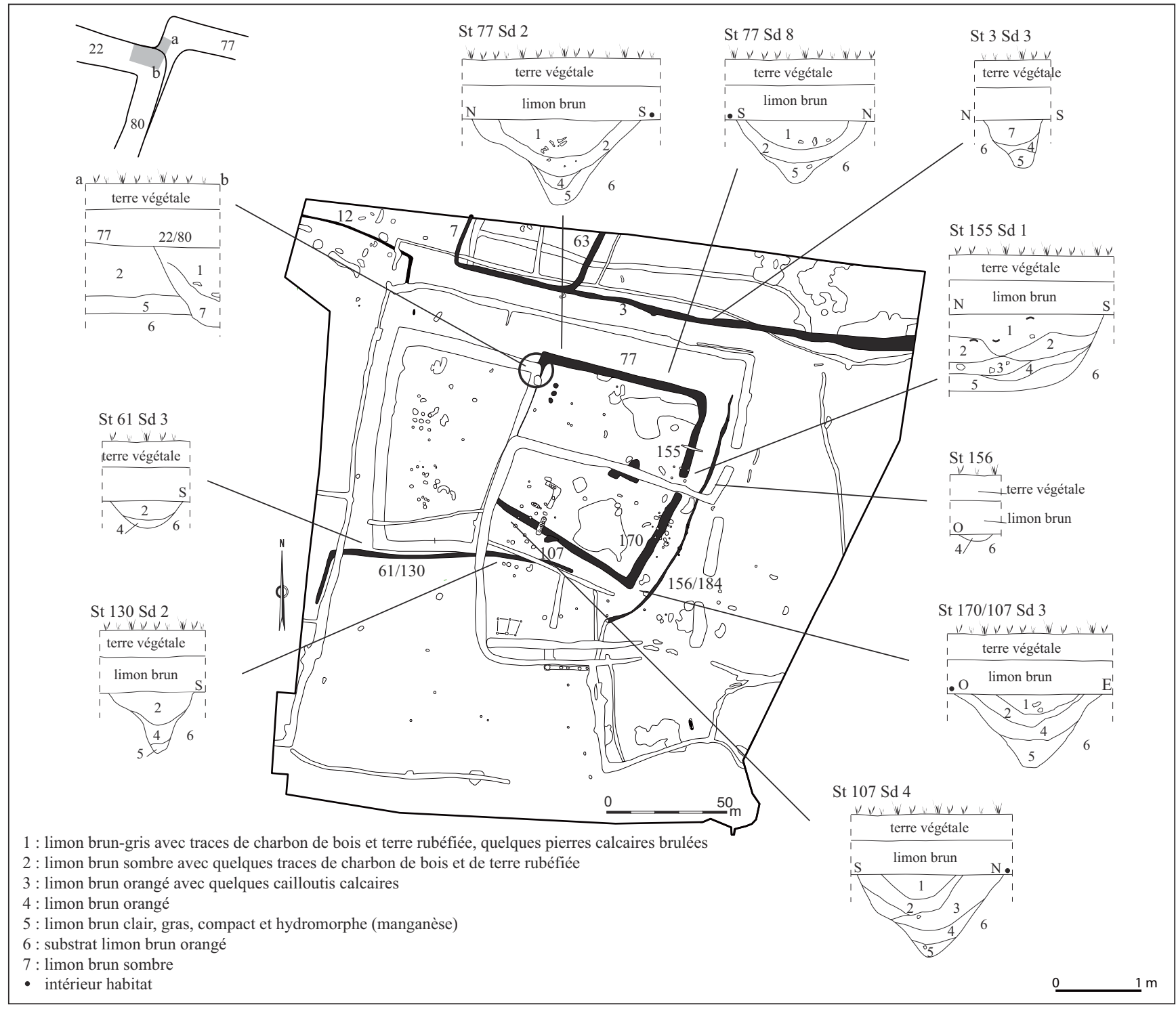

Figure 8 : Falaise «Expansia ", fossés de la phase 1. M. Besnard/Inrap.

Figure 8: Falaise "Expansia", ditches from the first period. M. Besnard/Inrap. 
1,4 mètre sous le sol actuel et large de 0,80 mètre au niveau de son apparition. Son comblement est constitué de limon brun orangé compact au fond, plus sombre et légèrement anthropisé au sommet.

Dans le secteur au nord de l'habitat est apparu un ensemble de fossés parallèles, regroupés, dont la suite a été mise en évidence sur plus de 200 mètres dans les tranchées de diagnostic à l'est de la zone de fouille (fig. 26). Espacés de 5 à 6 mètres, ce faisceau rappelle la configuration des axes viaires à fossés bordiers qui relient les établissements laténiens de la périphérie caennaise. Il faut envisager que ces fossés témoignent des aménagements successifs d'un chemin en terre en face de l'habitat. Pour cette première phase, l'axe est matérialisé par deux fossés rectilignes, l'un dans le prolongement de l'autre (fossés 3 et 12), constituant le point d'appui pour des limites parcellaires au nord (fossés 7 et 63). Un passage d'une dizaine de mètres marque l'accès vers ces parcelles. L'ensemble de ces fossés présentent des creusements en $\mathrm{U}$ ouvert dont la profondeur varie entre 0,90 et 1,4 mètre sous le sol actuel. Leurs comblements limoneux, parfois hydromorphes, sont assez stériles, mais l'un des fossés a tout de même livré un élément de céramique ( $\left.{ }^{\circ} 12.5\right)$ ayant permis de caler ce premier parcellaire à La Tène ancienne.

\section{Les aménagements internes}

En raison de la superposition des différentes phases d'aménagement des clôtures et en l'absence de mobilier céramique discriminant, bon nombre de vestiges internes ne peuvent être attribués avec certitude aux différentes enceintes. Quelques structures montrent un lien probable avec la première au regard de leur disposition, comme cela semblerait être le cas pour trois fosses alignées parallèlement au côté occidental (fosses 81,82 et 87 ). Il s'agit de petites excavations d'environ un mètre de profondeur sous le sol actuel, comblées de limons grisâtres mêlés à des rejets de combustion. Une excavation polylobée (fosse 96), sans doute constituée de trois fosses agglomérées, se rattacherait également à cette phase en raison de son antériorité au fossé d'enclos de la dernière phase. Profonde d'un mètre, son comblement est constitué de limon brun orangé dépourvu d'artéfacts.

\section{Une sépulture isolée}

Parmi les deux sépultures isolées retrouvées au sein de l'habitat, l'une d'elles remonte probablement à cette première phase d'occupation (sépulture 203, fig. 9). Cette inhumation, dont il ne reste plus que quelques débris osseux, est localisée au sud-est de l'habitat et s'oriente nord-nord-ouest/ sud-sud-est. Le défunt était paré d'un torque, suggérant l'orientation de la tête au nord. Le torque, en fer, est un jonc filiforme ouvert, orné de fines incisions disposées par paires sur toute la circonférence et soulignant la présence d'une ou plusieurs olivettes, celles-ci étant mal conservées $\mathrm{du}$ fait de l'oxydation (diamètre du jonc : $14 \mathrm{~cm}$; section : $7 \mathrm{~mm}$ ). Un autre torque en fer est issu de l'une des inhumations découvertes dans les fosses d'extraction au sud-est de la ZAC Expansia (Hérard, 2006). Les torques massifs en fer sont placés, selon la chronologie établie pour la Champagne, entre 530 et 500 av. J.-C. (Hatt et Roualet, 1977, p. 10 ; Aisne-Marne IA, Demoule, 1999, p. 143). Quant au type de torques à olivettes, les comparaisons régionales, sous sa version en bronze ou en fer et bronze (bipartite), renvoient plutôt à des contextes de La Tène ancienne (Chanson $e t$ al., 2010). Sachant que la fondation du site remonte au $\mathrm{IV}^{\mathrm{e}}$ siècle av. J.-C., c'est probablement dans la période de La Tène B1 que doit être placée cette inhumation.

\section{La deuxième phase : un nouvel espace clôturé}

Un nouvel enclos, daté de la fin de La Tène ancienne et du début La Tène moyenne (fin IV ${ }^{\mathrm{e}}$-fin III ${ }^{\mathrm{e}}$ siècle av. J.-C.), est créé à l'ouest du précédent, en reprenant son tracé oriental. La clôture décrit un plan trapézoïdal de près de 1200 mètres carrés de superficie. En l'absence d'observation d'une entrée aménagée, celle-ci est supposée à l'est, où elle serait effacée par la reprise du tronçon oriental lors de la troisième phase. Le secteur aux alentours de l'habitat connaît quelques nouveaux aménagements, dont la création d'un petit espace clos au sud-est et la réfection des limites parcellaires au nord. Les vestiges d'habitation associés à ce nouvel enclos et les mobiliers domestiques piégés dans ses fossés de clôture confortent l'hypothèse de la création d'une nouvelle aire d'habitat, en intégrant peutêtre l'ancienne enceinte comme aire de pâturage.

\section{Les clôtures}

\section{L'enceinte}

Le fossé d'enclos présente un profil en $\mathrm{V}$ à fond arrondi aux dimensions assez variables (fossés $22,23,80$ et 285 ; fig. 10). Le tracé oriental est creusé de 1,5 et 1,7 mètre sous le sol actuel pour une ouverture d'environ 2 mètres, tandis que les côtés sud et ouest s'approfondissent entre 1,8 et 2,1 mètres. Le tronçon nord est excavé jusqu'à 2,7 mètres à la hauteur de l'angle nord-ouest. Ces différences de profondeur semblent résulter d'un souhait de drainer l'eau vers des points plus bas, en l'occurrence vers les angles nord-ouest et sud-est où le substrat calcaire mis au jour a dû faciliter l'infiltration des eaux de pluie (le limon argileux étant peu perméable). Les comblements, fortement stratifiés, sont le résultat d'un colmatage progressif d'une structure ouverte. Les dépôts inférieurs se caractérisent par des limons argileux hydromorphes, de texture grasse et compacte, avec de nombreuses concrétions de manganèse. Ils sont recouverts de limons brun orangé, ponc- 


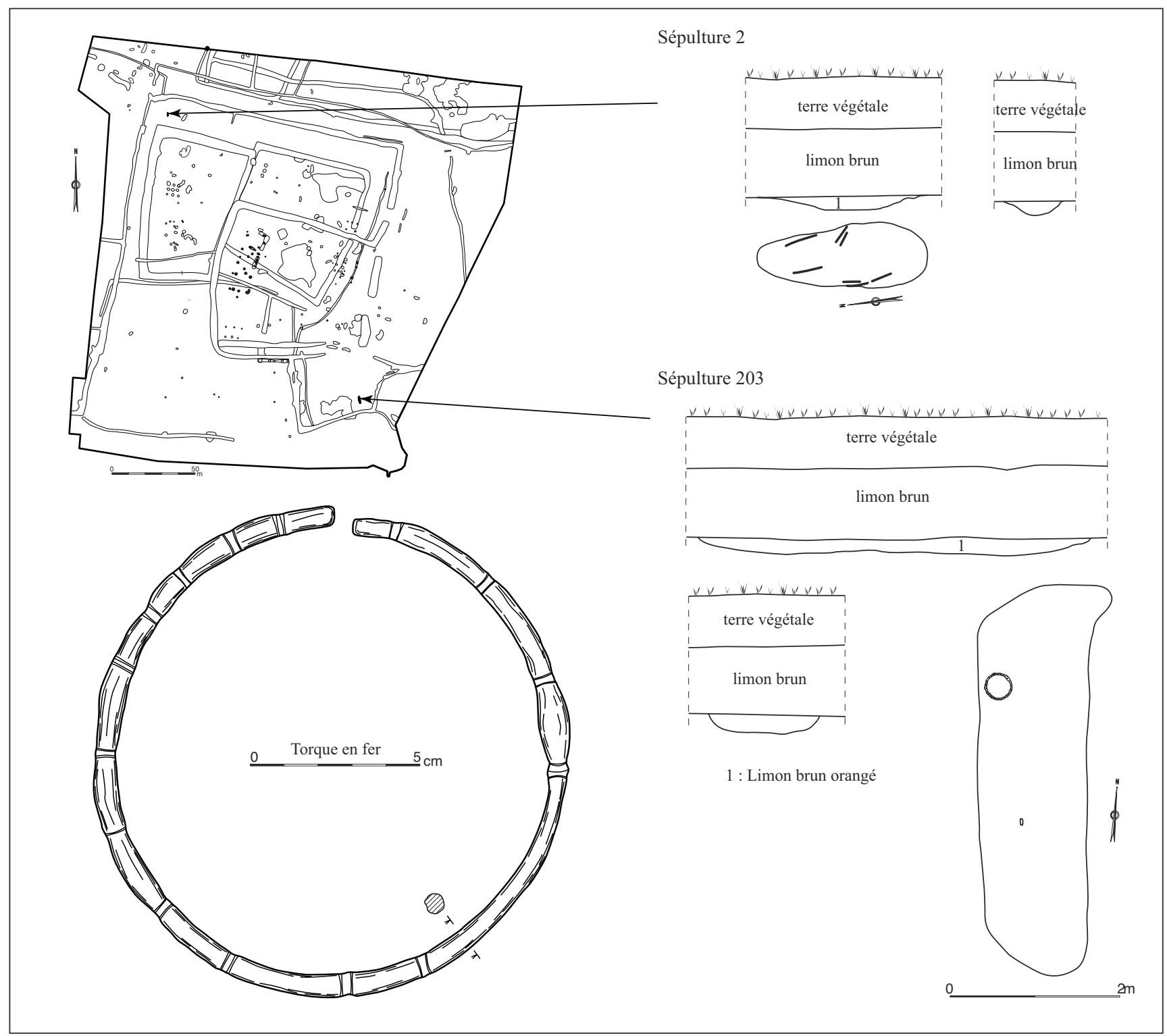

Figure 9 : Falaise "Expansia », les sépultures. M. Besnard/Inrap. Figure 9: Falaise "Expansia”, burials. M. Besnard/Inrap.

tués de cailloutis aux endroits où le calcaire a été atteint. Les limons brun sombre des niveaux supérieurs sont les plus riches en rejets anthropiques (rejets de combustion, mobilier céramique, restes fauniques, éléments de meule). Le doublement de cette clôture par un talus bordier interne est supposé à partir de certains indices dans le remplissage, notamment des apports de sédiments plus volumineux depuis l'intérieur de l'habitat (coupe 80-sd.6).

\section{L'espace clos accolé}

Cet aménagement externe à l'habitat est matérialisé par un fossé qui se raccorde à l'angle sud-est de l'enceinte (fossé 129) et délimite avec trois autres fossés un espace de cinq cents mètres carrés (fossés 135, 282 et 147, fig. 10). Cette clôture associe fossé ouvert et palissade. Les fossés 129, 135 et 282 semblent avoir fonctionné à ciel ouvert. Il s'agit de creusements en $\mathrm{V}$ d'un mètre de profondeur sous le sol actuel, comblés de limon brun orangé au fond, recouvert de limon brun sombre. En revanche, le fossé 147, qui forme la limite méridionale et orientale, est une tranchée de palissade, présentant au fond des excavations régulièrement espacées correspondant aux emplacements de poteaux. La profondeur de ces trous oscille entre 0,80 et 1,2 mètre sous le sol actuel. Ce dispositif de fossés aurait fonctionné simultanément d'une part en raison de la cohérence spatiale de l'ensemble, et d'autre part au vu de leurs relations stratigraphiques avec 


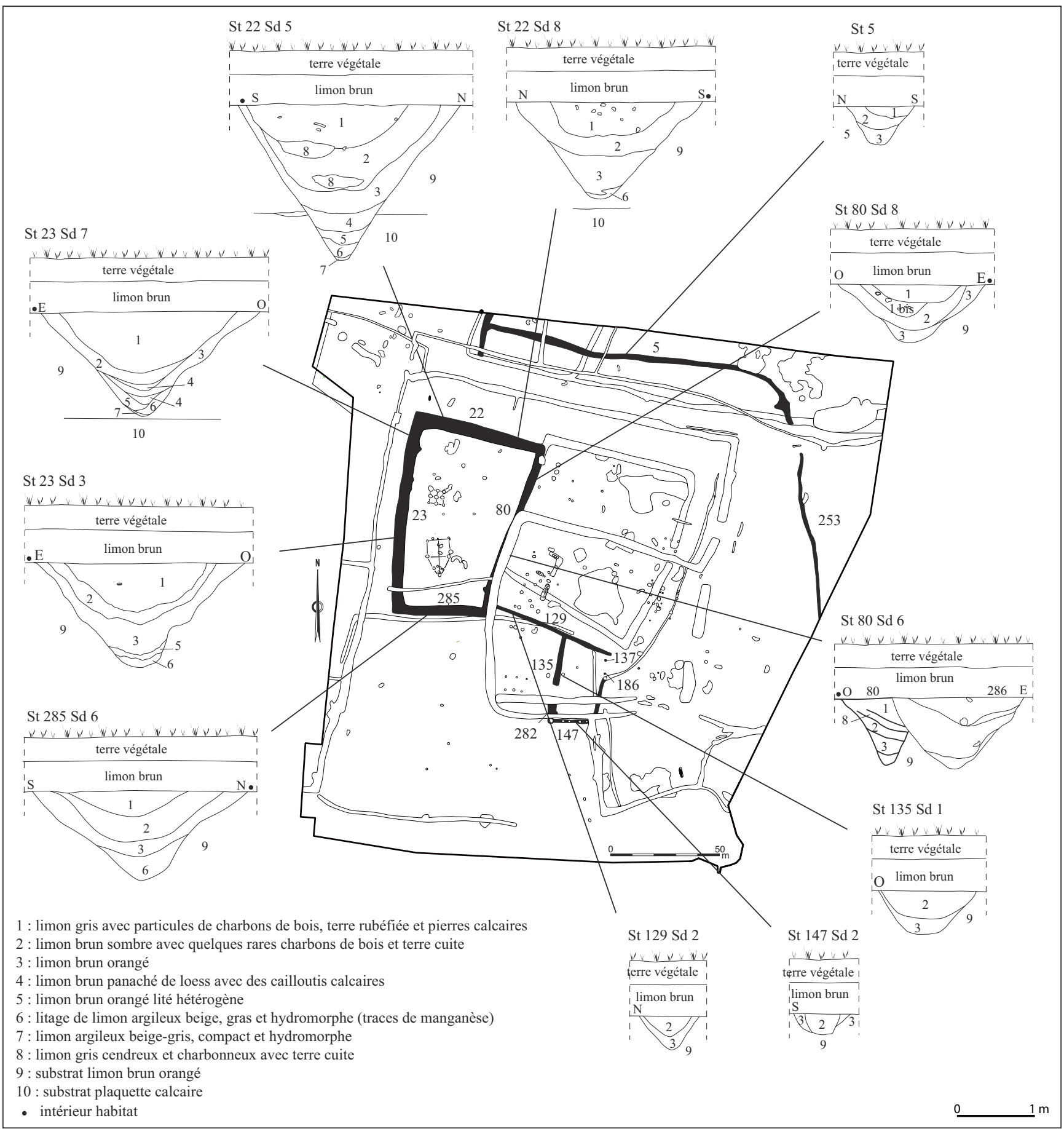

Figure 10 : Falaise "Expansia ", fossés de la phase 2. M. Besnard/Inrap.

Figure 10: Falaise "Expansia", ditches from the second period. M. Besnard/Inrap.

les fossés de la première et dernière phase. Le rôle de ces clôtures réside probablement dans le souhait de réaménager le passage créé lors de la première phase par la palissade en face de l'enclos. Il est d'ailleurs possible que celle-ci ait été maintenue durant cette phase, puisque le dispositif palissadé se situe dans son prolongement. Il n'est sans doute pas un hasard d'observer dans cette configuration deux trous de poteau (137 et 186), implantés au niveau du passage entre l'extrémité du fossé 129 et la palissade 147. Espacés de 2,5 mètres, leur disposition peut résulter d'un aménagement de porte. Sa création ne prend son réel intérêt que dans l'hypothèse où l'espace de la première phase ait continué à être 
fréquenté et que ses clôtures aient été encore visibles. Dans ce cas, la destination de ce premier enclos aurait évolué vers celle d'une aire de pâturage par exemple.

Le parcellaire

La limite parcellaire au nord a subi une transformation par le creusement d'un nouveau fossé à quelques mètres (fossé 5 , fig. 10). Contrairement au tracé rectiligne initial, ce fossé s'incline à l'est de l'habitat en direction du sud (fossé 235), en marquant une interruption de sept mètres de large correspondant à l'emplacement présumé du chemin. Son creusement montre un profil en $\mathrm{V}$ à fond arrondi de 1,2 mètre de profondeur sous le sol actuel. Son comblement est composé de limon brun orangé compact, recouvert de limon brun sombre faiblement anthropisé.

\section{Les aménagements internes}

Hormis quelques chablis, les vestiges au sein de cet enclos se composent de deux ensembles de trous de poteau, correspondant aux fondations de bâtiments en bois (fig. 11). Malgré le chevauchement de la dernière phase à celle-ci, le rattachement des deux édifices à cette étape est présumé en raison de leur orientation parallèle au côté occidental de l'enclos, suivant un axe nord-sud légèrement incurvé.

Le bâtiment au nord est de plan carré sur neuf poteaux, de quatre mètres de côté soit une superficie de seize mètres carrés. Les trous mesurent entre 50 et $80 \mathrm{~cm}$ de diamètre pour des profondeurs oscillant entre 75 et $90 \mathrm{~cm}$ sous le sol actuel. Leurs comblements sont constitués de limon brun sombre stérile. La position rapprochée des trous de poteau sur une aussi petite surface suggère une construction à plancher, généralement interprétée comme un grenier surélevé.

Le bâtiment au sud est représenté par un ensemble de trous de poteau formant un plan rectangulaire à abside triangulaire. Les dimensions et comblements des trous sont semblables à ceux du grenier. La longueur de l'édifice est de 8,5 mètres par 5 mètres de large. Le poteau à l'extrémité de l'abside, situé dans l'axe médian, se trouve à 5 mètres des poteaux corniers les plus près. Sa superficie correspond à un peu plus de 31 mètres carrés. Il faut admettre toutefois que la surface couverte est probablement plus importante. Des parallèles sont connus dès le premier âge du Fer à Basly (Lepaumier et al., 2005), en contexte de La Tène ancienne à Mosles (Marcigny et al., 1999) ou plus tardivement à Soulangy, Pont-Hébert et Quetteville "La Gohaigne », pour n'en citer que quelques exemples régionaux (Jahier et Vauterin, 2010).

\section{La troisième phase : le plein essor de l'habitat}

Cette troisième et dernière phase est marquée par l'aménagement de nouvelles clôtures, restructurant entière-

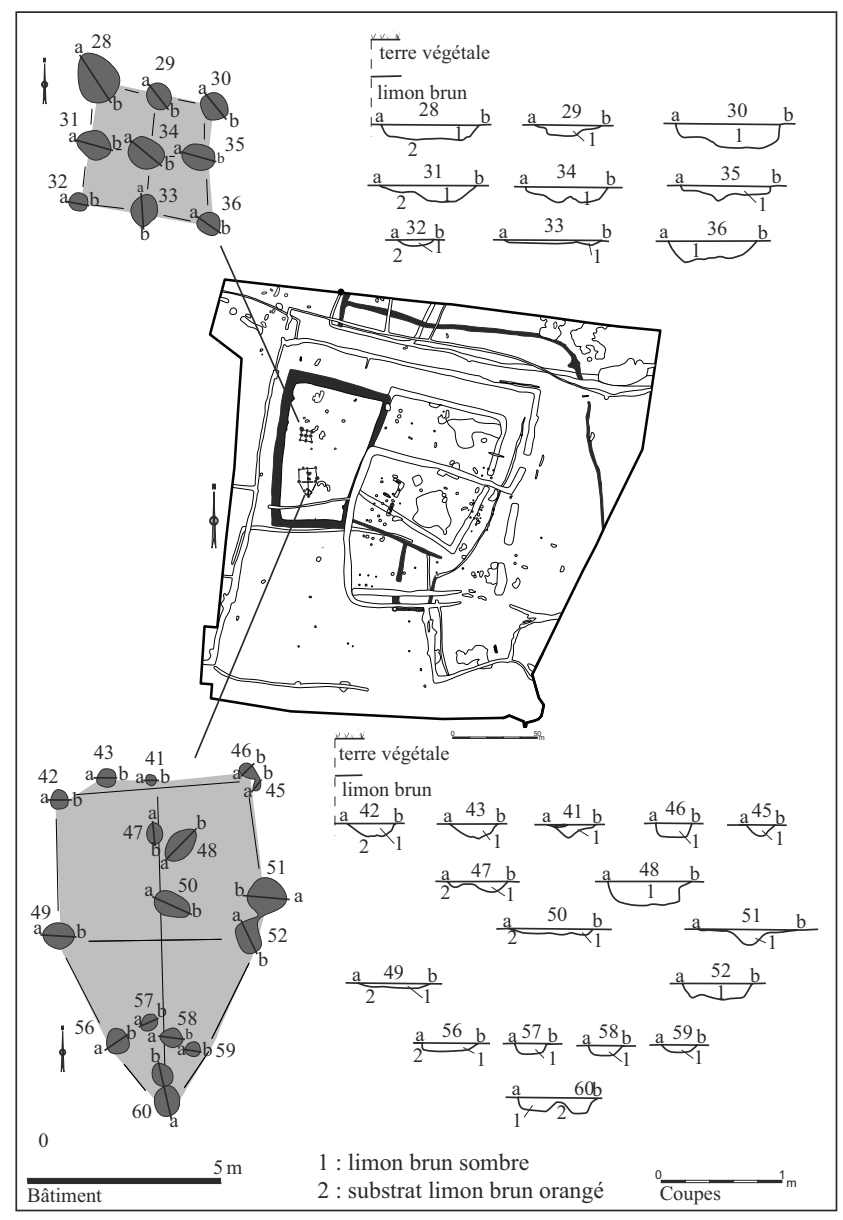

Figure 11 : Falaise "Expansia ", bâtiments de la phase 2. M. Besnard/Inrap.

Figure 11: Falaise "Expansia", constructions from the second period. M. Besnard/Inrap.

ment l'habitat. Celui-ci est compartimenté en différentes zones qui impliquent une gestion structurée de l'espace fonctionnel : partie résidentielle, espace agricole, secteur artisanal... L'ensemble couvre une superficie d'environ 7500 mètres carrés. Cette phase d'occupation s'échelonne entre La Tène moyenne et la première moitié de La Tène finale (II siècle-milieu $\mathrm{I}^{\mathrm{er}}$ siècle av. J.-C.). Le cœur de l'habitat est ceinturé par un enclos trapézoïdal entouré d'un espace périphérique, lui-même cerné par une clôture. Une sépulture isolée et non datée, située près de cette clôture, pourrait éventuellement appartenir à cette phase. Au sudest de l'habitat vient s'accoler un petit enclos dépourvu de vestiges. Pour la troisième fois consécutive, le parcellaire au nord de l'habitat connaît des re-creusements entraînant des modifications de tracés, tandis qu'un réseau parcellaire se développe à l'ouest de l'habitat. 


\section{Les clôtures}

\section{L'enceinte centrale}

L'enclos central décrit un plan trapézoïdal de 1800 mètres carrés de superficie (fig. 12). Le côté occidental emprunte partiellement le tracé oriental de la deuxième phase (fossé 131/286). Le côté méridional est formé par un double fossé (fossés 146 et 251), tandis que la limite orientale est constituée de deux tronçons de fossés, interrompus sur six mètres pour aménager une entrée (fossés 192 et 222). Cette façade est détachée des autres côtés, puisqu'une interruption d'à peine deux mètres la sépare du côté nord (fossé 97) et qu'un intervalle d'une dizaine de mètres la dissocie du double fossé du côté sud. Si l'intervalle à l'angle nord-est semble trop faible pour constituer un véritable passage ${ }^{4}$, celui à l'angle sud-est donne accès à l'aire clôturée accolée à l'enceinte centrale. L'ensemble des fossés comportent des creusements à profil en $\mathrm{V}$ et fond arrondi. Sur les côtés ouest, nord et est, leur profondeur varie entre 1,7 et 2 mètres sous le sol actuel pour une ouverture entre 2 et 2,5 mètres au niveau du décapage. Sur le côté sud, les dimensions du double fossé sont plus faibles avec une profondeur moyenne de 1,3 mètre sous le sol actuel et une ouverture de 1,2 mètre. Leurs comblements stratifiés sont le résultat d'un colmatage progressif

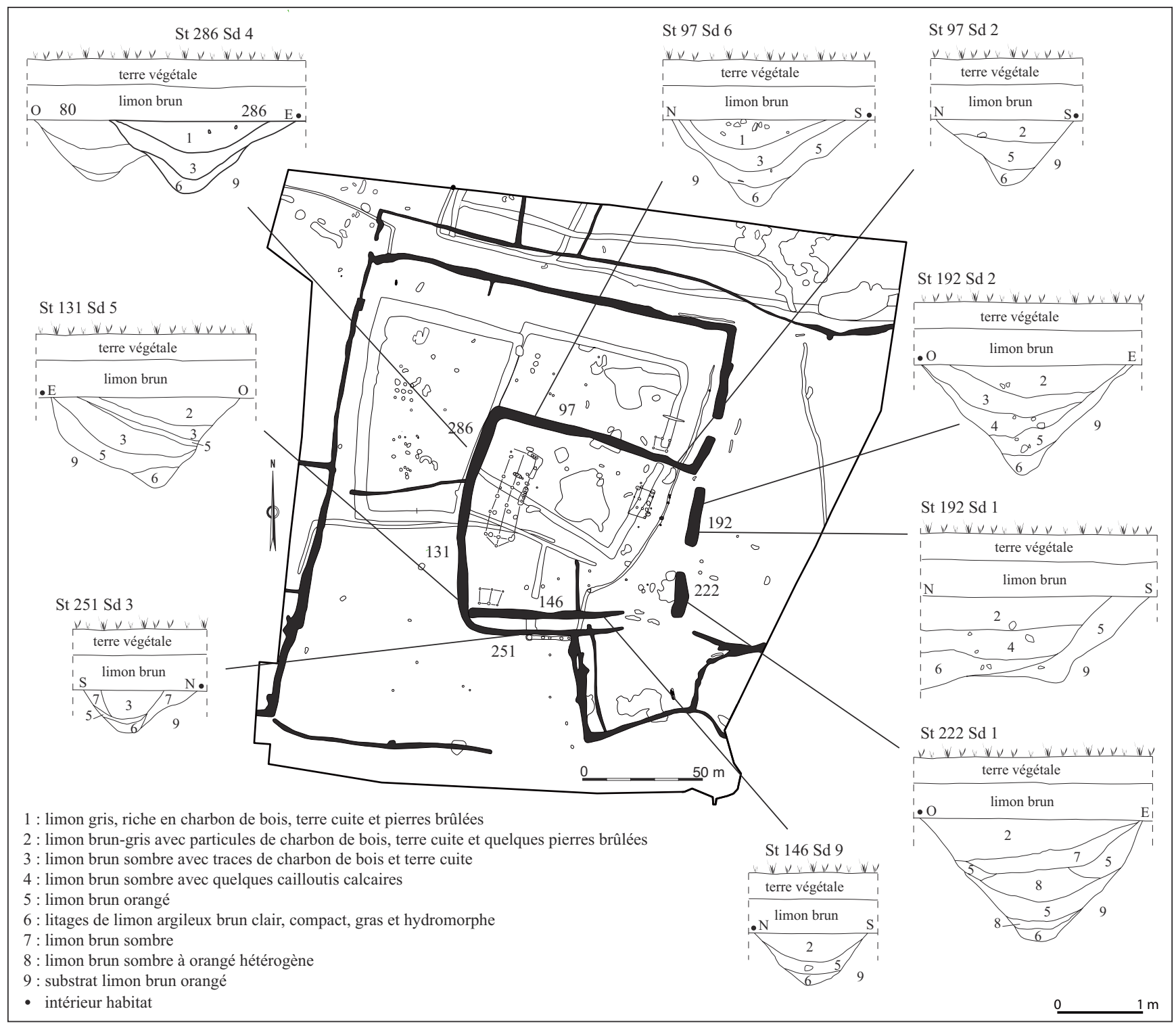

Figure 12 : Falaise "Expansia ", fossés de l'enceinte centrale de la phase 3. M. Besnard/Inrap.

Figure 12: Falaise "Expansia", ditches the central enclosure from the third period. M. Besnard/Inrap.
4. En restituant l'épaisseur décapée au profil des fossés, cet intervalle est estimé à moins de 1,5 mètre. Il est donc probable qu'il ne s'agisse pas d'un passage mais d'une discontinuité dans la partie excavée de la clôture, sans que ce soit le cas dans la partie talutée. 
d'une structure ouverte. Les premiers dépôts, amenés par le lessivage des flancs du fossé et de ses rives, sont composés de sédiments argilo-limoneux, stériles et hydromorphes, apparaissant parfois sous forme de litage. Ils sont recouverts de plusieurs strates de limons bruns, plus ou moins sombres, auxquels se sont mêlés des détritus anthropiques. Certains endroits, surtout dans la moitié ouest de l'habitat, révèlent des concentrations de rejets de combustion (charbons de bois, pierres brûlées, nodules de terre rubéfiée, éléments de sole de four) ou de mobilier domestique (céramique, restes fauniques, matériel lithique dont des fragments de meule), qui s'expliquent par la proximité des habitations.

Comme pour les fossés des phases précédentes, la disposition symétrique des strates dans la largeur du creusement n'apporte guère d'indices sur l'emplacement d'un talus bordier, mais on observe à certains endroits une inclinaison des strates, suggérant une provenance de la rive interne du fossé (par exemple, fossé 131-coupe 5). Ces dépôts, de nature limoneuse stérile, pourraient être issus de l'érosion d'un talus dressé avec les terres extraites, sur la face interne du fossé. L'éloignement des vestiges d'habitat des abords du fossé semble confirmer cette disposition. Sur le double tracé méridional, le talus a, par contre, vraisemblablement été dressé dans l'intervalle des fossés.

\section{L'espace périphérique}

Au nord, à l'ouest et au sud-ouest de l'enceinte centrale s'étend un espace périphérique de 25 à 30 mètres de large, délimité par une seconde clôture (fossés 185, 154, 1, 19, 72 et 253 , fig. 13). Cet espace est subdivisé par un fossé de sépa-

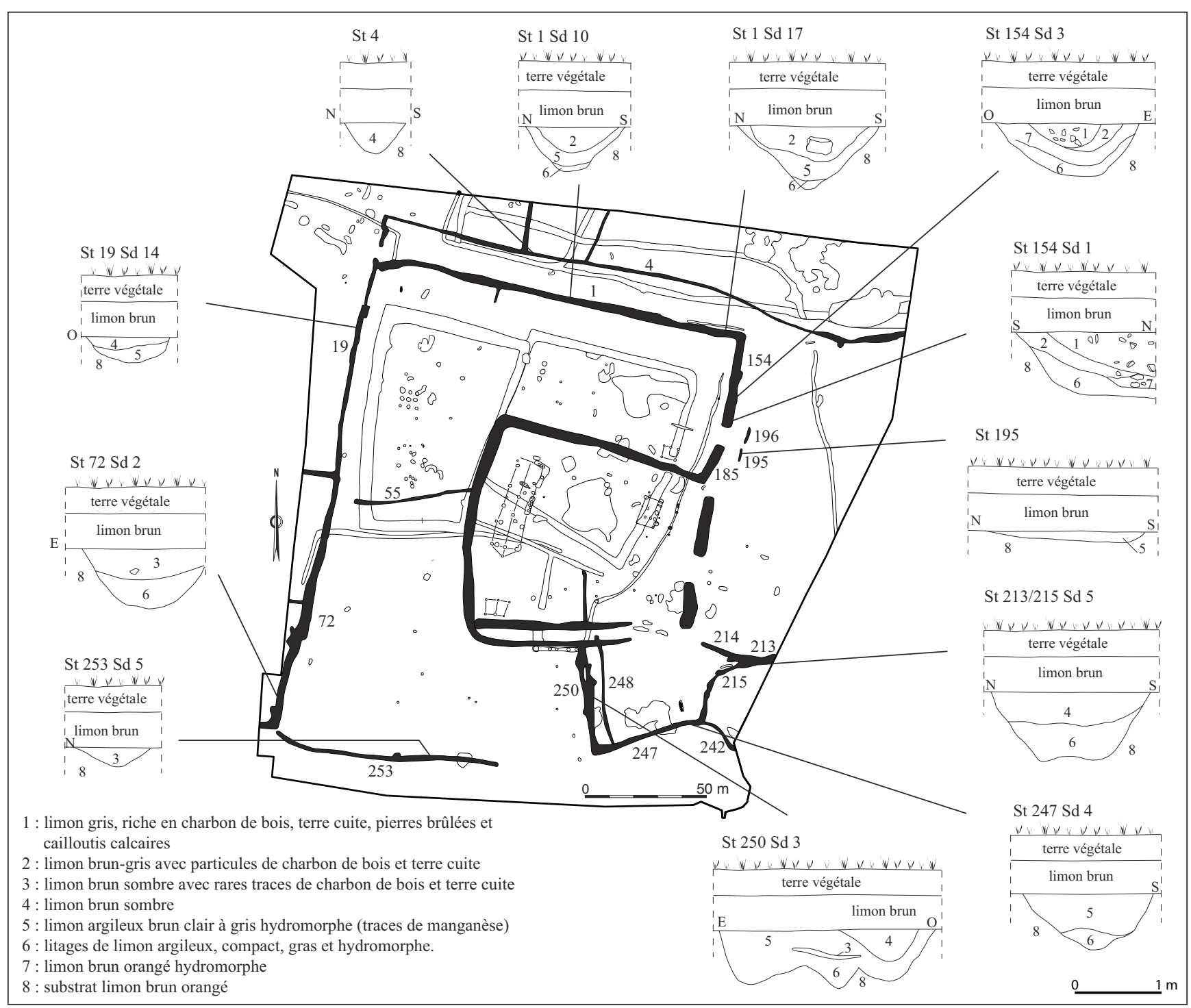

Figure 13 : Falaise "Expansia ", fossés des espaces périphériques de la phase 3. M. Besnard/Inrap.

Figure 13: Falaise "Expansia", ditches of peripherial areas from the third period. M. Besnard/Inrap. 
ration au milieu de la partie occidentale (fossé 55). Le côté oriental de la clôture, formé par la suite du fossé entourant l'aire centrale, présente une interruption de quatre mètres de large, faisant office d'entrée. Sur cette section, le fossé apparait le plus puissant avec une profondeur de 1,5 mètre sous le sol actuel pour une ouverture de deux mètres au niveau du décapage. Du côté nord, le creusement s'affaiblit légèrement vers l'ouest où il mesure 1,1 mètre de profondeur pour 1,2 mètre d'ouverture au niveau du décapage. Du côté ouest, la profondeur du fossé varie entre 0,90 mètre au nord et 1,5 mètre au sud. À cet endroit, la structure tourne à angle droit vers l'ouest, hors emprise de fouille, alors que le côté méridional est formé par un fossé indépendant (fossé 253), laissant un intervalle de l'ordre d'un mètre au niveau du décapage mais qui ne devait pas exister sur le profil original. Le comblement du tronçon oriental et septentrional se présente de manière semblable, composé au fond d'une sédimentation de limons argileux hydromorphes, brun grisé et compact, recouvert d'une ou deux couches de limon brun orangé, également de texture grasse et compacte avec des traces de manganèse. Les niveaux supérieurs sont formés de limons gris anthropisés avec la présence de pierres brûlées, de charbons de bois et de nodules de terre rubéfiée, ainsi que des fragments de céramique, des ossements de faune, des déchets scoriacés et des éléments de creusets. Sur le côté occidental, le remplissage composé de limon brun sombre, hydromorphe au fond, est nettement moins anthropisé. Au vu de ces comblements, ces fossés ont fonctionné à ciel ouvert. La question reste posée sur l'existence d'un talus au regard des stratigraphies des comblements peu démonstratives. Compte tenu de la profondeur progressive du fossé septentrional vers l'est, celui-ci a dû drainer l'eau de pluie vers le fossé de façade, jouant le rôle de collecteur. Les dépôts argilo-limoneux hydromorphes des horizons inférieurs et intermédiaires plaident dans ce sens. De même, la pente progressive du fossé à l'ouest a dû favoriser l'évacuation de l'eau vers le sud et ensuite vers l'ouest, si l'on considère la profondeur du fossé sur cet angle.

Deux petits tronçons de fossés, longs de 3 et 4 mètres (fossés 195 et 196), ont été observés en face de l'entrée sur le côté oriental. Parallèles à la clôture, ils se situent à 3,5 mètres et semblent interrompus sur 1,5 mètre. Leur creusement présente la forme d'une petite cuvette, très faiblement marquée sous le niveau du décapage. Cet aménagement rappelle la tranchée de palissade longeant la façade orientale de la première phase.

\section{Le petit espace accolé}

D'une superficie d'environ 600 mètres carrés, ce petit enclos vient s'accoler au sud-est de l'aire centrale et est accessible par celle-ci, ainsi que par une ouverture sur l'extérieur de l'habitat. Alors que le côté ouest (fossé 250) se dirige perpendiculairement sur la face méridionale de la clôture centrale, le côté sud (fossé 247) se divise à l'est en deux fossés curvilignes, l'un se dirigeant vers le sud-est hors emprise de fouille (fossé 242) et l'autre vers le nord-est formant la limite orientale de ce petit enclos (fossé 215). Sur ce dernier se raccorde un autre fossé (fossé 213), fermant partiellement cet espace au nord-est. L'ensemble de ces fossés montre des creusements en $\mathrm{U}$ ouvert, dont les dimensions vont de 1 à 1,3 mètre de profondeur sous le sol actuel pour 0,90 à 1,4 mètre de largeur au niveau du décapage. Le côté ouest a subi plusieurs re-creusements, montrant un léger déplacement du tracé (fig. 13, coupe 250-sd.3). Un petit fossé en parallèle et distant d'environ 3 mètres (fossé 248) constitue sans doute une étape dans ces multiples réaménagements. Les comblements de ces fossés sont constitués de limons brun orangé assez homogènes. Les niveaux inférieurs sont piquetés de traces de manganèse, indiquant une stagnation de l'eau au fond d'une structure restée à ciel ouvert. La configuration de cet enclos, et en particulier le double tracé curviligne des fossés à l'est (242 et 215), les reprises du tracé à l'ouest et la jonction des fossés à l'est (213 et 215), suggère un aménagement qui ne s'est pas réalisé en une seule fois.

\section{Le parcellaire}

La dernière phase d'aménagement parcellaire est formée par un fossé, qui reprend l'axe ouest-nord-ouest/est-sud-est des précédentes phases (fossé 4, fig. 13). À la hauteur de l'angle nord-ouest de la clôture périphérique de l'habitat, la structure s'incline à angle droit et s'arrête à trois mètres de cette clôture pour former un passage. Sur son tracé à l'est, le fossé s'incurve légèrement, comme pour éviter les fosses d'extraction à cet endroit. Le creusement montre un $U$ ouvert d'environ un mètre de profondeur sous le sol actuel pour une largeur de 0,60 mètre au niveau du décapage. Il est comblé de limon brun sombre. Ce fossé constitue le point d'appui pour deux limites parcellaires au nord. L'un d'eux a piégé dans son niveau supérieur des éléments de céramique gallo-romaine à pâte sombre commune, indiquant une ouverture encore partielle durant les premiers siècles de l'Antiquité. Lors de cette troisième phase, le parcellaire se développe également à l'ouest de l'habitat sous la forme de trois fossés qui prennent leur départ à la clôture périphérique de l'habitat.

\section{Les aménagements internes}

Ces divers vestiges domestiques excavés - fosses, trous de poteau et restes de fours - sont essentiellement présents dans l'aire centrale et en moindre nombre dans l'espace périphérique. En revanche, dans le petit espace clos accolé au sud-est n'ont été enregistrés que des chablis et des fosses d'extraction de lœess, sans relation avec cette occupation. 


\section{Les bâtiments}

Dans l'enceinte principale sont apparus trois plans de bâtiments : un grand plan d'une construction qu'il faut concevoir comme l'habitation principale (bâtiment A), un autre au sud de bien moindre superficie (bâtiment B), et un troisième à l'est qui est probablement incomplet (bâtiment $\mathrm{C}$ ). Les bâtiments $\mathrm{A}$ et $\mathrm{C}$ sont en partie installés dans le comblement des clôtures des deux précédentes phases.

Le bâtiment $\mathrm{A}$ correspond à un long édifice rectangulaire à deux nefs symétriques avec une petite abside triangulaire au sud (fig. 14 et 15). Il est disposé parallèlement à la clôture occidentale, à quelque quatre mètres de distance. Mesurant vingt mètres de long par six mètres de large, sa superficie porteuse est de l'ordre de 120 mètres carrés. Le plan montre une trentaine de trous de poteau répartis sur les trois axes parallèles. La plupart des poteaux des axes latéraux sont régulièrement espacés en vis-à-vis avec des intervalles de 3 à 4 mètres. D'autres sont implantés de façon rapprochée dans des tranchées de fondation, l'une au milieu de la façade orientale et l'autre marquant l'angle nord-est. Une troisième tranchée à l'intérieur du bâtiment et un trou de poteau dans le même alignement semblent séparer le quart nord du bâtiment du reste de l'intérieur (structure 284 et 284bis). Les trous de poteau ont des creusements tronconiques de 0,90 à 1,2 mètre de profondeur sous le sol actuel, tandis que les tranchées de fondation sont profondes en moyenne d'un mètre avec des empreintes de poteaux s'approfondissant jusqu'à 1,2 mètre. Les remplissages de ces excavations sont constitués de limons brun sombre, homogènes ou mêlés à des traces de charbons de bois, des nodules de terre rubéfiée ou des éléments de torchis présentant parfois des traces de clayonnage. Dans les tranchées de fondation, les emplacements de poteaux ont conservé des calages de pierres calcaires. Le plan d'ensemble de cet édifice n'est pas sans rappeler les longues " fermes étables " de l'âge du Bronze. Pour l'âge du Fer, des comparaisons régionales peuvent être faites avec l'édifice rectangulaire aux dimensions identiques de Plomb «Le Champ du Puits» (Manche; Jahier, 2001), daté de La Tène moyenne ou finale, ou avec le bâtiment à paroi périphérique de Creully "Le Clos de l'Épinette ", en contexte du III $^{\mathrm{e}}-\mathrm{I}^{\mathrm{er}}$ siècle av. J.-C. (Jahier, 2006). Des rapprochements moins évidents peuvent être faits avec le long bâtiment à abside de Hautot-le-Vatois (Seine-Maritime), en contexte Hallstatt final-La Tène ancienne (Blancquaert et Desfossés, 1994; Blancquaert et Adrian, 2006), ou avec le bâtiment à abside triangulaire de Saint-Denis (Seine-SaintDenis), daté de La Tène finale (Giraud et al., 2005).

Le bâtiment $B$, situé tout près de l'angle sud-ouest de l'espace central, offre un plan rectangulaire à six poteaux (fig. 16). Long de cinq mètres par trois de large, il occupe

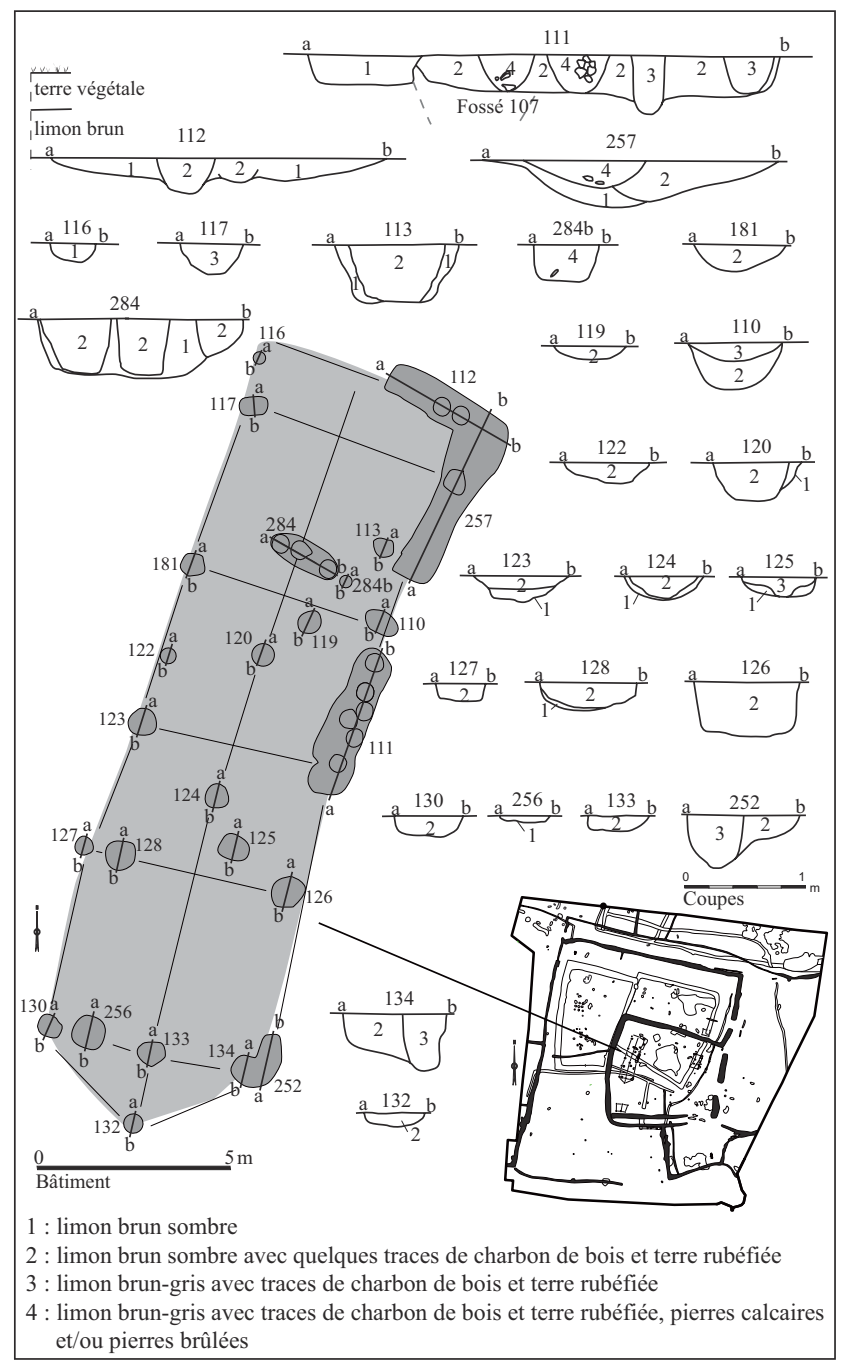

Figure 14 : Falaise "Expansia ", le bâtiment A de la phase 3. M. Besnard/Inrap.

Figure 14: Falaise "Expansia", building A from the third period. M. Besnard/Inrap.

une superficie de quinze mètres carrés. Son orientation respecte celle de la face méridionale de la clôture. Les trous de poteau, profonds de 0,80 à 1 mètre sous le sol actuel, sont comblés de limon brun sombre, contenant parfois des pierres calcaires. Sa petite superficie évoque plutôt une dépendance agricole, comme un grenier par exemple.

Le bâtiment $C$ est matérialisé par un plan incomplet, plus ou moins rectangulaire, formé par treize poteaux (fig. 16). Il suit l'orientation du bâtiment A. Un certain nombre de poteaux, notamment au niveau de l'angle sud-ouest, sont peut-être passés inaperçus dans le comblement du fossé d'enclos de la première phase. Le côté oriental constitue l'alignement le plus complet, formé par six poteaux dont deux côte à côte. L'ensemble mesure 6,5 mètres de long par 3,5 mètres de large, pour une superficie d'environ 23 mètres 


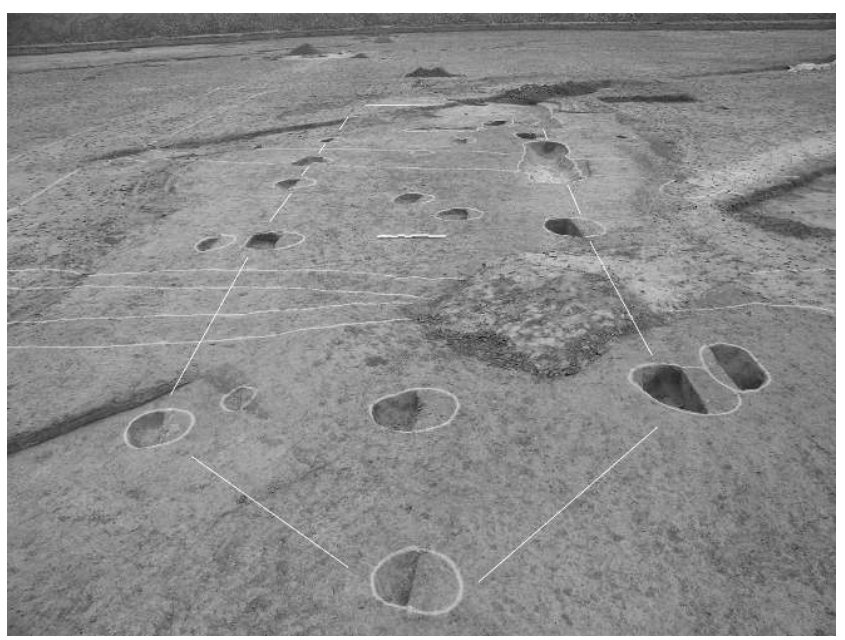

Figure 15 : e bâtiment A vu du sud. En premier plan : l'abside triangulaire. Cliché C.-C. Besnard-Vauterin.

Figure 15: Falaise "Expansia", building A seen from the south. In the foreground: the triangular apse. Photo C.-C. Besnard-Vauterin. carrés. Les creusements à profil tronconique mesurent 0,80 à 1 mètre de profondeur sous le sol actuel, à l'exception du trou à l'angle nord-est dépassant 1,4 mètre de profondeur (st. 288bis). Installé dans le comblement d'une fosse de même profondeur (st. 288, cf. infra), son enfoncement était sans doute nécessaire pour remédier à l'instabilité de l'encaissant. De nombreuses pierres dans le comblement ont dû renforcer le calage du poteau. Les autres trous sont comblés de limons brun sombre mêlés de particules charbonneuses, de nodules de terre rubéfiée et parfois d'éléments de torchis avec traces de clayonnage. En raison du plan incomplet, l'interprétation est délicate. Plus petit que le grand bâtiment perçu comme l'habitation principale, cet édifice sera placé dans la catégorie des dépendances et autres annexes.

Dans l'espace périphérique n'a été décelé qu'un ensemble de trous de poteau dont le plan correspond à un édifice (bâtiment D, fig. 16). Celui-ci se situe au nord de l'aire centrale, tout près de la clôture, de laquelle il adopte l'orientation. En partie installé dans le comblement du fossé d'en-

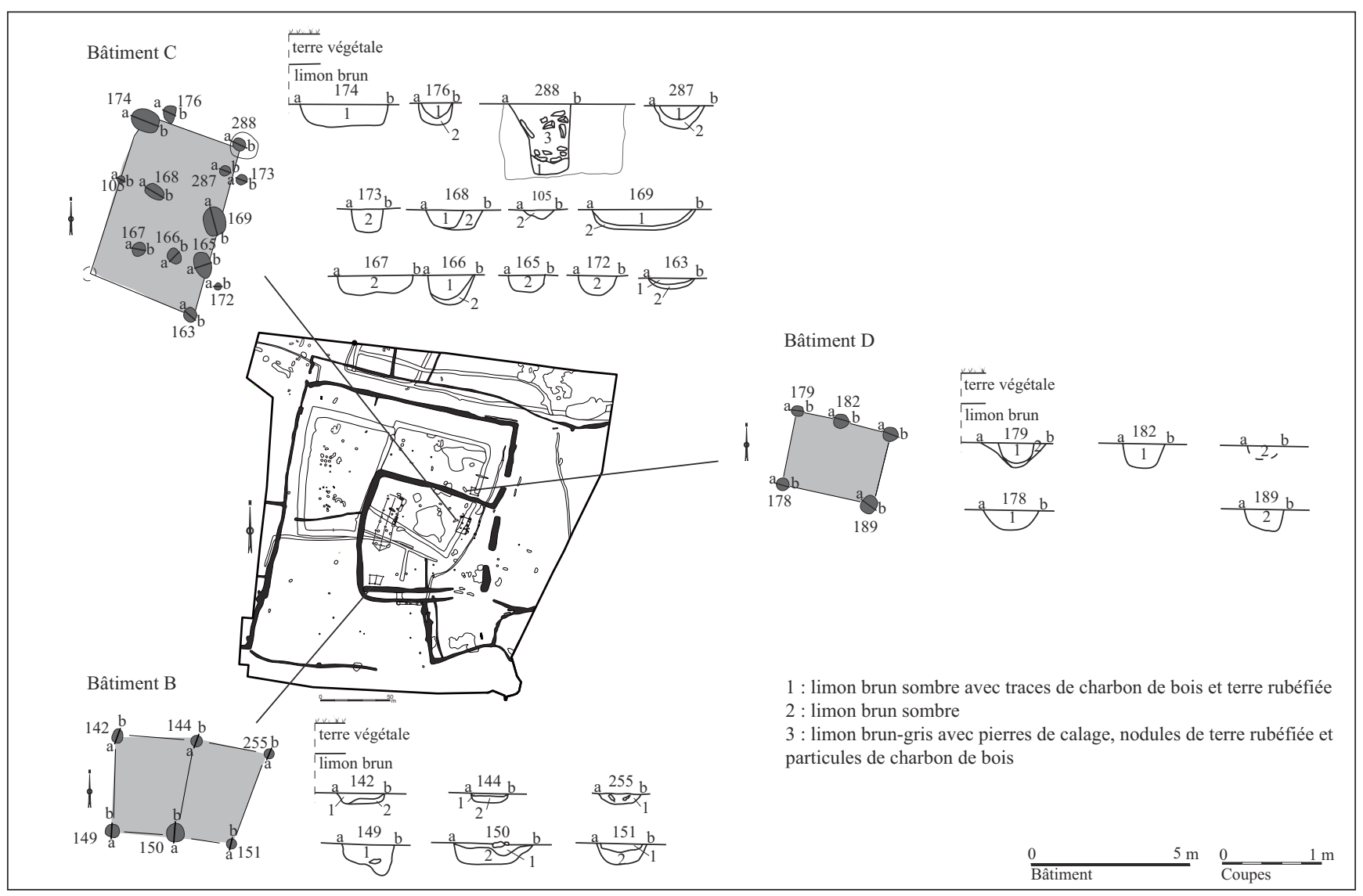

Figure 16 : "Falaise Expansia », les bâtiments B, C et D de la phase 3. M. Besnard/Inrap. Figure 16: "Falaise Expansia", buildings B, C and D of the third period. M. Besnard/Inrap. 
clos de la première phase, son plan quadrangulaire de trois mètres de long par 2,5 mètres de large est formé par cinq poteaux, dont un centré sur le côté nord. Les creusements montrent des profils en $U$ d'un mètre de profondeur sous le sol actuel et sont comblés de limons brun sombre. Cet édifice entrerait une nouvelle fois dans la catégorie des greniers. Une vingtaine de trous de poteau ont été repérés de manière dispersée sur tout le reste de la surface périphérique, constituant autant de témoins isolés d'aménagements dont le rattachement à cette phase demeure incertain.

\section{Les fosses}

Hormis des fosses d'origine anthropique douteuse et des traces de chablis, cinq fosses uniquement témoignent d'un aménagement intentionnel lié à cet habitat. Deux de ces structures (fosses 164 et 288, fig. 17) comportent des creusements cylindriques interprétés généralement comme des silos pour le stockage en atmosphère anaérobique (Gransar,
2000). Avec un diamètre de 1,2 à 1,3 mètre au niveau du décapage et une profondeur de 1,4 mètre sous le sol, leur volume de stockage peut être estimé à plus de deux mètres cubes pour chacun. Les comblements ne révèlent aucun indice quant à la nature des denrées conservées, puisqu'ils ne restituent que des rejets de combustion mêlés à des limons. Une troisième fosse (fosse 99) présente un plan sub-quadrangulaire d'environ deux mètres de côté et un creusement en forme de cuvette de 1,35 mètre de profondeur. Ni la forme, ni le remplissage composé de strates de limon brun sombre ponctué de traces charbonneuses et de nodules rubéfiés, ne permettent de se prononcer sur la fonction initiale de cette structure.

Il faut signaler la présence d'une vaste fosse occupant une place centrale, en face du long bâtiment (fosse 100). Une autre fosse semblable à celle-ci se situe dans la zone périphérique au nord, en face de l'entrée. Il s'agit de dépressions de plan irrégulier d'une envergure de 12 mètres par 10 pour

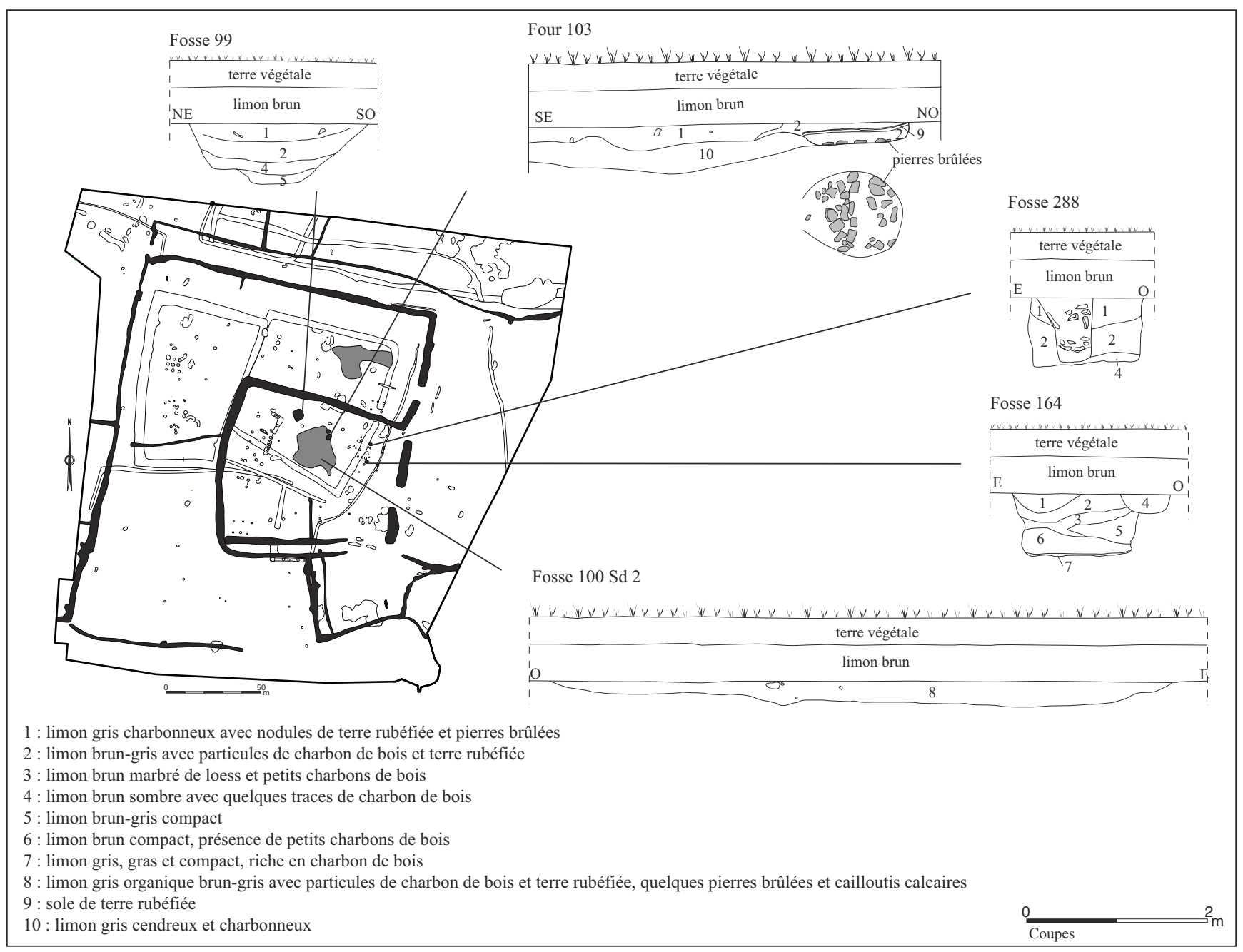

Figure 17 : Falaise "Expansia ", structures diverses attribuables à la phase 3. M. Besnard/Inrap.

Figure 17: Falaise "Expansia", various remains from the third period. M. Besnard/Inrap. 
celle dans l'enclos principale et de 16 mètres par 9 pour l'autre. Leur profil en cuvette à pentes douces mesure moins d'un mètre sous le sol actuel, dont à peine une trentaine de centimètres sous le niveau du décapage. Leur colmatage est composé de limon organique brun-gris, contenant des particules charbonneuses, des traces rubéfiées et des pierres calcaires. Ce comblement en apparence non stratifié semble avoir subi une forte homogénéisation par la bioturbation. Des restes osseux et des tessons de céramique de toutes tailles y sont associés, ces derniers permettant de confirmer le rattachement de ces structures à cette phase. Par leur étendue, ces fosses rappellent les vastes dépressions au cœur de certains habitats de la plaine de Caen (Mondeville, Cormelles-leRoyal, Ifs, Fleury-sur-Orne), dont l'interprétation comme mare, cour excavée, carrière d'extraction de loss ou fosse à fumier a été avancée suivant le type de creusement et la nature du comblement (Besnard-Vauterin, 2009a; Van den Bossche et al., 2009; Jahier et Vauterin, 2010; Lepaumier et al., 2010). Les dépressions de cet habitat, bien moins profondes, pourraient résulter d'un creusement opéré tout au long de l'occupation par les piétinements des animaux de ferme et un raclage saisonnier des sols pour ramasser le fumier destiné à l'amendement des champs.

\section{Les structures de combustion}

Malgré de nombreux rejets de combustion dans les comblements des vestiges excavés, un seul four est conservé au sein de l'habitat dont il ne reste plus que la sole et la base de la voûte (four 103; fig. 17). Située au bord de la vaste dépression centrale, cette structure est constituée d'une chambre de cuisson excavée et d'une fosse de travail. La sole circulaire, d'environ un mètre de diamètre, comporte un niveau de terre rubéfiée indurée recouvrant un dallage de pierres calcaires fortement brûlées. La fosse d'accès, longue de trois mètres pour un mètre de profondeur sous le sol actuel, a servi de cendrier au vu de son comblement très charbonneux.

\section{Une sépulture isolée}

La seconde sépulture mise en évidence dans l'emprise de la fouille est une inhumation en pleine terre située dans l'angle nord-ouest de l'espace périphérique (sépulture 2, fig. 9). Dépourvue de mobilier, cette tombe n'est pas datée, mais sa contemporanéité avec l'habitat est supposée à partir de son orientation parallèle à la ceinture fossoyée. La disposition des rares fragments d'os longs indique que le corps était posé la tête au sud-sud-ouest.

\section{LES MOBILIERS TÉMOIGNANT DES ACTIVITÉS DOMESTIQUES ET AGROPASTORALES}

À travers les mobiliers, aussi peu nombreux qu'ils soient sur le site de L'Attache et pour les premières phases d'Expansia, il est possible de dresser un aperçu des différentes activités exercées dans ces habitats. Si le domaine culinaire est largement représenté par les céramiques (cf. infra), il est également suggéré par des plaques de cuisson. En revanche, les travaux artisanaux et agricoles sont difficiles à appréhender faute d'outillage métallique. Le taux d'acidité des terres argileuses a eu 7 manifestement un impact négatif sur la conservation des matériaux métalliques et des restes fauniques. L'état fortement altéré de ces derniers en a empêché l'étude 5 . Les divers résidus métallurgiques sur les deux sites apportent un témoignage indirect de la fabrication ou de la réparation d'objets, aussi bien en fer qu'en alliage cuivreux. Des éléments de sole perforée d'un four et un probable lissoir à céramique laissent également entendre l'existence d'un atelier de potier sur le site d'Expansia. En dehors de cet artisanat peu documenté pour le secteur, des outils de mouture et de filature complètent l'illustration d'activités quotidiennes d'ordre domestique voire artisanal.

\section{Plaques foyères}

Hormis le corpus céramique, le registre des terres cuites comporte également plusieurs plaques dont un élément a pu être identifié comme plaque foyère. Il provient de l'un des fossés de la troisième phase du site d'Expansia. La pièce, incomplète, présente une forme quadrangulaire à angle arrondi avec un rebord en bourrelet sur sa face supérieure (fig. 18-1). Ces plaques mobiles vraisemblablement utilisées dans le domaine culinaire trouvent peu de comparaisons régionales. Absentes en plaine de Caen, elles sont en revanche attestées sur les plaines d'Argentan et d'Alençon, limitrophes des Pays de la Loire où elles ont été fréquemment identifiées (Vauterin et al., 2010).

\section{Des témoins probables d'un atelier de potier}

De nombreux fragments perforés en terre cuite, trouvés en position de rejet au sein des fossés de la dernière phase d'Expansia (127 fragments équivalent à $7 \mathrm{~kg}$ ), pourraient être interprétés comme les restes d'une sole perforée suspendue d'un four de potier. Modelés et épais de 4 à $7 \mathrm{~cm}$,

5. G. Auxiette in Besnard-Vauterin 2008. Sur le site d'Expansia, les espèces suivantes ont pu être distinguées : le bœuf (Bos taurus), le porc (Sus domesticus), les caprinés (Ovis aries/Capra hircus), le chien (Canis familaris) et le cheval (Equus caballus). Parmi les mammifères sauvages, seul le cerf (Cervus elaphus) a été clairement identifié. 


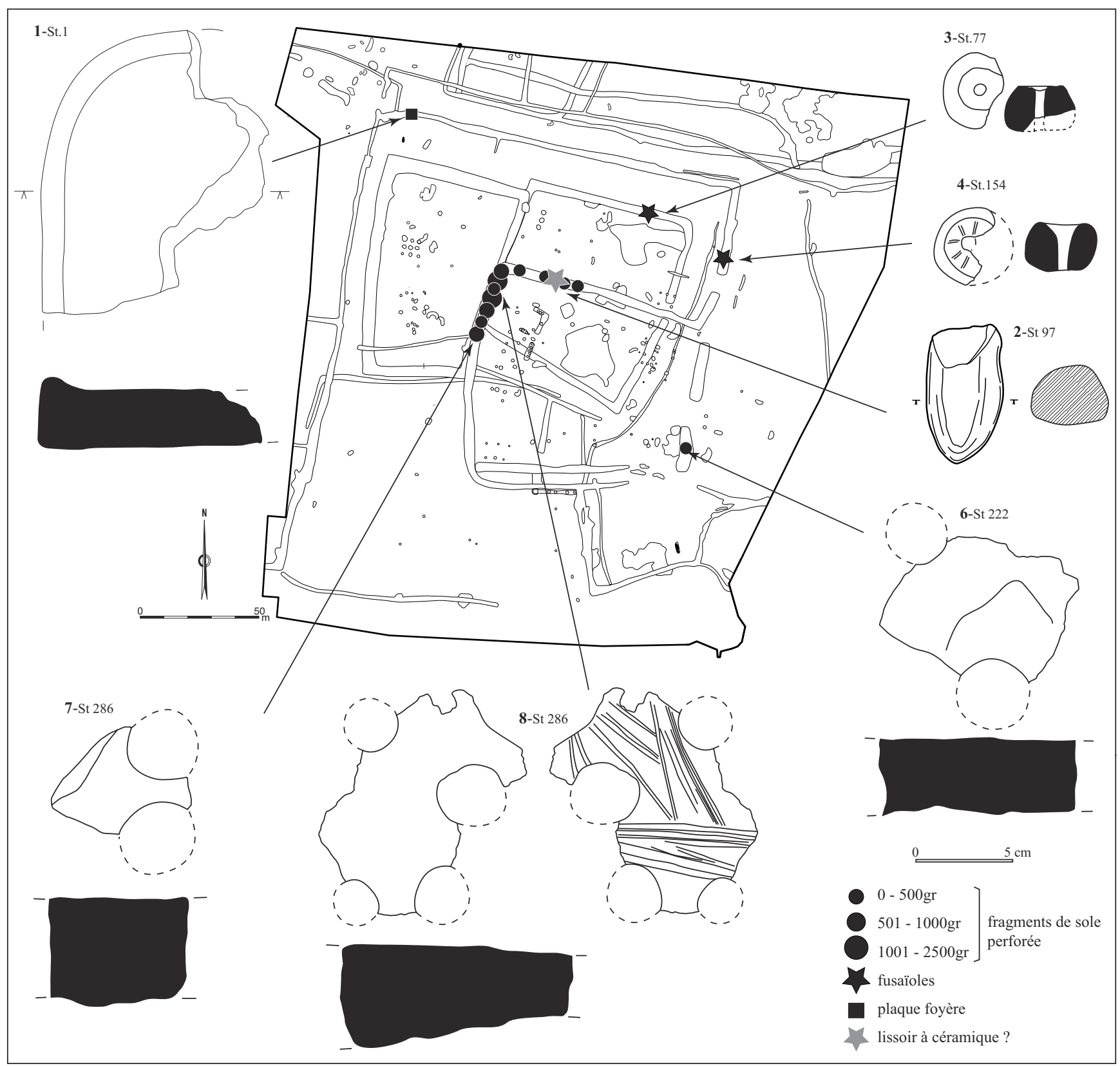

Figure 18 : Falaise "Expansia ", mobiliers divers. M. Besnard/Inrap. Figure 18: Falaise "Expansia", various artefacts. M. Besnard/Inrap.

ces fragments présentent des perforations de 3 à $5 \mathrm{~cm}$ de diamètre, irrégulièrement espacées de 8 à $12 \mathrm{~cm}$ de centre en centre (fig. 18-6 à 8). Ils possèdent une surface plane et une face inférieure brute et striée par des empruntes de boiseries, traces d'un support de branchage. À ce jour, un seul autre site dans la région, l'enclos $\mathrm{n}^{\circ} 8$ du plateau de Thaon, a livré des pièces semblables interprétées comme une sole de four de potier (San Juan et al., 1999, p. 174 et 192). Dans ces mêmes contextes a été découverte une pièce lithique qui a probablement été utilisée comme lissoir à céramique (fig. 18-2). Il s'agit d'un petit galet en roche noire métamorphique ou volcanique à grain très fin. La pièce, fracturée, montre une face plane lissée, sur laquelle de nombreuses stries de lissage sont visibles à la loupe binoculaire. L'association de ces éléments tend bien à supposer l'existence d'un atelier de potier sur le site d'Expansia, une activité artisanale encore très peu documentée à l'échelle régionale. 


\section{Le filage}

Une activité de filage est supposée sur le site d'Expansia à partir de la découverte de deux fusaïoles, outil indispensable dans la transformation de la filasse en fils torsadés. Il s'agit de deux objets en terre cuite de forme cylindrique, tous deux fragmentaires. L'un est issu du fossé d'enclos de la première phase (fig. 18-3); l'autre provient du fossé périphérique de la troisième phase (fig. 18-4). Ce dernier porte un décor sur sa partie supérieure composé de paires d'incisions parallèles, disposées en rayons autour de la perforation. Au regard de leur petite dimension $(3,3 \mathrm{~cm}$ de diamètre) et de leur faible poids ( 5 à $6 \mathrm{~g}$ ), ces fusaïoles ont vraisemblablement été destinées à la production de fils "fins " (E. Séhier in Besnard-Vauterin, 2008). Toutefois, cette information reste relative puisque l'on ne connaît pas les caractéristiques du fuseau employé. Bien que cette activité soit fréquemment représentée au sein des ensembles ruraux de cette période, aucun élément issu des fouilles de L'Attache ou d'Expansia ne permet de mettre en évidence les autres étapes nécessaires à la fabrication d'un textile, en l'occurrence le tissage et le traitement du produit fini par le foulage, la teinture ou la couture.

\section{La mouture}

Sur les deux sites, le mobilier lithique est parvenu en état très fragmentaire et donc difficilement identifiable. Sur le site de L'Attache n'ont été identifiés que deux fragments de meules de type rotatif, tous deux en granite et issus d'une fosse de la deuxième phase. Le matériel de mouture du site d'Expansia est attesté par huit fragments de granite. Possédant une face travaillée lissée, leur état fragmentaire, et brûlé pour certains, ne permet pas d'identifier s'il s'agit du type à va-et-vient ou rotatif. En revanche, une molette en pierre calcaire appartient bien au type à va-et-vient. Ces éléments de meules sont répartis sur les trois phases d'occupation avec une pièce pour la première phase, deux pour la deuxième et six pour la troisième (dont la molette).

\section{L'activité métallurgique}

Les résidus métallurgiques recueillis sur les sites de L'Attache et d'Expansia témoignent uniquement de la pratique de la forge (culots de forge) et du travail des alliages base cuivre (creuset). Aucune structure n'a pu être identifiée, mais des éléments de parois de foyers métallurgiques ont été découverts avec les déchets, révélant leur présence à proximité.

L'étude des restes métallurgiques sur le site d'Expansia (N. Zaour in Besnard-Vauterin, 2008) a permis de diffé- rencier deux zones de rejet pour la troisième phase d'occupation, l'une située à l'angle sud-ouest de l'enclos central (zone 1) et la seconde sur l'entrée de l'enclos périphérique (zone 2; fig. 19). Elles se distinguent d'une part par la différence de concentration et d'autre part par la nature des vestiges. La première zone a livré des culots de forge dont un double culot (fig. 19-1), alors que la seconde zone a livré quantitativement plus de matériel mais de taille plus petite et de poids plus faible, avec six petites scories de forge, un fragment de paroi scoriacée, un élément de ventilation et quatre fragments de creusets (fig. 19-2 et 3). La différence de matériel entre ces deux secteurs pourrait suggérer la présence de deux ateliers distincts, l'un travaillant uniquement le fer et l'autre utilisant aussi bien le fer que les alliages base cuivre.

La diversité dans les formes et les tailles de cette dizaine de culots de forge évoquent des activités différentes et variées plutôt qu'un travail standardisé. Les forgerons de Falaise ont dû alors fabriquer, réparer, souder, mais aussi travailler des objets en alliage base cuivre si l'on se réfère à la présence de plusieurs creusets. La petite quantité de déchets recueillis indique aussi qu'il s'agit plus certainement d'une simple forge domestique permettant de répondre à la demande de matériel nécessaire au bon fonctionnement de la ferme, plutôt que d'une forge réalisant une production excédentaire aux besoins du site.

\section{LES MOBILIERS CÉRAMIQUES DES SITES DE L'ATTACHE ET D'EXPANSIA}

Les corpus céramiques des deux sites de Falaise sont très inégaux. Celui d'Expansia atteint 2342 tessons qui correspondent à un poids total de $27 \mathrm{~kg}$. À L'Attache, l'ensemble se compose de 446 tessons pour un poids de $5,3 \mathrm{~kg}$. Le NMI, comptabilisé à partir des parties supérieures des vases, se limite à un peu plus d'une centaine d'éléments. Seules dix formes sont archéologiquement complètes et sont, de ce fait, à considérer comme des rejets primaires. Le reste est essentiellement constitué de rejets secondaires, qui ont vraisemblablement subi des remaniements lors des réaménagements successifs des fossés.

Sur chacun des deux sites, le mobilier céramique provient en majeure partie des fossés. Sur le site d'Expansia, les fossés de la première phase d'aménagement ont livré moins de $9 \%$ du total, trois éléments de bords et une forme archéologiquement complète. La deuxième phase a livré dans ses fossés $13 \%$ du lot. Le NMI compte une douzaine de pièces, dont une forme archéologiquement complète. Les fossés de la troisième phase constituent un lot important représentant $65 \%$ du corpus. Le NMI s'élève à 70 , dont cinq vases archéologiquement complets. La grande partie de ce mobi- 


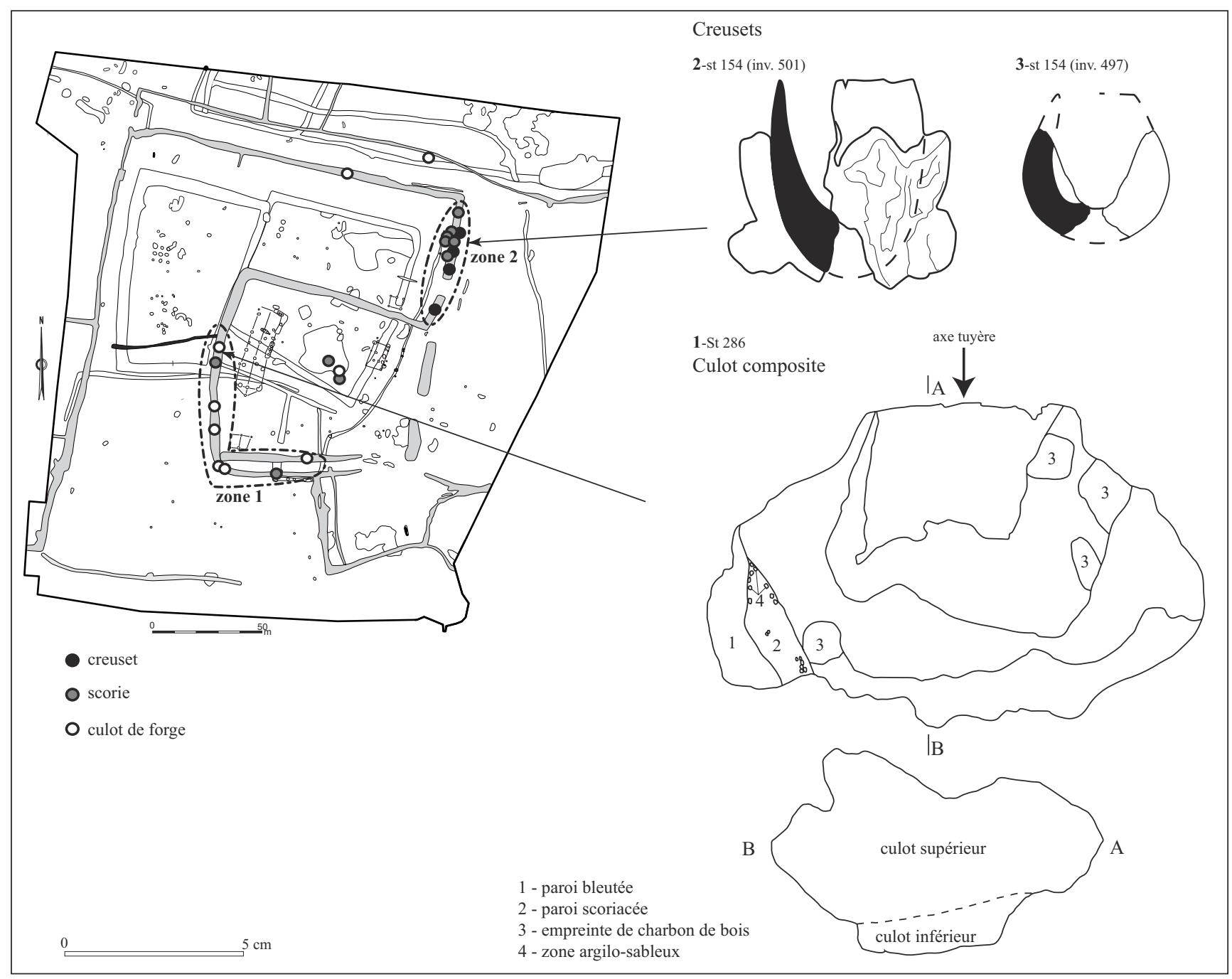

Figure 19 : Falaise " Expansia », restes métallurgiques. N. Zaour et M. Besnard/Inrap. Figure 19: Falaise "Expansia", metallurgical artefacts. N. Zaour and M. Besnard/Inrap.

lier provient des fossés qui délimitent le cœur de l'habitat (fossés 97, 131/286 et 146), et plus particulièrement des zones autour du bâtiment principal. Les $13 \%$ restants du lot céramique concernent les autres vestiges : les fosses, les trous de poteau et les fossés non rattachés à l'une des phases. Sur le site de L'Attache, la moitié des formes céramiques sont issues des fossés d'enclos (fossés 1, 5/6/27, 12/26/78). Le reste du mobilier provient des fosses de dimensions importantes situées au sein de l'habitat (fosses 31, 33, 43, 49, 57, 71, 87).

\section{Aspects techniques et décoratifs}

La céramique est modelée pour environ deux tiers de l'ensemble. Les proportions de vases tournés semblent augmenter légèrement durant les phases finales des occupations. Les vases ont subi une cuisson en atmosphère réductrice primitive, caractérisée par des surfaces de couleurs sombres variées. Les traitements de surface les plus courants consistent en une simple égalisation au doigt ou un léger peignage effectué en mouvement irrégulier, vertical ou horizontal avec un bouchon végétal ou un instrument denté. D'autres sont lissés sommairement à l'aide d'un galet. Le lissage soigné est uniquement réservé aux jattes sinueuses.

Les éléments décoratifs sont plutôt bien représentés dans les corpus céramiques : près de la moitié des lots en sont pourvus. Le répertoire apparaît très varié et concerne aussi bien des décors "archaïsants ", hérités du premier âge du Fer, que des motifs largement répandus à la fin de la période laténienne (fig. 20).

Les éléments " archaïsants " regroupent les décors impressionnés, représentés sur les lèvres et les carènes d'une douzaine de récipients. Ils sont réalisés au doigt, à l'ongle ou à 


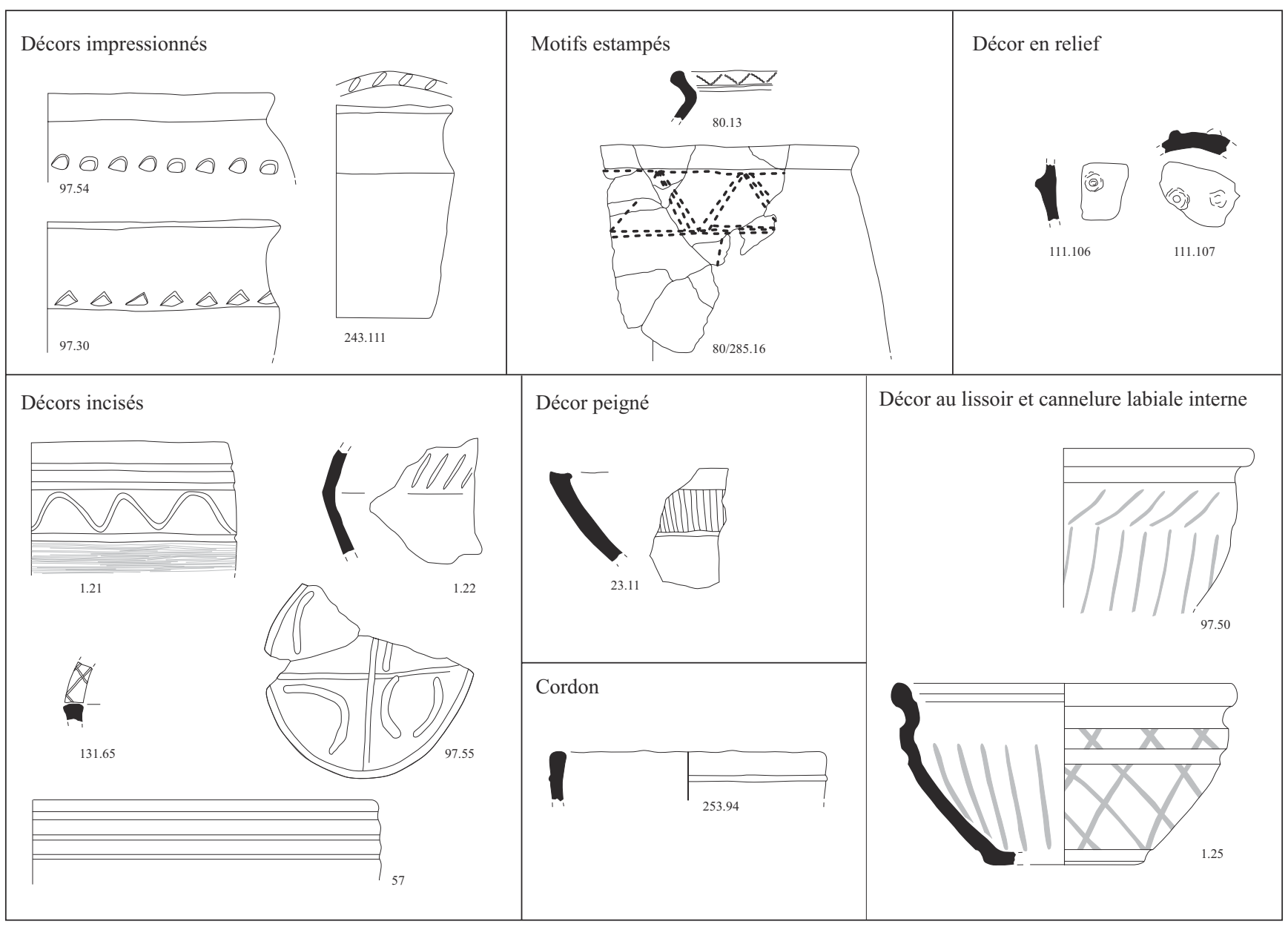

Figure 20 : Falaise "L'Attache " et "Expansia », les registres décoratifs des céramiques. C.-C. Besnard-Vauterin/Inrap. Figure 20: Falaise "L'Attache" and "Expansia", decorated pottery. C.-C. Besnard-Vauterin/Inrap.

l'aide d'un objet pointu (couteau, spatule, baguette?), mais la différence n'est pas toujours évidente. Ce type de décor est récurrent sur les ensembles de La Tène ancienne et du début de La Tène moyenne. Dans le Calvados, de nombreuses séries du $\mathrm{IV}^{\mathrm{e}}$ et du $\mathrm{III}^{\mathrm{e}}$ siècle av. J.-C. en ont livré, comme celles de Mosles "La Pièce du Pressoir " (Marcigny et al., 1999) et de Fierville-les-Parcs (Jahier et al., 2002) ou encore, dans l'Orne, celle de Marcei « Le Marais " (Jahier, 2006). Les décors impressionnés apparaissent sporadiquement dans les séries du $\mathrm{II}^{\mathrm{e}}$ siècle av. J.-C., comme à SaintMartin-des-Entrées (Marcigny et al., 2004) ou dans celles du I ${ }^{\text {er }}$ siècle av. J.-C., comme sur la ZAC de Beaulieu à Caen sous forme d'un décor onglé sur le bord (Besnard-Vauterin et Navarre, 2008).

Des motifs estampés sont présents sur deux récipients, l'un sous forme de petites stries piquetées en chevrons dans la cannelure labiale interne d'une jatte sinueuse et l'autre formant des chevrons pointillés encadrés de lignes horizontales sur le col d'une forme haute. Ce dernier motif est probablement exécuté à l'aide de dents de peigne. Ces deux motifs trouvent également des références dans des ensembles de La Tène ancienne. C'est le cas à Marcei «Le Marais " pour les petites stries piquetées (Jahier, 2006). La ponctuation chevronnée est connue sur le site d'Avion "La République » où ce décor apparaît autour de 400-350 av. J.-C. et perdure dans la phase suivante, daté globalement jusqu'à 250 av. J.-C (Hurtrelle et al., 1990). En milieu armoricain, les motifs estampés disparaissent au tout début de La Tène finale (fin $\mathrm{II}^{\mathrm{e}}$-début $\mathrm{I}^{\mathrm{er}}$ siècle; Daire, 1992).

Un décor en relief composé d'un alignement de petits boutons pincés aux doigts caractérise deux fragments de panse d'un même vase. Malgré les apparentés avec le répertoire de la fin de l'âge du Bronze, ce décor trouve une référence à Saint-Riquier-en-Rivière "Au-dessus du Val d'Aulnoy " avec un godet à tétons issu d'une sépulture de contexte La Tène moyenne (Mantel et al., 2002). Des ressemblances sont à évoquer avec les points diamantés sur un vase de Saint- 
Aubin-Routot, dans un contexte de La Tène A/B ou début C (Blancquaert et Desfossés, 1994).

Les décors incisés, l'ornementation la plus courante, sont appliqués sous différentes formes. La configuration la plus simple est une ou plusieurs cannelures sur le col ou l'épaulement. Deux vases portent des registres de traits obliques, espacés régulièrement sur l'épaulement. Un élément porte des incisions en croisillons sur le méplat de la lèvre. Un autre décor consiste en une ligne ondulée marquant le haut de la panse. Sur le dessous d'un fond plat figure un décor libre, composé d'un cercle et de deux lignes croisées divisant le fond en quatre champs dans lesquels s'inscrivent des traits courbés. Hormis les traits obliques, qui sont un décor récurrent durant tout le second âge du Fer, les autres décors sont associés aux ensembles bas-normands du $\mathrm{III}^{\mathrm{e}}$ au I $\mathrm{I}^{\mathrm{er}}$ siècle av. J.-C.

Le peignage apporté à titre décoratif est présent sur deux éléments, ornés au niveau du col d'un registre de traits verticaux encadré de cannelures. Il se retrouve dans les mêmes assemblages céramiques que les précédents décors.

La présence de cordons, caractéristiques des poteries fines de l'Armorique et ses régions limitrophes pour la fin du second âge du Fer (Daire, 1989), est ici attestée sur un seul élément, au niveau d'un col droit.

Les décors au lissoir, réalisés à la pointe mousse et apparaissant sur la céramique en très légère dépression, se retrouvent sous forme de lignes croisées couvrant la panse, de traits obliques et de stries rayonnantes à l'intérieur du vase. Ces décors ornent couramment les céramiques des régions armoricaines et avoisinantes pour des périodes couvrant La Tène moyenne et finale (Daire, 1992). Au Boisanne, ils apparaissent dans la phase III, datée du milieu du III $^{\mathrm{e}}$ au milieu du $\mathrm{I}^{\mathrm{er}}$ siècle av. J.-C., avec des cas de perduration possible jusqu'au début de l'Antiquité (Menez, 1996, p. 115). Les croisillons semblent plutôt liés à La Tène finale (Daire, 1989, p. 47). Les décors au lissoir sont généralement associés à des jattes à profil sinueux.

La cannelure labiale interne, que l'on ne peut guère considérer comme élément décoratif, est une autre particularité des céramiques armoricaines du second âge du Fer, que l'on retrouve aussi bien dans les départements avoisinants : le Calvados, la Manche, la Sarthe, la Mayenne, le Maine-etLoire et la Loire-Atlantique. Vers la fin de La Tène, cette cannelure s'affine progressivement et disparaît. Ici, une dizaine de récipients en sont dotés.

\section{Typologie}

L'état fragmentaire des céramiques a rendu le classement habituel en formes basses, moyennes et hautes difficile, voire impossible. La typologie s'est donc surtout centrée sur le profil général des vases, après un premier découpage entre formes ouvertes et fermées. Il en ressort huit types (fig. 21).
Quatre concernent des formes ouvertes, largement dominantes dans les ensembles, alors que les formes fermées se décomposent en trois types, représentés par seulement quelques exemples. Une dernière catégorie concerne les couvercles, représentés ici par un seul élément issu de l'ensemble de Falaise " Expansia ».

\section{Formes ouvertes}

Type $1:$ les profils tronconiques

Les formes $1 \mathrm{~A}$ concentrent les pots à profil continu droit avec un bord droit ou très légèrement rentrant. Le soustype $1 \mathrm{~B}$ regroupe les terrines à profil continu évasé avec un bord dans le prolongement de la panse. Dans le soustype $1 \mathrm{C}$, ce bord est légèrement redressé par rapport à l'axe évasé de la panse. Les formes $1 \mathrm{D}$ présentent un bord droit et la liaison avec la panse est plus marquée. Les lèvres sont arrondies ou aplaties.

\section{Type 2 : les profils carénés}

Les vases de ce type montrent une panse rectiligne évasée surmontée d'un col concave droit ou légèrement rentrant. La liaison entre le col et la panse est anguleuse dans le soustype $2 \mathrm{~A}$, plus adoucie en $2 \mathrm{~B}$. La lèvre est souvent épaissie vers l'extérieur et aplatie. Le profil caréné de la forme $2 \mathrm{C}$ se détache des précédentes silhouettes par une panse légèrement convexe et se rapproche alors des profils sinueux.

Type 3 : les profils sinueux bas/moyens

Ces jattes sont pourvues d'un col concave, droit ou légèrement éversé. Elles ont été divisées en trois sous-types. Les formes $3 \mathrm{~A}$ rassemblent les jattes sinueuses pourvues d'une cannelure labiale interne, celles du 3B n'en possèdent pas. La jatte $3 \mathrm{C}$ quant à elle, possède un col haut légèrement concave. Les lèvres sont toutes arrondies, parfois épaissies ou en bourrelet externe.

Type 4 : les profils sinueux hauts

Ce type rassemble des pots à profil sinueux élancé. Les formes $4 \mathrm{~A}$ montrent un col concave droit et une lèvre épaissie arrondie. Dans le sous-type $4 \mathrm{~B}$, la panse est quasiment rectiligne, surmontée d'un col concave éversé. Le vase $4 \mathrm{C}$ differre des précédents par son col droit à double courbure. La lèvre est légèrement éversée et épaissie.

\section{Formes fermées}

Type 5 : les profils globulaires à col droit

Ces jarres à corps globulaire, probablement de grand volume, sont surmontées d'un petit col droit. La lèvre est souvent en bourrelet externe, arrondi ou aplati. L'un des 


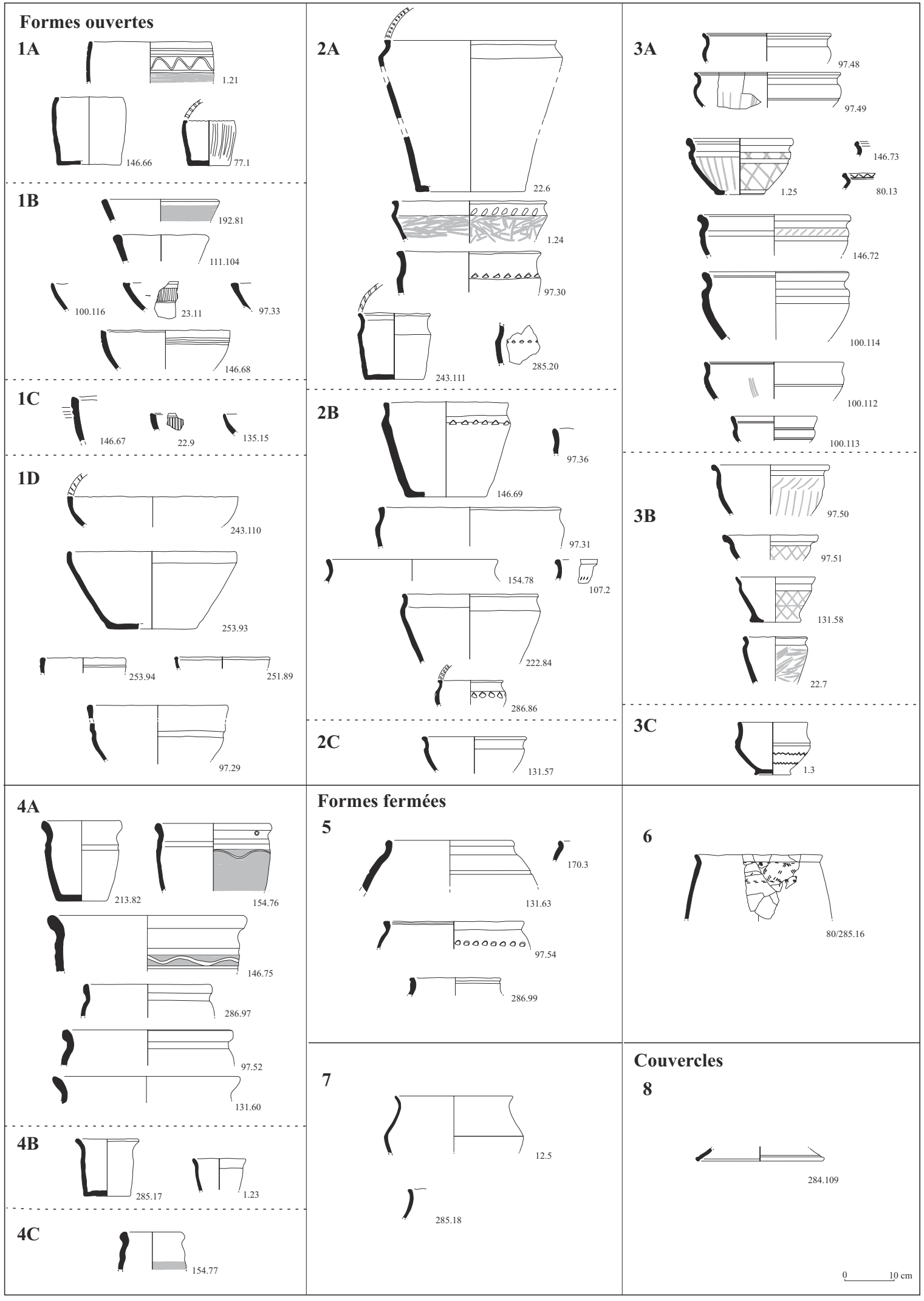

Figure 21 : Falaise "L'Attache » et " Expansia », représentation typologique des céramiques. C.-C. Besnard-Vauterin/Inrap. Figure 21: Falaise "L'Attache" and "Expansia", pottery typology. C.-C. Besnard-Vauterin/Inrap. 
récipients était muni d'anses à œillet, mais un recollage s'est révélé impossible (non dessiné).

Type 6 : un profil tronconique à bord éversé

Ce vase caréné, que l’on peut imaginer à corps ovoïde, montre dans sa partie sommitale une panse rectiligne rentrante, surmontée d'un petit bord éversé à lèvre arrondie. Cet individu, unique dans ce lot, est orné sur le haut de la panse de chevrons pointillés.

Type 7 : les profils sinueux carénés à bord éversé

Cette forme, très fine, à épaulement caréné se caractérise par un haut col rentrant et un bord éversé. La lèvre est arrondie.

\section{Couvercles}

Type 8 : couvercle

Cet élément montre un profil rectiligne et une lèvre en bourrelet arrondi. L'extrémité épouse parfaitement le bord de certaines jattes à large cannelure labiale interne.

\section{Comparaisons chronologiques}

Bien que les vases à profil continu de type 1 constituent une forme ubiquiste durant tout le second âge du Fer, ceux ornés de multiples cannelures et de registres de décors incisés ou peignés sont largement représentés dans les séries calvadosiennes du $\mathrm{III}^{\mathrm{e}}$ au $\mathrm{I}^{\mathrm{er}}$ siècle av. J.-C. Ils sont particulièrement présents dans les ensembles de la plaine de Caen, dont on peut citer, parmi d'autres, ceux de Fleury-sur-Orne (San Juan et al., 1994, Lepaumier, 2012), d'Ifs « Object'Ifs Sud " (Le Goff, 2002), de Cormelles-le-Royal (Carpentier et al., 2002, Lepaumier, 2009), de Mondeville «L'Étoile " (Besnard-Vauterin, 2009a) et du "MIR " (PeuchetGeilenbrügge et Morzadec, 2001). On les retrouve dans le Pays d'Auge au sein des séries de Quetteville (Lepaumier, 2002) et de Saint-Gatien-des-Bois (Paris, 1997) et, dans la vallée de la Seulles, dans celles du plateau de Thaon, bien qu'ici en moindre nombre (San Juan et al., 1999).

Les références chronologiques pour le type 2 s'échelonnent entre le tout début du second âge du Fer et le début de sa phase finale. Les comparaisons les plus hautes s'accordent aux silhouettes carénées du sous-type $2 \mathrm{~A}$. On les retrouve associées à des décors digités dans la phase I du Boisanne, datée de la fin $\mathrm{du}^{\mathrm{e}}$ à la première moitié $\mathrm{du}_{\mathrm{IV}}^{\mathrm{e}}$ siècle av. J.-C. (Menez, 1996) ou dans la série de Mosles « La Pièce du Pressoir » du Iv siècle av. J.-C. (Marcigny et al., 1999). Le profil du vase 97.30 (fig. 24) se retrouve dans la série de Marcei «Le Marais » dans la première phase, datée du III $^{\mathrm{e}}$ siècle av. J.-C. (Jahier, 2006). D'autres pièces à carène vive et décor digité sont signalées en contexte de La Tène moyenne, comme à Saint-Riquier-en-Rivière "Au-dessus du Val d'Aulnoy " (Mantel et al., 2002) ou à Cottévrard "La Plaine de la Buccaille" (Blancquaert, 2002). Une jarre à décor onglé sur le plat de la lèvre est signalée à Bois-Guillaume "Les Bocquets " en contexte funéraire de La Tène C2-D1 (200/180- 70/50 av. J.-C.; Merleau et al., 2002). Le sous-type $2 B$ trouve des références plus récentes avec la phase 3 de Marcei "Le Marais ", dont la datation est supposée autour du début du $\mathrm{I}^{\text {er }}$ siècle av. J.-C. Des profils similaires associés à un décor onglé sur le bord sont encore connus au début du $\mathrm{I}^{\mathrm{er}}$ siècle av. J.-C. sur la ZAC de Beaulieu à Caen (Besnard-Vauterin et Navarre, 2008).

La série du type 3 trouve de nombreuses correspondances dans les ensembles laténiens, plus particulièrement dans celles de la péninsule armoricaine et ses marges, notamment pour les jattes à cannelure labiale interne. Lélément à large cannelure labiale ornée d'un décor estampé (80.13, fig. 23) figure dans les séries les plus anciennes et trouve une comparaison avec certaines jattes, comme celles de la phase II tardive du Boisanne, datée de la seconde moitié du $\mathrm{IV}^{\mathrm{e}}$ et de la première moitié du III $^{\mathrm{e}}$ siècle av. J.-C. (Menez, 1996) et celles de Saint-Jacut-de-la-Mer, datée du II $^{\mathrm{e}}$ siècle av. J.-C. (Daire, 1989). De nombreuses références régionales sont à citer pour les autres jattes, telles que celles ornées de stries rayonnantes dans les séries du $\mathrm{III}^{\mathrm{e}}$ au I $\mathrm{I}^{\mathrm{er}}$ siècle av. J.-C. sur le plateau de Thaon (San Juan et al., 1999), d'Ifs " Object'Ifs Sud " (Le Goff, 2002) et de Mondeville "L'Étoile" (Besnard-Vauterin, 2009a) ou celles ornées de croisillons ou de lignes obliques issues des contextes de $\mathrm{La}$ Tène finale de Mondeville "L'Étoile » et de Putot-en-Bessin (Hérard, 1996), ou, dans l'Orne, de Marcei "Le Maréchal " et de Nécy « La Martinière " (Besnard-Vauterin et al., 2006).

Les profils des types $4 A$ et $4 B$ se retrouvent dans des séries bas-normandes du III $^{\mathrm{e}}$ au $\mathrm{I}^{\mathrm{er}}$ siècle av. J.-C., comme dans celles du plateau de Thaon, de Putot-en-Bessin et d'Ifs "Object'Ifs Sud " ou, dans des contextes laténiens finals, comme à Nécy « La Martinière » et Marcei «Le Maréchal ». Le vase 154.76 (fig. 24) se compare à une pièce quasiment identique d'Aubigny, dans un contexte de la fin de La Tène moyenne et de La Tène finale (Jahier et Peuchet, 1994). La forme 4C, bien moins commune, se rapproche d'un élément à col ondulé de Putot-en-Bessin, ici à lèvre rentrante. Son contexte est daté de 125 à 50 av. J.-C. Un autre parallèle peut être établi avec deux cols ondulés de Saint-Martin-desEntrées, pour lesquels des apparentés avec les jattes à haut col du domaine armoricain ont été émis (Marcigny et al., 2004, fig. 19, type 8).

L'un des récipients de type 5 muni d'anses à oillet n'a pas pu être restitué faute de collage. Ce type d'anse fait son apparition comme moyen de suspension dans le domaine armoricain et ses marges vers le milieu du III $^{\mathrm{e}}$ siècle av. J.-C. 
et perdure jusqu'à la première moitié du $\mathrm{I}^{\mathrm{er}}$ siècle av. J.-C. On cite comme exemple le Boisanne, Saint-Jacut-de-la-Mer et Paule (Menez et Arramond, 1997). Les séries calvadosiennes connaissent cette anse pour les mêmes périodes. Citons pour la plaine de Caen celles de Fleury-sur-Orne, d'Ifs "Object'Ifs Sud ", de Mondeville "L'Étoile " et le " MIR », et pour le Bessin celles de Saint-Martin-des-Entrées, de Putot-enBessin et du plateau de Thaon. Les vases globulaires fermés se rencontrent dans ces mêmes contextes. Des formes identiques au $\mathrm{n}^{\circ} 131.63$ (fig. 24) sont connues à Mondeville "L'Étoile » et à Marcei « Le Maréchal » ou encore aux Genâts dans le Sud-Vendée en contexte de La Tène finale (Nillesse, 2003). Le no 97.54 (fig. 24), à lèvre renflée aplatie et décor digité sur l'épaulement, trouve un parallèle à Verberie " Le Buisson Campin " dans l'Oise (Malrain et al., 1996), daté de la fin de La Tène moyenne.

Hormis son décor, le vase de type 6 montre des affinités avec des séries du Bronze final, notamment avec les vases à parois sub-verticales et bord éversé de Catenoy « Le Camp César » dans l'Oise (Blanchet et Talon, 1987) et, en contexte bas-normand, avec ceux de Cussy " La Pointe » (Marcigny et Ghesquière, 1998). Ce profil se retrouve dans des ensembles datés de la transition de la fin du premier et le début de second âge du Fer, comme à Ifs " Object'Ifs Sud-dernière tranche " (Vauterin, 2011, type 8a-d). Le décor ponctué trouve également des références au début du second âge du Fer (Hurtrelle et al., 1990).

Le type 7 s'apparente à des jattes carénées à haut col concave de la fin du premier et du début du second âge du Fer, mais l'épaulement se présente ici plus arrondi. Sur le site du Boisanne, cette forme accompagne la phase I calée entre la fin $\mathrm{du} \mathrm{v}^{\mathrm{e}}$ et la première moitié $\mathrm{du} \mathrm{Iv}^{\mathrm{e}}$ siècle av. J.-C. (Menez, 1996).

Les éléments de comparaison avec le type 8 sont rares. Un rebord de couvercle est signalé à Isigny-sur-Mer " Le Tuilley " (Calvados) en contexte daté du milieu du $\mathrm{II}^{\mathrm{e}}$ au

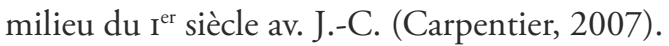

\section{Chronologie des phasages}

\section{Falaise "L'Attache »}

Phase 1

Le matériel céramique attribué à la première phase du site (fig. 22) est modeste et semble indiquer une datation de La Tène moyenne, peut-être de La Tène ancienne.

\section{Phase 2}

Le mobilier issu de la deuxième phase d'occupation (fig. 22) comporte des formes dont les caractéristiques permettent de les associer à la période de La Tène finale.
C'est le cas des jattes à profil ouvert, ornées de multiples cannelures et réalisées à partir d'un dégraissant coquillier (fosse 57). D'autres formes rappellent quant à elles des productions de La Tène moyenne. Il s'agit de jattes basses à épaulement marqué et cannelure labiale interne (fosse 43, fossé $5 \mathrm{sd}$. 2). Cette deuxième phase semble ainsi se situer dans une fourchette chronologique comprise entre la phase finale de La Tène moyenne et le courant de La Tène finale. Aucune forme tardive, caractérisant des contextes augustotibériens, n’est attestée.

\section{Falaise " Expansia»}

Les comparaisons régionales et extrarégionales permettent de placer ce corpus céramique dans une fourchette chronologique se situant entre la fin du $\mathrm{v}^{\mathrm{e}}$ s. et le milieu du $\mathrm{I}^{\mathrm{er}}$ siècle av. J.-C. Cet ensemble résulte d'une occupation couvrant une période de l'ordre de trois cent cinquante ans, rythmée par trois grands aménagements de clôture dont le phasage a été mis en évidence à travers les stratigraphies. Comme déjà évoqué, ces différents aménagements s'installent en partie dans les comblements des vestiges antérieurs, ce qui a pu provoquer des bouleversements dans les rejets mobiliers.

\section{Phase 1}

Le peu de matériel issu des comblements de fossés de la première phase n'a livré que quatre formes susceptibles d'apporter une indication chronologique, ce qui est bien peu, d'autant plus que trois de ces fragments sont de petite taille (fig. 23). La datation de cette première installation est donc établie sur tout le corpus céramique et supposée dans la deuxième moitié de La Tène ancienne, soit le $\mathrm{IV}^{\mathrm{e}}$ siècle av. J.-C. Aucun élément ne permet d'affirmer clairement une installation antérieure à ce siècle.

\section{Phase 2}

Le mobilier issu des fossés de la deuxième phase d'aménagement apparaît chronologiquement proche de la précédente phase. Plusieurs éléments (fig. 23) trouvent en effet un parallèle dans les séries de Mosles et Fierville-les-Parcs, notamment le vase caréné ${ }^{\circ} 22.6$ à décor impressionné sur le bord (Jahier et al., 2002) et le profil sinueux 22.8 à décor onglé sur la lèvre et l'épaule (Marcigny et al., 1999). Le haut col rentrant $\mathrm{n}^{\circ} 285.18$ rappelle la forme 12.5 de la première phase. D'autre part, les décors estampés de la lèvre à cannelure interne $\mathrm{n}^{\circ} 80.14$ et sur la panse de la forme énigmatique 80/285.16 font référence à des séries du Iv ${ }^{e}$ et de la première moitié du III $^{\mathrm{e}}$ siècle av. J.-C. (cf. supra). Les registres de décors peignés des fragments $\mathrm{n}^{\text {os }} 22.9$ et 23.11 et la ligne ondulée du $\mathrm{n}^{\circ} 80.14$ apparaissent un peu plus récents, généralement entre le $\mathrm{III}^{\mathrm{e}}$ et le $\mathrm{I}^{\mathrm{er}}$ siècle av. J.-C. en plaine de Caen. On peut en déduire que la datation de cet 


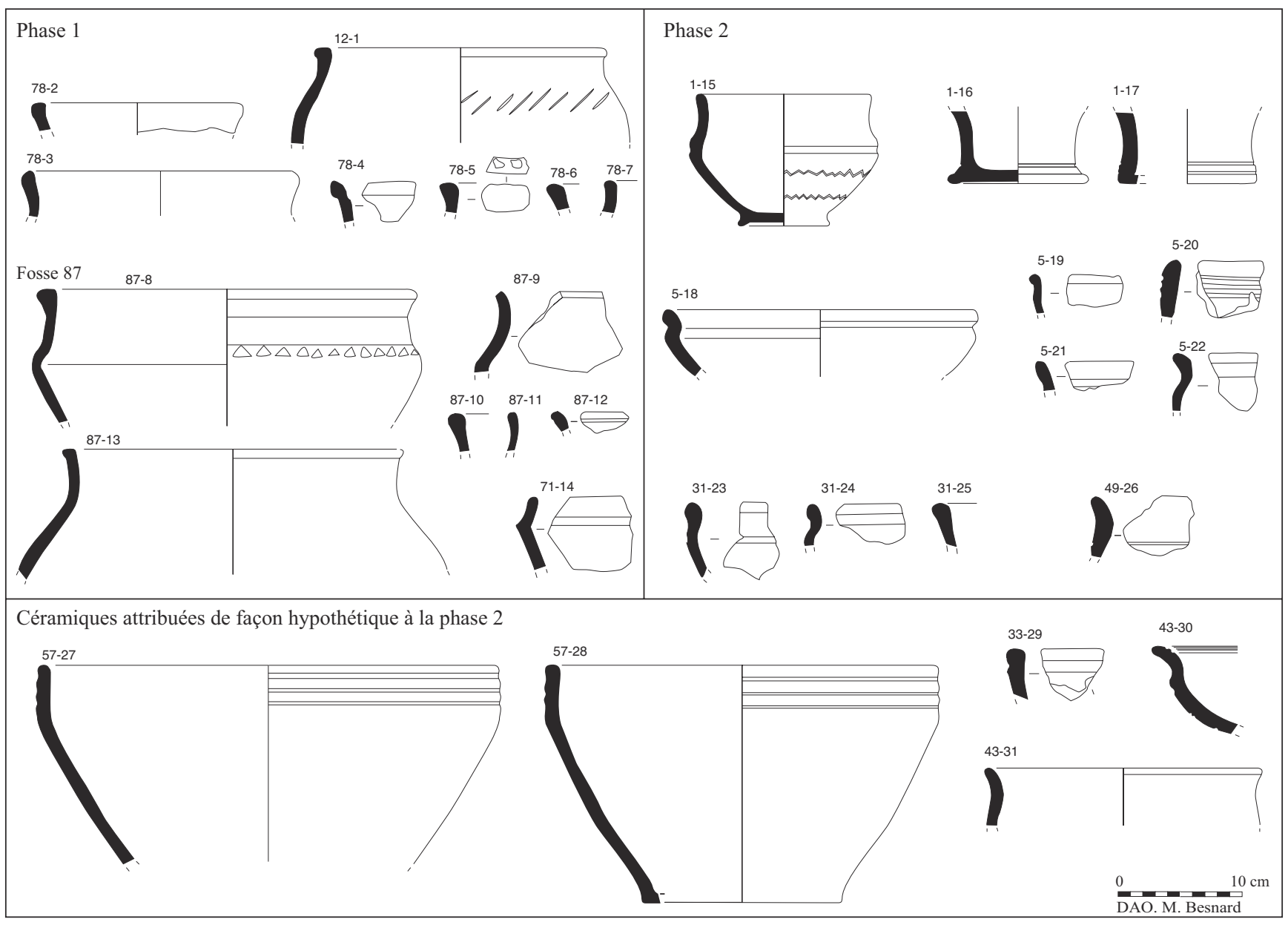

Figure 22 : Falaise "L'Attache », céramiques des deux phases d'occupation. M. Besnard/Inrap. (Le numéro de structure est suivi d'une numérotation continue).

Figure 22: Falaise "L'Attache", pottery from the two phases of occupation. M. Besnard/Inrap. (The structure number is followed by a continuous number).

ensemble s'échelonne grosso modo entre la fin du rve et la fin du III siècle av. J.-C. (fin La Tène ancienne / début La Tène moyenne).

Phase 3

Dans le lot de la troisième phase (fig. 24-25), les éléments archaïsants comme les vases carénés aux décors impressionnés côtoient les céramiques caractéristiques des phases finales de La Tène. Certaines des pièces « archaïsantes » sont vraisemblablement à considérer comme du matériel résiduel remanié, comme le vase 286.96 à décor digité, issu du fossé occidental de l'enclos central - correspondant au côté recreusé - ainsi que les panses ornées de boutons 111.106107 en provenance du bâtiment A. L'ensemble voit l'apparition de nombreuses formes sinueuses, des anses à œillet et des décors au lissoir, dont entre autres des registres en croisillons, caractéristiques de La Tène finale. Ces éléments permettent de proposer une datation de La Tène moyenne à la première moitié de La Tène finale ( $\mathrm{II}^{\mathrm{e}}$ siècle jusqu'au milieu du $\mathrm{I}^{\mathrm{er}}$ siècle av. J.-C.). Les formes laténiennes tardives, comme les poteries de type Besançon, sont absentes. À partir de ce constat, on peut supposer un abandon du site autour de la conquête.

\section{Étude pétrographique}

Une étude pétrographique a été réalisée sur les céramiques issues des trois phases d'occupation du site d'Expansia, soit 143 formes. Quant au mobilier céramique provenant du site de L'Attache, il a fait l'objet d'une observation à l'œil nu et à la loupe binoculaire. Seules les céramiques dessinées et utiles à l'établissement de la typologie ont été retenues pour l'analyse des résultats. 


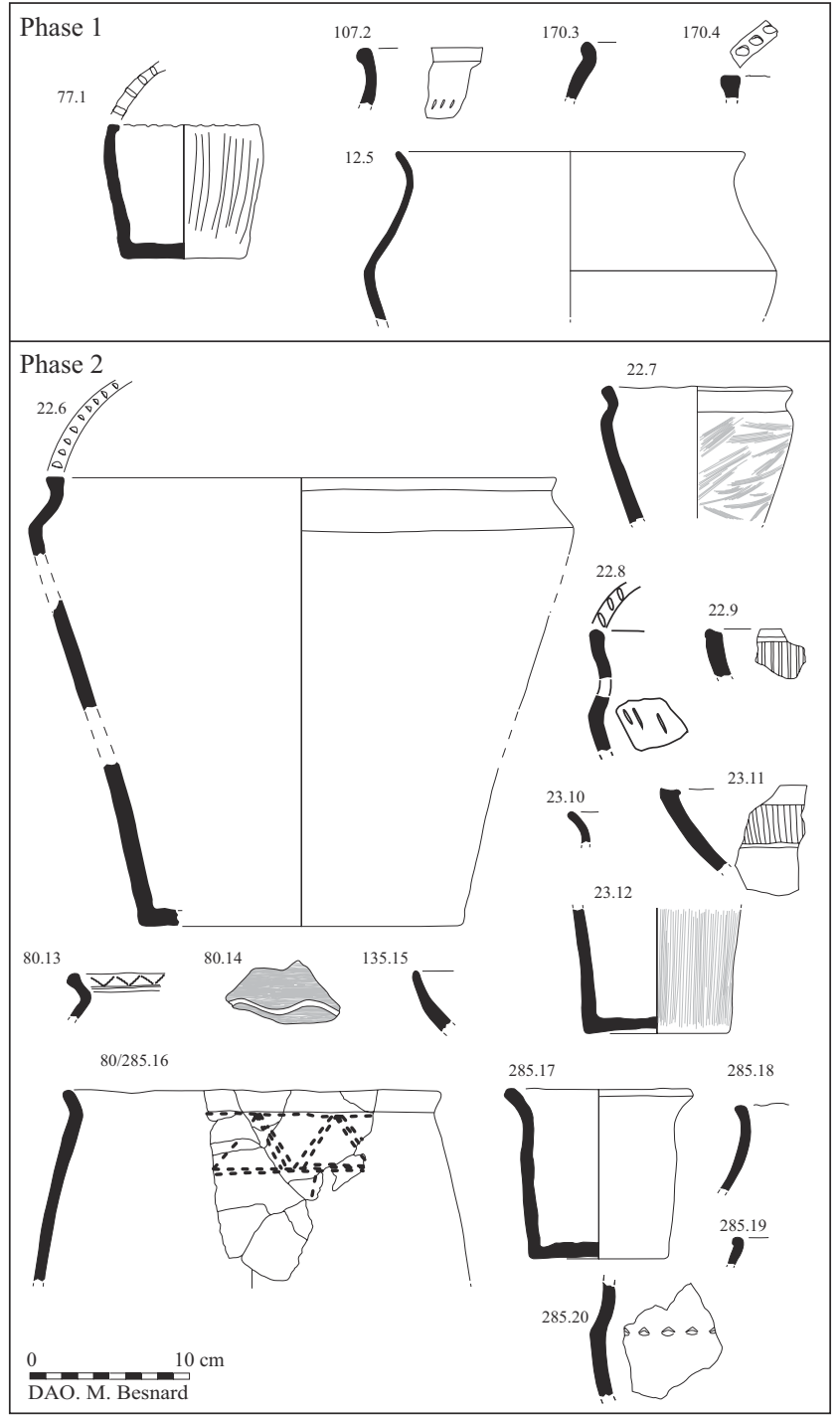

Figure 23 : Falaise "Expansia ", céramiques des deux premières phases d'occupation. M. Besnard/Inrap. (Le numéro de structure est suivi d'une numérotation continue).

Figure 23: Falaise "Expansia", pottery from the two first phases of occupation. M. Besnard/Inrap. (The structure number is followed by a continuous number).

\section{Définition des types pétrographiques}

L'ensemble du corpus céramique a fait l'objet d'une observation à la loupe afin de déterminer les différents groupes pétrographiques. Un échantillonnage a ensuite été effectué pour chaque type de pâtes. L'intérêt des formes céramiques (formes typiques ou plus originales) ainsi que la particularité de certaines pâtes ont également été pris en compte. Au final, trente lames minces ont été réalisées dans le but d'affiner les données obtenues en macroscopie. La confrontation entre les observations macroscopiques et microscopiques permet de faire ressortir cinq grands types de pâtes, eux- mêmes parfois subdivisés en plusieurs sous-types, ainsi que des pâtes dites "particulières ".

Type $1:$ Pâtes à coquilles

Type 2 : Pâtes à éléments granitiques

- Sous-type 2.1 : Pâtes classiques à éléments granitiques : quartz, feldspath anguleux et peu de biotite

- Sous-type 2.2 : Pâtes à éléments granitiques : quartz et feldspath rosé, plus ou moins fortement altéré

- Sous-type 2.3 : Pâtes à éléments granitiques très riches en quartz et feldspath blanc

- Sous-type 2.4 : Pâtes fines à éléments granitiques : quartz, feldspath et grains orangés

- Sous-type 2.5 : Pâtes à éléments granitiques et à biotite

Type 3 : Pâtes à glauconie et à quartz fin

Type 4 : Pâtes à éléments granitiques et glauconieuses

- Sous-type 4.1 : Pâtes à grains glauconieux majoritaires par rapport aux grains granitiques

- Sous-type 4.2 : Pâtes à grains glauconieux fins et à grains granitiques en quantité équivalente

- Sous-type 4.3: Pâtes à grains granitiques majoritaires par rapport aux grains glauconieux fins

Type 5 : Pâtes à glauconie, éléments granitiques et grains calcaires

Type 6 : Pâtes vacuolaires avec traces de végétaux supposés.

\section{Discussion}

Les pâtes à coquilles de lamellibranches (type 1) sont identiques à celles retrouvées plus au nord, dans la plaine de Caen. Elles sont très peu représentées sur le site d'Expansia alors qu'elles dominent largement les productions potières de la plaine de Caen au cours de La Tène moyenne (voire La Tène ancienne). Elles concernent principalement deux formes, l'une est une jatte moyenne récoltée dans les structures non phasées du site (243.110), l'autre est un grand vase de stockage à profil segmenté issu de la phase 2 (22.6). Ces céramiques sont les témoins les plus au sud de ce que l'on considère comme la production "typique " de la plaine de Caen et pourraient constituer des importations à moyenne distance en nombre limité.

Les pâtes à éléments granitiques (type 2) sont les plus nombreuses, notamment au cours de la phase III d'Expansia (près de la moitié de la production). La forme et la nature des éléments retrouvés dans ces pâtes pourraient indiquer qu'elles ont été travaillées à partir d'arènes granodioritiques ayant subi une altération plus ou moins poussée. Ces arènes peuvent avoir pour origine le massif granodioritique d'Athis. À noter que parmi ces pâtes, celles qui sont les plus représentées sont les pâtes de sous-type 2.1 et 2.2 , soit respectivement $24,7 \%$ et $13,5 \%$ de la production totale pour la phase III. Les autres sous-types $2.3,2.4$ et 2.5 sont plus marginaux. Plus particulièrement, en ce qui concerne les 


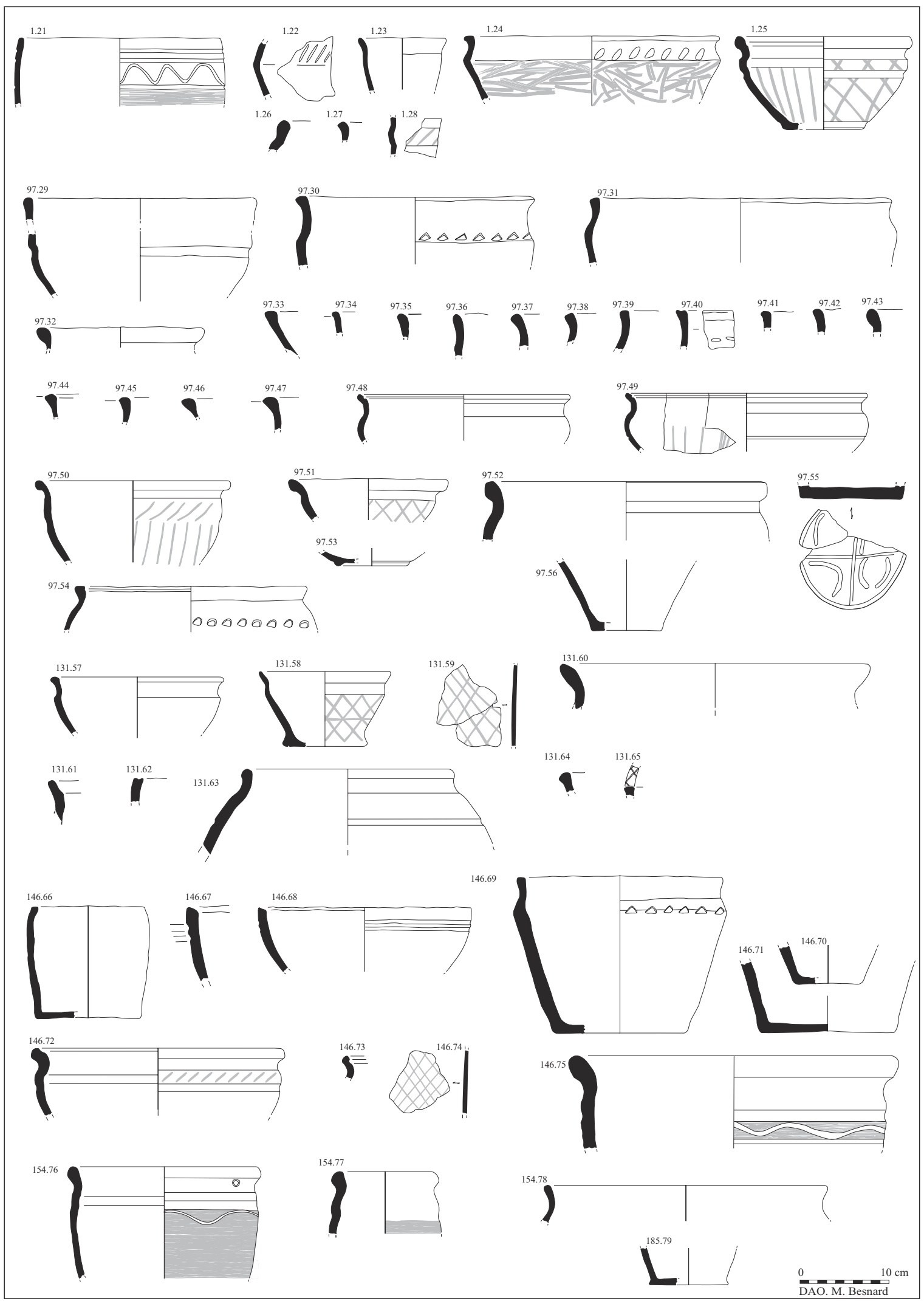

Figure 24 : Falaise "Expansia ", céramiques de la troisième phase d'occupation. M. Besnard/Inrap. Figure 24: Falaise "Expansia", pottery from the third phase of occupation. M. Besnard/Inrap. 


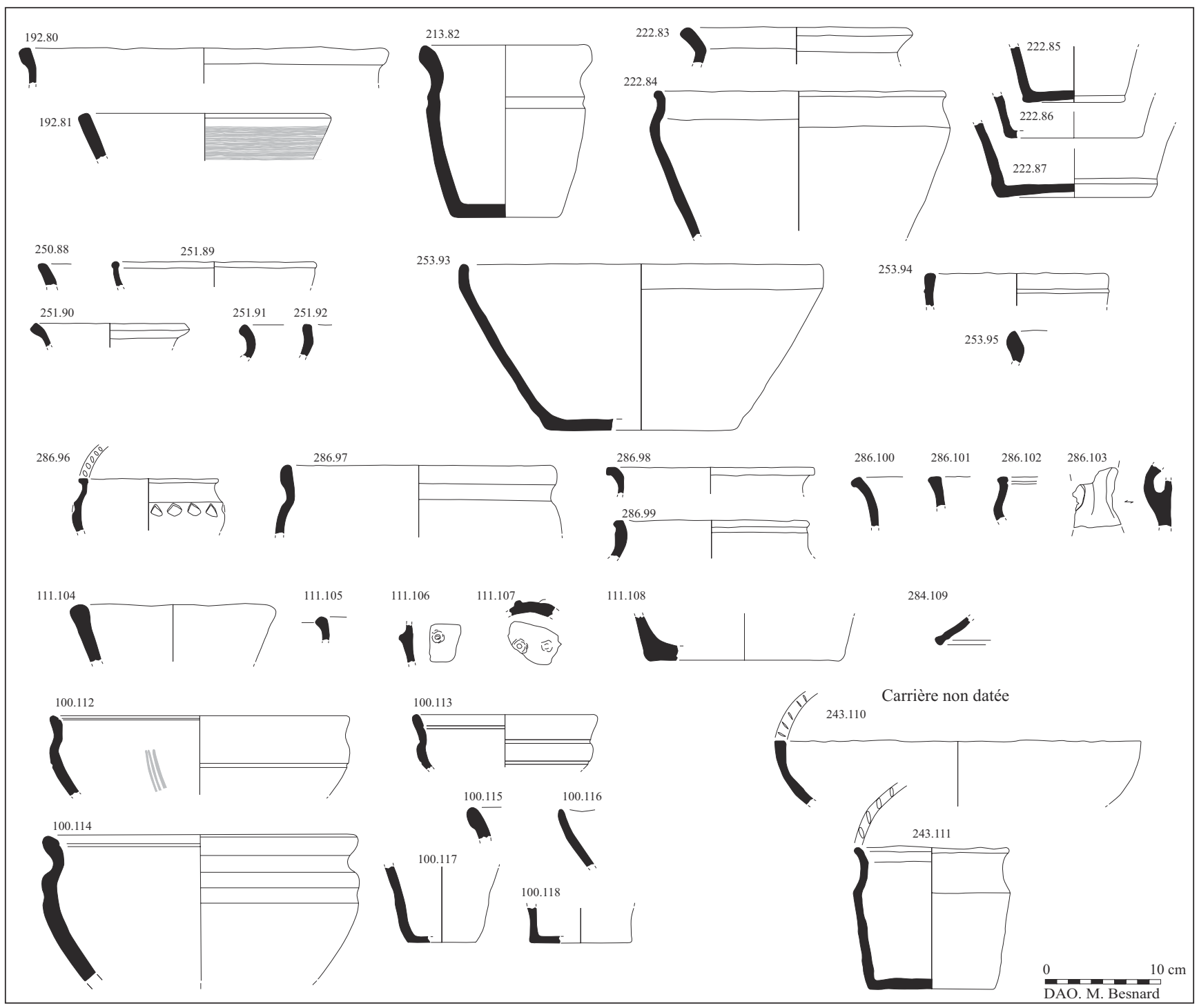

Figure 25 : Falaise "Expansia ", céramiques de la troisième phase et autres. M. Besnard/Inrap. Figure 25: Falaise "Expansia", pottery from the third phase and various. M. Besnard/Inrap.

pâtes fines de sous-type 2.4, de semblables sont connues sur le site d'Ifs «Object'Ifs Sud " (moins de 5 \% pour La Tène moyenne, voire La Tène ancienne). Toutefois, les pâtes d'Ifs paraissent plus détritiques, avec une plus grande teneur en limons, la présence de grains de siltite et de feldspath moins altérés. Cette catégorie de pâtes concerne tous les groupes typologiques définis par l'analyse des formes sur le site.

Les pâtes glauconieuses de type 3 forment un groupe pétrographique très homogène, avec une quantité égale de grains de glauconie et de quartz. Leur composition correspond tout à fait au faciès de la Glauconie de Base. À Falaise, ces pâtes représentent $20 \%$ de la production potière pour la phase I (taux très certainement exagéré du fait du peu de céramiques impliqués dans cette phase), 6,7\% pour la phase II et $9 \%$ pour la phase III. À titre de comparaison, les pâtes glauconieuses d'Ifs " Object'Ifs Sud ", de composition identique, constituent moins de $10 \%$ du corpus céramique pour la même phase chronologique. Ces pâtes glauconieuses exemptes d'éléments granitiques sont surtout représentatives des céramiques du groupe $3 \mathrm{~A}$, c'est-à-dire des jattes basses à moyennes à profils globalement en " $S$ ", comme celles récoltées dans la plaine de Caen.

En ce qui concerne les pâtes à glauconies et grains granitiques (type 4), on constate que les grains granitiques sont identiques à ceux qui composent les pâtes de type 2. On peut donc en déduire que ces grains ont la même origine et qu'ils sont issus de l'altération d'un massif granodioritique. De plus, la présence de glauconies dans les pâtes indique 
certainement l'existence d'une source glauconieuse à proximité. Les zones d'approvisionnement en matières premières sont donc probablement à rechercher dans la région sud de Falaise où affleurent des massifs granodioritiques et des niveaux témoins du Crétacé (Glauconie de Base). Les pourcentages variables en grains glauconieux et granitiques (sous-types $4.1,4.2$ et 4.3 ) sont très certainement dépendants du niveau de prélèvement dans les arènes. Les pâtes de type 4 sont peu présentes dans les deux premières phases de l'occupation du site d'Expansia (moins de $7 \%$ ). Elles sont beaucoup plus nombreuses au cours de la troisième phase ( $25,8 \%$ de la production totale). La typologie de ce type est assez large et assez comparable à celle du type 3 .

Les pâtes à glauconies, grains granitiques et grains carbonatés (type 5) sont rares sur les sites de Falaise. Seule une céramique façonnée avec ce type de pâte a pu être précisément datée de la phase III d'Expansia. Les caractéristiques physiques des grains qu'elle renferme sont identiques à celles des pâtes à glauconies et grains granitiques. Les zones d'approvisionnement sont donc sans doute très proches de celles du type 4 (sud de Falaise), avec en plus un apport assez faible de lithoclastes calcaires provenant probablement des terrains jurassiques de la même région. Des pâtes de composition semblable ont été retrouvées sur le site d'Ifs "Object'Ifs Sud " pour la période de La Tène moyenne voire La Tène ancienne. Cependant, on note plusieurs dissemblances entre les deux sites. En effet, les pâtes de Falaise sont plus riches en glauconies et grains granitiques. De plus, les éléments calcaires sont de nature sensiblement différente. À Falaise, il s'agit surtout de lithoclastes sparitiques, tandis qu'à Ifs, on retrouve essentiellement des bioclastes.

Pour finir, quelques rares formes céramiques à pâtes vacuolaires (type 6) ont été découvertes sur les sites de Falaise. Ces pâtes, datées de la phase III d'Expansia, ne constituent que $3,4 \%$ de production céramique de cette époque. Au regard de la morphologie filamenteuse des pores et des rares restes organiques présents, on peut supposer que les pâtes de type 6 ont été élaborées à partir d'un dégraissant végétal rajouté dans une argile fine.

\section{Problématiques et perspectives de l'étude pétrographique}

Les groupes technologiques maintenant bien connus de la plaine de Caen nous permettaient de bien cibler, dans cet ensemble de sites, la part de productions locales et d'établir des hypothèses quant aux échanges de céramiques à plus longue distance : dans le cas qui nous intéresse ici, entre le Pays d'Auge et la plaine de Caen. Les sites de Falaise appor- tent des éléments nouveaux à notre réflexion, notamment sur l'éventualité de production de céramiques glauconieuses dans le sud du Pays d'Auge.

D'abord, les pâtes à éléments dits " granitiques » dominent le corpus céramique. L'analyse pétrographique devra s'attacher à déterminer l'origine de la matière première utilisée pour la fabrication des vases, c'est-à-dire poser la problématique de la reconnaissance des matériaux « sources ». S'agit-il d'arènes d'altération de granites mancelliens présents au sud de Falaise (massif d'Athis par exemple) ou d'argiles d'altération de certains grès riches en feldspaths, inscrits dans la succession gréseuse du synclinal de la zone bocaine? Quoi qu'il en soit, ces pâtes semblent pouvoir être qualifiées de productions « locales » au regard de leur fréquence, de l'éventail typologique qu'elles représentent et de leur adéquation avec le milieu géologique environnant.

Dans ces pâtes, les éléments " granitiques " sont associés à des grains de glauconie dans une proportion importante de pâtes. La glauconie est présente à quelques kilomètres de Falaise dans les premiers contreforts du sud Pays d'Auge (Crétacé). Il convient alors de s'interroger sur l'origine anthropique ou naturelle de ces mélanges et, dans l'éventualité d'un mélange naturel, sur la possibilité de circonscrire les zones potentielles d'approvisionnement aux zones de contact entre le massif ancien et les niveaux argileux du Pays d'Auge. Une prospection géologique pourrait alors déboucher sur une meilleure connaissance de ces zones et indiquer une éventuelle production locale de céramiques à pâtes mixtes ("éléments granitiques » et glauconies).

Enfin, des pâtes glauconieuses exemptes d'éléments « granitiques » sont également fréquentes. Elles posent d'emblée la problématique d'une production de céramiques glauconieuses dans cette partie du département, à partir de sources glauconieuses comparables à celles observées dans les mélanges précédents. Une analyse microscopique plus poussée des grains de glauconie viserait à comparer ces sources dans ces pâtes et dans les pâtes mixtes de Falaise. Sur le plan typologique, les céramiques exclusivement glauconieuses sont à première vue comparables à celles déjà bien connues sur les sites laténiens de la plaine de Caen. Généralement attribuées à des productions du nord Pays d'Auge (Peuchet-Geilenbrügge et Morzadec, 2001), ces dernières pourront faire l'objet d'une analyse comparative visant à identifier une éventuelle parenté avec celles de Falaise. Dans le cas d'une correspondance parfaite entre les sources glauconieuses, l'éventualité d'une production de céramiques à glauconie dans le sud du Pays d'Auge serait alors une nouvelle piste de travail. 


\section{ESPACES ET TERRITOIRE : LES ÉTABLISSEMENTS DE FALAISE DANS LEUR CONTEXTE RÉGIONAL}

\section{Le réseau parcellaire intra-site}

L'étude des habitats de Falaise permet d'avancer quelques réflexions sur l'organisation parcellaire dans laquelle les établissements gaulois s'insèrent. Ce réseau parcellaire, qui s'est développé autour du site d'Expansia tout au long du second âge du Fer, montre de légères divergences dans les orientations (fig. 26). Les directions ouest-nord-ouest/est-sud-est, d'une part, et nord-nord-est/sud-sud-ouest, d'autre part, ont dicté les principaux axes fossoyés de cet habitat et se retrouvent à l'ouest du site dans les fossés laténiens observés à l'emplacement du bassin d'orage d'Aubigny. Les clôtures du site de L'Attache au sud se basent sur ces mêmes orientations. En revanche, les fossés parcellaires à l'est de l'habitat d'Expansia et ceux qui délimitent le chemin protohistorique s'inclinent légèrement et s'orientent alors nord/sud et est/ouest. Ces axes constituent également la base d'orientation de l'habitat d'Aubigny au nord. Ces divergences d'orientation ne semblent, a priori, pas résulter de différentes phases d'aménagement, puisque l'organisation du site d'Expansia emprunte dès la première phase d'occupation ces deux directions, par les clôtures d'habitat d'une part, et par les fossés bordant le chemin protohistorique d'autre part. Cette différence dans la structuration spatiale au nord et à l'est par rapport à celle au sud et à l'ouest de l'habitat semble concorder avec l'inclinaison que suit l'axe de circulation à l'est de l'habitat. Des raisons topographiques peuvent en être la base. Ce maillage gaulois est par la suite partiellement repris par le parcellaire antique, notamment à la hauteur du site d'Aubigny, alors qu'il subit une inclinaison sur la ZAC d'Expansia et à la hauteur de la villa de Vaston.

\section{La création d'un réseau de fermes}

La compilation des données de fouille et de diagnostic permet de se former une première image du déroulement de l'occupation dans ce secteur au nord de Falaise, allant de la création des premiers établissements jusqu'au développement d'un réseau de fermes à l'échelle micro-régionale.

La première installation dans le secteur remonte à La Tène ancienne avec la mise en place d'un établissement à caractère artisanal à Soulangy " Déviation de la RN158 " (Peuchet et Naizet, 1994). D'après les données de fouille très succinctes, cette installation qui aurait été orientée vers le travail de l'os et de peaux se serait mise en place au $\mathrm{V}^{\mathrm{e}}$ siècle av. J.-C. Elle aurait ensuite connu une deuxième phase à vocation domestique vers le milieu du $\mathrm{III}^{\mathrm{e}}$ siècle av. J.-C. jusqu'au milieu du $\mathrm{I}^{\text {er }}$ siècle av. J.-C. En raison d'une part de son éloignement de plus de deux kilomètres au nord des établissements de Falaise et d'autre part de l'absence d'indices de sites dans l'intervalle, il nous semble difficile à ce jour d'intégrer ce site dans le réseau d'exploitations du secteur nord de Falaise et d'y voir ainsi un point de création. Les investigations archéologiques futures apporteront sans doute un lot d'informations susceptibles d'éclairer la question de l'étendue de ce réseau. À l'heure actuelle, il semble que le site fondateur soit l'établissement d'Expansia, prenant ses racines au début du Iv ${ }^{\mathrm{e}}$ siècle av. J.-C. Ce site s'inscrit alors dans le mouvement de création d'unités domestiques encloses qui marque le début du second âge du Fer au niveau régional et perdure jusqu'à la conquête (Jahier et Vauterin, 2010). Plus de la moitié de ces premiers établissements sont abandonnés au cours du III $^{\mathrm{e}}$ siècle av. J.-C. L'habitat d'Expansia s'en démarque par sa longévité, l'accroissement de son domaine et, par ce biais, l'affirmation d'une vraisemblable prospérité. Sur une durée de trois siècles et demi, l'occupation est en effet rythmée par trois phases d'aménagement et de réorganisation engendrant à chaque fois l'extension de l'établissement.

C'est probablement plus d'un siècle après la création de cet établissement que le réseau de fermes se développe autour avec l'implantation du site de L'Attache, à 500 mètres au sud, et celui d'Aubigny, à 700 mètres au nord. Établis vers le début de La Tène moyenne, ces habitats témoignent d'une coexistence entre le milieu du III $^{\mathrm{e}}$ et la fin du Ir siècle av. J.-C. Ces deux sites s'intègrent dans la grande vague de création qui a eu lieu vers le milieu du $\mathrm{III}^{\mathrm{e}}$ siècle av. J.-C. à l'échelle de la plaine de Caen et sur son extension méridionale, mais aussi à l'échelle régionale.

Par leur proximité et leur contemporanéité, ces trois établissements agricoles suggèrent l'idée d'un groupement fonctionnel, sans doute reliés par des chemins et des parcelles agricoles. D'autres indices de sites doivent être pris en considération pour préciser les formes d'occupation du sol dans ce secteur : le système d'enclos partiel et le parcellaire laténien diagnostiqués à l'ouest à l'emplacement du bassin d'orage d'Aubigny (Ghesquière, 2003), les trois enclos quadrangulaires repérés par prospection aérienne à l'est, aux lieux-dits «Les Sentes » et " Rougemont ». On peut d'ores et déjà estimer l'étendue de la portion de terroir exploité à l'époque gauloise à au moins 150 hectares. L'ensemble s'apparenterait de ce fait au maillage territorial du nord de la plaine de Caen, et plus précisément celui sur la rive droite de l'Orne en périphérie sud-est de l'agglomération caennaise (communes de Mondeville, Cagny, Cormelles-le-Royal, Ifs et Fleury-sur-Orne). Ce groupement d'habitats enclos rapprochés s'y développe dans un paysage parcellaire structuré englobant une étendue de près de 1400 hectares. Si les premières installations y apparaissent dès la fin du premier âge 


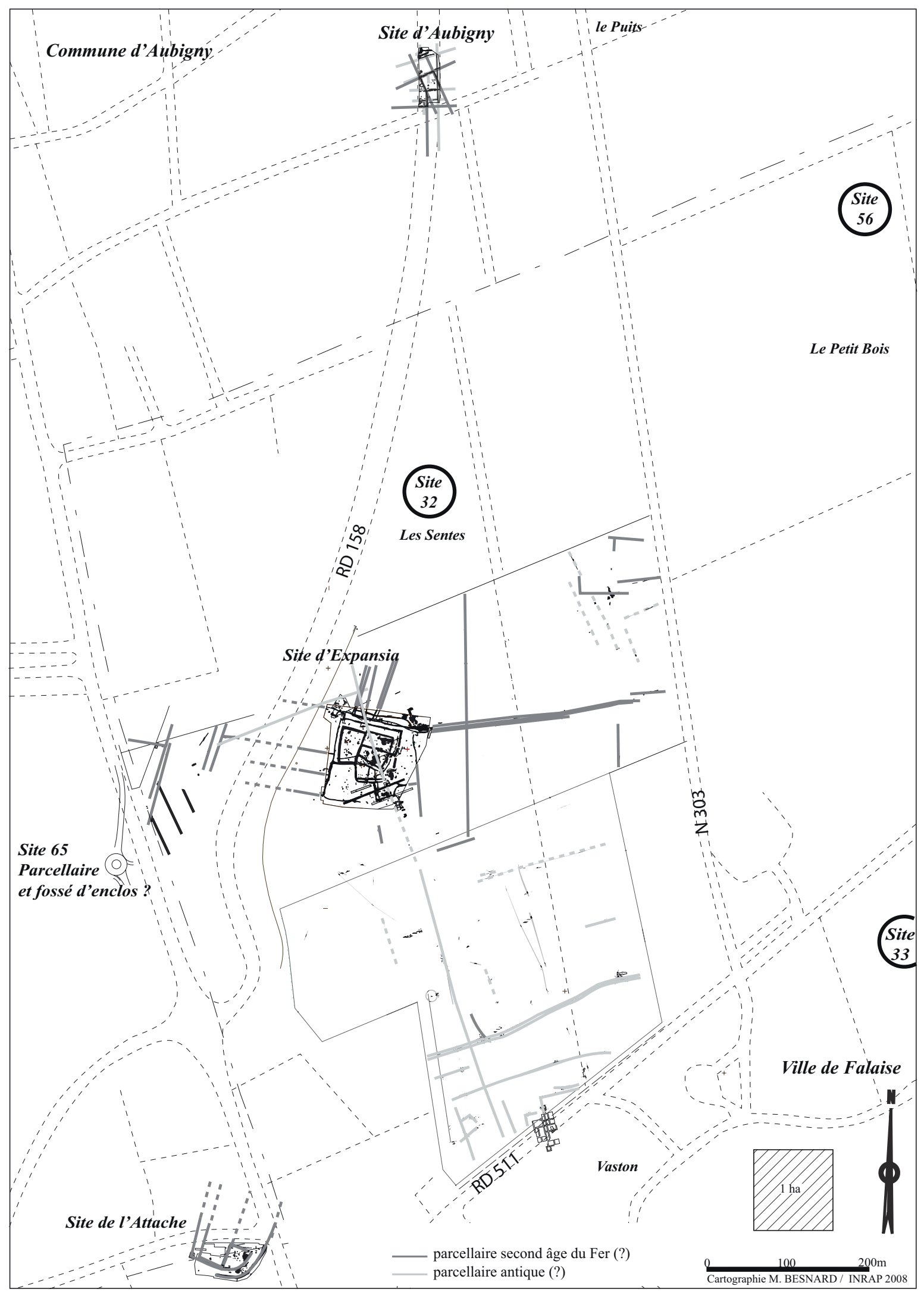

Figure 26 : Secteur nord de Falaise, parcellaire intra-site. M. Besnard, C.-C. Besnard-Vauterin/Inrap. Figure 26: Northern area of Falaise, intra-site field systems. M. Besnard, C.-C. Besnard-Vauterin/Inrap. 
du Fer, le développement de ce réseau ne prend réellement son essor qu'à partir du $\mathrm{III}^{\mathrm{e}}$ siècle av. J.-C. Une configuration semblable, bien qu'à moindre échelle, est attestée sur le plateau de Thaon dans le bassin aval de la Seulles, où un groupement de fermes a fonctionné conjointement au cours des deux derniers siècles av. J.-C. sur une superficie d'environ 250 hectares. De cette rapide comparaison ressort une convergence chronologique entre le réseau d'exploitations du nord de Falaise et celui de la plaine de Caen, trouvant leurs origines et leurs développements un ou deux siècles avant le réseau de fermes du plateau de Thaon. Ce dernier s'inscrit dans une fourchette chronologique plus répandue pour ce type de réseaux dans le Nord et l'Ouest de la France et pour lesquels une installation autour du $\mathrm{II}^{\mathrm{e}}$ siècle av. J.-C. est généralement supposée (Buchsenschutz, 2004), concordant avec la forte expansion agraire et démographique qui a marqué le nord de la Gaule jusqu'au moment de la Conquête romaine.

\section{Parallèles et divergences avec les réseaux de fermes de la plaine de Caen et du plateau de Thaon}

Si des parallèles se manifestent au niveau de la densité de l'occupation au second âge du Fer entre ce groupement de fermes au nord de Falaise et les réseaux d'exploitations de la plaine de Caen et de la vallée de la Seulles, des disparités sont à observer sur l'organisation de l'habitat même. L'une des différences majeures consiste en l'absence de caves de stockage sur le gisement d'Expansia, alors qu'elles caractérisent tant les habitats laténiens de la plaine de Caen que ceux de la vallée de la Seulles et du Bessin ${ }^{6}$ sous la forme d'innombrables fosses parallélépipédiques associées parfois à des souterrains (Besnard-Vauterin et al., 2009). La fonction de ces structures comme architectures de stockage des récoltes céréalières et de légumineuses est attestée à travers des dépôts de semences carbonisées. À Falaise " Expansia », le moyen de stockage privilégié est le grenier et exceptionnellement le silo. Sur les habitats de L'Attache et d'Aubigny, ces tendances semblent se confirmer, même si on y note tout de même la présence d'une ou deux fosses parallélépipédiques. D'une manière générale, les différents modes de stockage (grenier, silo, cave) s'avèrent bien moins représentés sur les habitats de Falaise. En effet, pour la dernière phase d'occupation d'Expansia par exemple, qui apparaît pourtant comme la plus développée, les structures de stockage se limitent à deux silos et deux greniers, auxquels il faut peut-être ajouter une grange de plain-pied (bâtiment C?).

6. Pour le Bessin, citons l'exemple de Saint-Martin-des-Entrées (Marcigny et al., 2004).
Si le volume de stockage des greniers est important mais non quantifiable (Gransar, 2000), celui des silos est chiffré à moins de cinq mètres cubes fonctionnels. En comparaison, la capacité de stockage estimée pour les établissements de Mondeville «L'Étoile " varie de 100 à 140 mètres cubes par phase d'occupation (Besnard-Vauterin, 2009a). Par rapport à ces données, les moyens de stockage des sites de Falaise paraissent bien dérisoires. Ces différences significatives démontrent clairement pour les sites de Falaise la finalité domestique du stockage pour une consommation endogène et la conservation des semences annuelles. En revanche, ceux des exploitations des plaines plus au nord sont probablement à l'échelle intercommunautaire. Au niveau régional, les sites de Falaise se rapprochent alors plus des établissements ornais où le stockage en greniers est privilégié par rapport aux caves et silos, comme à Neuville-près-Sées (BesnardVauterin, 2005), à Marcei «Le Maréchal » (Jahier, 2005) et à Buré (Forfait, 1997), même si leur existence est bien attestée à Nécy (Besnard-Vauterin et al., 2006). Les capacités de stockage sur ces sites y apparaissent aussi bien inférieures à celles établies pour les plaines septentrionales du Calvados.

\section{Une culture céramique aux portes de l'entité culturelle ornaise}

La situation géographique des sites de Falaise rend l'étude du mobilier céramique particulièrement propice à des comparaisons d'ordre typo-culturel. En effet, les deux occupations se situent d'une part dans le prolongement de la plaine de Caen pour laquelle les productions céramiques sont aujourd'hui bien identifiées et d'autre part à proximité du département de l'Orne, dont les vestiges archéologiques ont livré ces dernières années des lots céramiques importants laissant entrevoir l'existence d'un faciès tout à fait distinct.

Les comparaisons avec ces deux secteurs géographiques se sont révélées riches en observations. Les productions des sites de Falaise possèdent un certain nombre d'affinités avec celles de la plaine de Caen au rang desquelles on peut tout d'abord placer les formes tronconiques du type 1 qui prédominent au sein des lots de la plaine de Caen. De même, l'association fréquente de triples cannelures sur la partie haute de ces vases en plaine de Caen est une caractéristique observée sur les vases de type 1D du site de L'Attache.

Dans un autre registre, la présence de pâtes à coquilles identifiées sur chacun des deux sites rappelle les ensembles de la plaine de Caen au sein desquels ces types peuvent représenter plus de $80 \%$ de la production. Enfin, l'étude pétrographique a permis d'observer une catégorie de jattes à pâte glauconieuse, qui semble devoir être rattachée aux productions mises au jour sur la plaine de Caen et dont l'origine se situerait dans le Pays d'Auge. Les influences entre 
les ensembles céramiques de Falaise et ceux des sites septentrionaux se perçoivent ainsi à travers les types de formes, de décors et de pâtes.

Néanmoins, on observe d'avantage d'affinités entre les lots de Falaise et les productions céramiques de l'Orne. Ces dernières s'expriment à travers des répertoires typologiques communs, notamment avec les sites de Sarceaux « Projet de plateforme logistique" (Lepaumier, étude en cours), Mortrée « Le Pré du Palluel » (Morzadec, 2005), Marcei « Le Marechal » (Jahier, 2005) et Nécy « La Martinière » (BesnardVauterin et al., 2006). L'ensemble des formes mises au jour sur les sites de Falaise y sont connues, en particulier les vases de type 3 , au sein desquels les productions à cannelure labiale interne et panse moulurées tiennent une place importante. En revanche, ces caractéristiques sont rarement observées en plaine de Caen. De façon générale, on note une prédominance des profils sinueux au sein des lots de Falaise qui constitue une affinité supplémentaire avec les ensembles ornais tandis que les productions de la plaine de Caen se caractérisent par des profils tronconiques largement majoritaires.

Les types de façonnage viennent appuyer ces observations. En effet, les vases sont principalement modelés en plaine de Caen : le façonnage au tour ne représentant guère plus de $5 \%$ des productions et cela même à la fin de la période gauloise (Besnard-Vauterin, 2009a). Sur les sites ornais en revanche, ces proportions peuvent représenter entre $20 \%$ et plus de $50 \%$ des productions d'un site, fourchette dans laquelle se situent les ensembles céramiques de Falaise.

Enfin, la comparaison des types de pâtes permet de relayer les tendances observées. Elle indique elle aussi une certaine rupture avec les productions de la plaine de Caen qui se caractérisent par une prédominance de pâtes bioclastiques. Bien que les sites de Falaise aient livré des productions à pâte coquillée, leurs proportions en font un type minoritaire. En revanche, les pâtes à inclusions granitiques prédominent au sein des lots de Falaise "Expansia " et "L'Attache " et constitue une affinité supplémentaire avec le faciès céramique ornais.

Les ensembles céramiques des deux occupations de Falaise semblent témoigner d'un secteur géographique de transition entre les productions de la Plaine de Caen et les celles du département de l'Orne, ces dernières s'apparentant davantage au domaine armoricain à travers les modes de façonnage, la prédominance des profils sinueux et la forte présence des cannelures labiales internes.

\section{La fin du ${ }^{\text {er }}$ siècle av. J.-C. et l'effacement du paysage agraire}

La stabilité d'occupation qu'ont connue les établissements d'Expansia, de L'Attache et d'Aubigny est finalement interrompue dans le courant du $\mathrm{I}^{\mathrm{er}}$ siècle av. J.-C. On suppose que cet événement s'est produit à la fin de l'indépendance gauloise ou au plus tard dans la décennie suivante, puisqu'aucun vestige augustéen n'atteste une présence sur ces trois sites dans le dernier tiers du $\mathrm{I}^{\mathrm{er}}$ siècle av. J.-C. L'impact de la Conquête romaine se manifeste au niveau régional ou extrarégional de façon inégale, sous la forme d'abandon pour la majorité des sites et de repli ou de continuité pour un certain nombre d'autres. Le constat d'une période de bouleversement est non seulement illustré par de nombreux sites bas-normands (Jahier et Vauterin, 2010), mais apparaît aussi clairement à travers des bilans régionaux comme ceux établis pour la Picardie (Malrain et al., 2005; Malrain et Pinard, 2006; Pion et al., 1996), la Bretagne (Menez, 1996) ou la région parisienne (Séguier, 2005).

Après l'abandon des ces habitats gaulois, l'occupation se restructure nettement vers la seconde moitié du $\mathrm{I}^{\text {er }}$ siècle apr. J.-C. avec l'implantation d'une villa antique au lieudit de Vaston et l'aménagement d'un réseau parcellaire qui s'organise autour jusqu'au site d'Aubigny. C'est de cette époque que date une nécropole aristocratique et des monuments funéraires mis au jour au sud-est du site d'Expansia (Besnard-Vauterin, 2009b; Hincker et al., 2012).

\section{Bibliographie}

Besnard-Vauterin C.-C., I994 - Falaise "L'Attache" (14.258.017.AH), DFS de fouille de sauvetage urgent, Afan, Caen, direction régionale des affaires culturelles, 23 p., 18 fig. Besnard-Vauterin C.-C., 2005 - "Une ferme de la fin de l'époque gauloise à Neuville-près-Sées "Les Ruisseaux" (Orne) ", Revue archéologique de l'Ouest, 22, p. 181-198.

Besnard-Vauterin C.-C., Besnard M., Corde D., Féret L. et Palluau J.-M., 2006 - Nécy "La Martinière ». Un habitat de la fin de la période gauloise et un sanctuaire du Haut-Empire (Orne), Rapport de fouille archéologique préventive, Inrap, Caen, DRAC, SRA, 86 p., 29 fig., 34 photos.

Besnard-Vauterin C.-C., 2008 - Falaise "Expansia " (Calvados). Un habitat du second âge du Fer et des vestiges de l'Antiquité et du Haut Moyen Âge, Rapport final de fouille archéologique préventive, Inrap, Caen, DRAC, SRA, 86 p., 49 fig., 18 photos, inventaires.

Besnard-Vauterin C.-C. et Navarre N., 2008 - «Un habitat de La Tène finale à l'époque gallo-romaine sur la ZAC de Beaulieu à Caen (Calvados) ", Revue archéologique de l'Ouest, 25, p. 163-186. Besnard-Vauterin C.-C. (dir.), 2009 - En Plaine de Caen. Une campagne gauloise et antique. L'occupation du site de l'Étoile à Mondeville, Rennes : Presses universitaires de Rennes, 2009, 312 p., 211 fig., XVI pl. (collection Archéologie et Culture). 
Besnard-Vauterin C.-C., 2009b - «Falaise. Un habitat clos du second âge du Fer à Falaise "Expansia" ", in Normandie celte et romaine (L'archéologue. Revue d'archéologie et d'histoire, $\mathrm{n}^{\circ}$ 102), p. 20-21.

Besnard-Vauterin C.-C., Jahier I. et Le Goff E., 2009 - « Les structures de stockage ", in Giraud P., Gaulois sous les pommiers. Découvertes de l'âge du Fer en Basse-Normandie IXe- $I^{e r}$ siècle av. J.-C., Conseil général du Calvados, service archéologie, éditions Cahier du Temps, p. 60-63.

Blanchet J.-C. et Talon M., I987 - « L'éperon barré du « Camp César " à Catenoy (oise), à l'âge du Bronze final. Premiers résultats ", in BLANCHET J.-C., Les relations entre le continent et les îles Britanniques à l'âge du Bronze. Congrès préhistorique de France, 1984, Actes du Colloque de Bronze de Lille, Société préhistorique française, Amiens (Revue archéologique de Picardie), p. 189-210.

Blancquaert G., 2002 - "Cottevrard "La Plaine de la Bucaille" et Saint-Aubin-Routot "Le Four à Chaux 1 et 2" ", in Six nécropoles du second âge du Fer en Haute-Normandie. Nord-Ouest Archéologie $\mathrm{n}^{\circ}$ 13, Centre de Recherches archéologiques et de diffusion culturelle, p. 331-393.

Blancquaert G. et Adrian Y.-M., 2006 - " Les occupations multiples de la plaine du Bosc Renault à Hautot-le-Vatois (Seine-Maritime) : la zone de stockage du premier âge du Fer et les vestiges antiques et domestiques ", Revue archéologique de l'Ouest, 23, p. 9-44.

Blancquaert G. et Desfosses Y., I 994 - "Les établissements ruraux de l'âge du Fer sur le tracé de l'autoroute A29 (Le Havre-Yvetot) ", in Buchsenschutz O. et Méniel P., Les installations agricoles de l'âge du fer en Île-de-France, Actes du colloque de Paris 1993, Études d'Histoire et d'Archéologie, IV, Presses de l'École Normale Supérieure, p. 227-254.

Buchsenschutz O., 2004 - Les celtes de l'âge du Fer dans la moitié nord de la France, Paris : éditions la Maison des Roches, 128 p.

Carpentier V., Marcigny C., Savary X. et Ghesquière E., 2002 - «Enclos et souterrain du second âge du Fer dans la plaine de Caen : l'exemple de Cormelles-le-Royal (Calvados) ", Revue archéologique de l'Ouest, $\mathrm{n}^{\circ} 19$, p. 37-60

Carpentier V., Barbier-Pain D., Besnard M., BesnardVauterin C.-C., Clément-Sauleau S., Deloze V., DietschSellami M.-F., Dupont C., Feret L. et Palluau J.-M., 2007 - Isigny-sur-Mer "Le Tuiley" (Calvados). Etablissements ruraux des bords de la Baie des Veys (La Tène - Haut-Empire), Rapport final d'opération, fouille archéologique préventive, Inrap, Caen, DRAC, SRA.

Chanson K., Delalande A., Jahier I., Le Goff I., Leon G., Texier M., Ropars A. et Vauterin C.-C., 20 io - « Les pratiques funéraires au second âge du Fer en Basse-Normandie : premiers éléments de réflexion ", in Barral P., Dedet B., Delrieu F., Giraud P., Le Goff I., Marion S. et Villard-Le Tiec A. (dir.), L'âge du Fer en Basse-Normandie. Gestes funéraires en Gaule au second âge du Fer. Actes du XXXIII colloque international de l'AFEAF, Caen, 20 au 24 mai 2009, Besançon : Presses universitaires de Franche-Comté, p. 45-78 (Annales littéraires, Série "Environnement, sociétés et archéologie »).

DaIre M.-Y., I 989 - "Les céramiques des Ébihens », in LANGoueT L. (éd.), Un village coriosolite sur l'île des Ébihens (Saint-Jacutde-la-Mer). Bilan de trois campagnes de fouilles, Rennes, centre régional d'archéologie d'Alet, p. 43-109

DAIRE M.-Y., I992 - Les céramiques armoricaines de la fin de l'âge $d u$ Fer, Travaux du Laboratoire d'Anthropologie de Rennes, $n^{\circ} 39$.

Demoule J.-P., I 999 - "Chronologie et société dans les nécropoles celtiques de la culture Aisne-Marne du vi ${ }^{\mathrm{e}}$ au $\mathrm{III}^{\mathrm{e}}$ siècle avant notre ère ", Revue archéologique de Picardie, $\mathrm{n}^{\circ}$ spécial 15, $406 \mathrm{p}$.

Feugere M., I985 - Les fibules en Gaule méridionale de la conquête à la fin du $\mathrm{v}^{e}$ siècle apr. J.-C., Revue Archéologique de Narbonnaise, supplément $\mathrm{n}^{\circ} 12$, Paris, éditions du Centre national de la recherche scientifique, 509 p.

Forfait N., I 997 - "Buré « Houssaye - La Sarthe ", in Bilan scientifique de la région Basse-Normandie 1996, Caen, DRAC, SRA, p. 92-93.

GALERON F., I 834 - Lettres sur les antiquités romaines trouvées à Vaston en 1834, et sur les origines de la ville de Falaise, Brée L'Aîné Editeur.

Ghesquière E., 2003 - A88. Échangeur d'Aubigny "Bassins d'orage ", Rapport de diagnostic archéologique, Inrap, Caen, DRAC, SRA.

Gigot P., Lupret L. et Le Gall J., I 999 - Carte Géologique de la France à 1/50 000, feuille Falaise (176). Carte et notice explicative, Orléans : BRGM, 154 p.

Giraud P., Louit S., Girardclos O., Roce C. et Matterne V., 2005 - "Un puits cuvelé de La Tène finale à Saint-Denis ", in Buchsenschutz O., Bulard A. et Lejars Th. (éd.), L'àge du Fer en Ile-de-France. Actes du 26 colloque de l'Association française pour l'étude de l'âge du Fer, Paris et Saint-Denis 2002, Revue archéologique du Centre de la France, p. 55-71.

Gransar F., 2000 - " Le stockage alimentaire sur les établissements ruraux de l'âge du Fer en France septentrionale : complémentarité des structures et tendances évolutives ", in Les installations agricoles de l'âge du Fer en France septentrionale, Études d'Histoire et d'Archéologie n ${ }^{\circ}$ 6, éditions Rue d'Ulm, p. 277-297.

Hatt J.-J. et Roualet P., I 977 - « La chronologie de La Tène en Champagne ", Revue archéologique de l'Est et du Centre-Est, $\mathrm{n}^{\circ} 28,1-2$, p. 7-36.

Herard A., I 996 - Putot-en-Bessin (Calvados). Échangeur de La Corneille Sud, Document final de synthèse d'évaluation, Afan, Caen : DRAC, SRA. 
Herard B., 2006 - Falaise "Zone d'activité Expansia - tranche II", Rapport de diagnostic archéologique, Inrap, Caen : DRAC, SRA.

Hincker V., Marie G., Niel C., Piolot A., Alduc-Le Bagousse A., Brunet V. et Bocquet-Liénard A., 2012 - «Une nécropole aristocratique rurale des $\mathrm{II}^{\mathrm{e}}-\mathrm{III}^{\mathrm{e}}$ siècles à Vaton (Falaise, Calvados) dans la cité des Viducasses ", in Nécropoles et sociétés. Cinq ensembles funéraires des provinces de Gaule (ier-ve siècle apr. J.-C.). Gallia, Archéologie de la France antique, Paris : CNRS Éditions, p. 115-165.

Hurtrelle J., Monchy, E., Roger F., Rossignol P. et Villes A., 1990 - Les débuts du second âge du Fer dans le Nord de la France, Les dossiers de Gauheria, 1, $254 \mathrm{p}$.

Jahier I., 200 I - A84. Plomb (Manche) "Le Champ du Puits". Document final de synthèse, Afan, Caen : DRAC, SRA.

Jahier I., Meniel P., Ozouf J.-C., San Juan G., Coutard J.-P., Lautridou J.-P., Larsonneur B., Levant M., Clet-Pellerin M., Ghesquière E., Cabboï S., Le Gaillard L. et Rohmer M.-A., 2002 - «Une petite ferme de La Tène ancienne au "Pré de la Val” à Fierville-les-Parcs (Calvados) ", Revue archéologique de l'Ouest, $\mathrm{n}^{\circ} 19$, p. 15-36.

Jahier I., 2005 - A88 - Marcei/Boissey-la-Lande "Le Maréchal " (Orne), Document final de synthèse, Inrap, Caen, DRAC, SRA.

JAhier I., 2006 - A88 - Marcei "Le Marais » (Orne), Rapport final de fouille de sauvetage urgent, Inrap, Caen, DRAC, SRA.

Jahier I., 2009 - « Creully " Le Clos de l'Épinette » (Calvados) », in Giraud P. (dir.), Gaulois sous les pommiers. Découvertes de l'âge du fer en Basse-Normandie ix $x^{e} i^{e r}$ siècle av. J.-C., Conseil général du Calvados, service archéologie, éditions Cahier du Temps, p. 26-28.

Jahier I. et Peuchet C., I 994 - "Aubigny. Déviation de la RN 158 ", in Bilan scientifique de la région Basse-Normandie 1993, Caen, DRAC, SRA, p. 19.

JAhier I. et VAuterin C.-C., 20 io - «Formes et composantes de l'habitat à l'âge du Fer en Basse-Normandie : architecture, chronologie, organisation, statut - un premier bilan ", in Barral P., Dedet B., Delrieu F., Giraud P., Le Goff I., Marion S., Villard-Le Tiec A. (dir.), L'áge du Fer en BasseNormandie. Gestes funéraires en Gaule au second âge du Fer. Actes du XXXIII colloque international de l'AFEAF, Caen, 20 au 24 mai 2009, Besançon : Presses universitaires de FrancheComté, p. 95-138 (Annales littéraires, Série « Environnement, sociétés et archéologie ").

LE GofF E., 2002 - Les occupations protohistoriques et antiques de la Z.A.C. Object'Ifs Sud̀̀ Ifs (Calvados), DFS de sauvetage urgent, Afan/Inrap, Caen : DRAC, SRA, 4 vol.

Lepaumier H., 2002 - «Les sites gaulois de Quetteville. Première approche pour une nouvelle définition du territoire des lexovii avant la conquête ", Bulletin de la société historique de Lisieux, $\mathrm{n}^{\mathrm{o}}$ 52, p. 5-15, 19 fig.
Lepaumier H., Marcigny C. et Ghesquiere E., 2005 "L'architecture des habitats protohistoriques de Normandie : quelques exemples du III $^{\mathrm{e}}$ millénaire au début du second âge du fer ", in Buchsenschutz O. et Mordant C. (éd.), Architectures protohistoriques en Europe occidentale du Néolithique final à l'âge du fer, Paris : Comité des travaux historiques et scientifiques, p. 231-264.

Lepaumier H. (dir.), 2009 - Cormelles-le-Royal (Calvados) "Aire des Gens du Voyage ", Un enclos du second âge du Fer en plaine de Caen, Document final de Synthèse, Inrap, Caen, DRAC, SRA, 218 p., 116 fig.

Lepaumier H., Vauterin C.-C., Le Goff E. et Villaregut J., 20 io - "Un réseau de fermes en périphérie caennaise ", in BARRAL P., Dedet B., Delrieu F., Giraud P., Le Goff I., Marion S., Villard-Le Tiec A. (dir.), L'âge du Fer en Basse-Normandie. Gestes funéraires en Gaule au second âge du Fer. Actes du XXXIII colloque international de l'AFEAF, Caen, 20 au 24 mai 2009, Besançon : Presses universitaires de Franche-Comté, p. 139-158 (Annales littéraires, Série « Environnement, sociétés et archéologie »).

Lepaumier H. (dir.), 2012 - Fleury-sur-Orne, Calvados, Les Mézerettes-ZL 7. Deux habitats enclos et une nécropole du second âge du Fer du réseau de fermes reconnu au sud-est de l'agglomération caennaise, Rapport final de fouille archéologique préventive, Inrap, Caen, DRAC, SRA, 2 vol., 439 et 433 p.

Malrain F., Pinard E. et Gaudefroy S., i 1996 - « Contribution à la mise en place d'une chronologie du second âge du Fer dans le département de l'Oise ", Revue archéologique de Picardie, $\mathrm{n}^{\text {os }}$ 3/4, p. 41-70.

Malrain F., Gaudefroy S. et Gransar F., 2005 - « La protohistoire récente : $\mathrm{III}^{\mathrm{e}}$ siècle- $\mathrm{I}^{\mathrm{re}}$ moitié du premier siècle avant notre ère ", in La recherche archéologique en Picardie : Bilans et Perspectives, Journées d'études, Amiens 2005, Revue archéologique de Picardie, nos 3-4, p. 127-176.

Malrain F. et Pinard E. (dir.), 2006 - «Les sites laténiens de la moyenne vallée de l'Oise du $\mathrm{v}^{\mathrm{e}}$ au I ${ }^{\mathrm{er}}$ siècle avant notre ère. Contribution à l'histoire de la société gauloise ", Revue archéologique de Picardie, no spécial 23, 268 p.

Mantel E., Devilliers S., Dubois S., Barbet P., Meniel P. et LE Goff I., 2002 - « Le cimetière gaulois de Saint-Riquier-enRivière "Au-dessus du Val d'Aulnoy " (Seine-Maritime) ", in Six nécropoles du second âge du Fer en Haute-Normandie, NordOuest Archéologie n ${ }^{\circ}$ 13, Centre de recherches archéologiques et de diffusion culturelle, p. 9-40.

Marcigny C. et Ghesquière E., I998 - «Un habitat Bronze final à Cussy "La Pointe " (Calvados) ", Revue archéologique de l'Ouest, 15, p. 39-57.

Marcigny C., Ghesquière E., Lecler E., Matterne V., Menager L., Clement-Sauleau S. et Richard J.-M., i 999 - "Un établissement agricole du IV siècle avant notre ère à Mosles "La Pièce du Pressoir " (Calvados) ", Revue archéologique de l'Ouest, 16, p. 97-130. 
Marcigny C., Lepaumier H., Carpentier V., Clement-Sauleau S., Matterne-Zeck V., Gaume E., Ghesquiere E. et Giazzon D., 2004 - "Un établissement agricole à caractère " aristocratique " du second âge du Fer à Saint-Martin-des-Entrées (Calvados)", Revue archéologique de l'Ouest, 21, p. 63-94.

Marcigny C., Flotté D., Desloges J. et Renault V., 2006 "Les petits ruisseaux font les grandes rivières ", l'exemple de la périphérie sud de Caen (Calvados)", Une archéologie des réseaux locaux. Quelles surfaces étudier pour quelle représentativité? Actes de la table ronde des 14 et 15 juin 2005 (Châlonsen-Champagne). Les Nouvelles de l'Archéologie, $\mathrm{n}^{\text {os }}$ 104-105, p. 61-63.

Menez Y., I 996 - "Une ferme de l'Armorique gauloise, Le Boisanne à Plouêr-sur-Rance (Côtes-d'Armor) ", Documents d'Archéologie française, 58, Paris : éditions de la Maison des sciences de l'homme, $267 \mathrm{p}$.

Menez Y. et Arramond J.-C., I 997 - « L'habitat aristocratique fortifié de Paule (Côtes-d'Armor) ", Gallia, 54, p. 119-155

Merleau M.-L., Adrian Y.-M., Dumont C., Gaston C., Perron d'Arc M. et Vertongen S., 2002 - " La Mort à Bois-Guillaume (Seine-Maritime) du $\mathrm{III}^{\mathrm{e}}$ au I ${ }^{\mathrm{er}}$ s. av. J.-C. Découvertes archéologiques sur la rocade nord de Rouen, déviation de la RD43 ", in Six nécropoles du second âge du Fer en Haute-Normandie, Nord-Ouest Archéologie $\mathrm{n}^{\circ} 13$, Centre de recherches archéologiques et de diffusion culturelle, 2002, p. $41-330$.

Morzadec H., 2005 - Mortrée : Le Pré-du-Palluel, Rapport final de fouille archéologique préventive, Inrap, Caen : DRAC, SRA, $81 \mathrm{p}$.

Nillesse O., 2003 - "Les établissements ruraux gaulois de la plaine de Luçon (Vendée) ", in Plouin S. et Jud P. (éd.), Habitats, mobiliers et groupes régionaux à l'âge du Fer, Actes du XX ${ }^{\mathrm{e}}$ colloque de l'AFEAF, Colmar-Mittelwihr : 1996, Revue archéologique de l'Est, 20, p. 275-385.

PAris P., I 997 - A29 sud. Saint-Gatien-des-Bois "Le Vert Buison", Document final de synthèse, Afan, Caen : DRAC.

Peuchet C. et Naizet F., I994 - "Soulangy. Déviation de la RN158 ", in Bilan scientifique de la région Basse-Normandie 1993, Caen, DRAC, SRA, p. 39-40.

Peuchet-Geilenbrügge C. et Morzadec H., 200 I - « The Iron Age in lower Normandy: a definition through ceramics ", in Collis J. (éd.), Society and settlement in Iron Age Europe, Actes

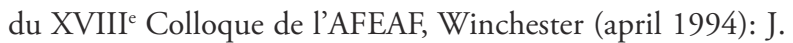
R. Collis Publication, Sheffield, p. 190-228

Pion P., Gransar F. et Auxiette G., I996 - « Les établissements ruraux dans la vallée de l'Aisne, de la fin du second âge du Fer au début du Haut-Empire romain (II ${ }^{\mathrm{e}}$ siècle av. J.-C./I $\mathrm{I}^{\mathrm{er}}$ siècle apr. J.-C.) : bilan provisoire des données et esquisse de syn- thèse ", in BAyard D. et Collart J.-L., De la ferme indigène à la villa romaine. La romanisation des campagnes de la Gaule, Actes du deuxième colloque de l'association AGER tenu à Amiens (Somme) du 23 au 25 septembre 1993, Revue archéologique de Picardie, Amiens, no spécial 11, p. 55-107.

San Juan G., Meniel P., Alduc-Lebagousse A. et Pilet-Lemiere J., I994 - "Un établissement rural du I ${ }^{\text {er }}$ siècle av. J.-C. à Fleury-sur-Orne (Calvados) ", Revue archéologique de l'Ouest, $\mathrm{n}^{\circ} 11$, p. 131-164.

San Juan G., Meniel P., Matterne-Zech V., Savary X. et Jardel K., I 999 - « L'occupation gauloise au nord-ouest de Caen. L'évaluation en sondage du plateau de Thaon (Calvados)", Revue archéologique de l'Ouest, $\mathrm{n}^{\circ}$ 16, p. 131-194.

SAN JuAN G., 2012 - «L'évolution des formes de l'habitat protohistorique au nord-ouest de Caen. L'exemple du plateau de Thaon-Basly après dix années de recherche programmée ", in Carpentier V. et Marcigny C. (dir.), Des Hommes aux Champs. Pour une archéologie des espaces ruraux du Néolithique au Moyen Âge, Rennes, PUR, coll. "Archéologie et Culture ", p. 99-109.

SÉGuier J.-M., 2005 - «Dynamiques d'occupation du secteur de confluence Seine-Yonne à la fin de l'âge du Fer et à l'époque romaine ", in Pетіт C. (dir.), Occupation et gestion des plaines alluviales dans le Nord de la France de l'àge du Fer à l'époque gallo-romaine. Actes de la table-ronde de Molesme 1999, Besançon, Presses universitaires de Franche-Comté, Annales littéraires, 786. Série « Environnement, sociétés et archéologie "; 8, p. 107-120.

Van Den Bossche B., Carpentier V. et Marcigny C., 2009 - «Évolution des formes de l'exploitation agricole dans la campagne normande (2500-30 av. J.-C.). L'exemple des fouilles préventives de la périphérie sud de Caen ", Revue archéologique de l'Ouest, $\mathrm{n}^{\circ} 26$ (2009), p. 57-83.

Vauterin C.-C., Chanson K., Zaour N., Feret L. et Le Forestier S., 2010 - " La culture matérielle de l'âge du Fer : un outil de réflexion sur les sites d'habitat de BasseNormandie ", in Barral P., Dedet B., Delrieu F., Giraud P., Le Goff I., Marion S. et Villard-Le Tiec A. (dir.), L'âge du Fer en Basse-Normandie. Gestes funéraires en Gaule au second âge du Fer. Actes du XXXIII colloque international de l'AFEAF, Caen, 20 au 24 mai 2009, Besançon : Presses universitaires de Franche-Comté, 2010, Annales littéraires, Série "Environnement, sociétés et archéologie », p. 203-230.

VAUTERIN C.-C. (dir.), 20 I I - Ifs "ZAC Object'Ifs Sud-dernière tranche" (Calvados). Habitats et lieux funéraires protohistoriques et vestiges antiques, Rapport final de fouille archéologique préventive, Inrap, Caen : DRAC, SRA, 3 vol., 812 p., 538 fig., invent. 
Zusammenfassung: Ein Netzwerk aus ländlichen Gehöften im Norden von Falaise (Calvados): Die eingehegten Gehöfte von „L'Attache“ und „Expansia“ - Nach zwei Ausgrabungskampagnen nördlich von Falaise (Calvados) im Bereich der Flurbezeichnungen "L'Attache“ und ,Expansia“ und unter Berücksichtigung von den Ergebnissen der Luftbildarchäologie und den durchgeführten Baggerprospektionen können wir heute für diesen Bereich das räumliche Siedlungsmuster und die Landschaftsnutzung vor der römischen Eroberung rekonstruieren. Diese fügen sich in ein Gesamtbild der latènezeitlicher Besiedlung im Norden der Ebene von Caen und im Becken von Seulles ein. Die Untersuchung der Befunde und der Funde aus diesen zwei ländlichen Siedlungen erlaubt es, regionale Unterschiede zwischen dieser Zone am Zugang zur Ebene von Argentan und Alençon sowie der Siedlungsstruktur der ländlichen Besiedlung im Norden der Ebene von Caen herauszuarbeiten. Dies betrifft insbesondere die Vorrichtungen und Möglichkeiten zur Vorratshaltung. Die typo-chronologische und petrographische Analyse der Keramikfunde trägt wichtige Informationen zur vergleichenden Untersuchung bei, indem sie ein keramisches Fundgut charakterisiert, dass randlich zur Keramikproduktion der Ebene von Caen liegt und dessen Produktion mehr im Bereich der Orne zu lokalisieren sein dürfte, einer Zone, bei der sich Einflüsse aus dem amorikanischen Gebiet bereits deutlich bemerkbar machen.

Resumen: Una red de granjas de la segunda Edad del Hierro al norte de Falaise (Calvados): los recintos de hábitat "L’Attache" y "Expansia" - Merced a dos campañas de excavaciones realizadas al norte de Falaise en las localidades "L'Attache" y "Expansia", a las que se añaden varios datos de vuelos aéreos y diagnósticos preventivos, es ahora posible abordar la cuestión de la organización espacial y de los modos de explotación de las tierras de este sector antes de la conquista romana, de la misma manera que se abordo el asunto para las redes de La Tène del norte del llano de Caen y de la cuenca de la Seulles. El estudio de los restos domésticos de estos dos establecimientos nos permite comprender las diferencias regionales, en particular en cuanto a los requisitos de almacenamiento entre esta zona situada en las afueras de la Llanura de Argentan y Alençon y las redes de granjas en el norte del llano de Caen. El estudio tipo-cronológico y petrográfico de los corpus cerámicos contribuye a esta pregunta sobre mobiliarios que constituyen una excepción comparándoles con las producciones del llano de Caen y más próximas a las del Orne, región más influenciada por el terreno armoricano.

Schlüsselwörter: Latènezeit, Gehöft, Siedlungsnetzwerk aus Gehöften, Siedlungsfunde, häusliche Fundobjekte, typo-chronologische und petrographische Analysen.

Palabras clave: La Tène, recintos de hábitat, redes de granjas, restos de hábitat, mobiliarios domésticos y agro-pastorales, cerámica, estudio tipo-cronológico y petrográfico. 